Check for updates

Cite this: Nat. Prod. Rep., 2017, 34, 1391

\title{
Chlorogenic acids and the acyl-quinic acids: discovery, biosynthesis, bioavailability and bioactivity $\dagger$
}

\author{
Michael N. Clifford, (D) a Indu B. Jaganath, (D) ${ }^{b}$ Iziar A. Ludwig (D) ${ }^{c}$ and Alan Crozier (D) *d \\ Covering: 2000 up to late 2017
}

\begin{abstract}
This review is focussed upon the acyl-quinic acids, the most studied group within the ca. 400 chlorogenic acids so far reported. The acyl-quinic acids, the first of which was characterised in 1846, are a diverse group of plant-derived compounds produced principally through esterification of an hydroxycinnamic acid and $1 \mathrm{~L}-(-)$-quinic acid. Topics addressed in this review include the confusing nomenclature, quantification and characterisation by NMR and MS, biosynthesis and role in planta, and the occurrence of acyl-quinic acids in coffee, their transformation during roasting and delivery to the beverage. Coffee is the major human dietary source world-wide of acyl-quinic acids and consideration is given to their absorption and metabolism in the upper gastrointestinal tract, and the colon where the microbiota play a key role in the formation of catabolites. Evidence on the potential of the in vivo metabolites and catabolites of acylquinic acids to promote the consumer's health is evaluated.
\end{abstract}

Received 11th May 2017

DOI: 10.1039/c7np00030h

rsc.li/npr

Discovery of chlorogenic acids

Nomenclature

Characterisation and quantification of acyl-quinic acids

3.1 Extraction

$3.2{ }^{1} \mathrm{H}-\mathrm{NMR}$

3.3 Chromatography

3.4 LC-MS

3.5 Calibrants

4 Biosynthesis of acyl-quinic acids

Role of acyl-quinic acids in planta

Acyl-quinic acids in coffee

Bioavailability and metabolism of acyl-quinic acids in humans

7.1 Studies involving volunteers with and without a functioning colon

7.2 Impact of dose on acyl-quinic acid bioavailability

7.3 Matrix effects and acyl-quinic acid bioavailability

7.4 Inter-individual variations in acyl-quinic acids excretion after coffee intake
8 Biomarkers of acyl-quinic acids intake

9 Bioactivity

10 Conflicts of interest

11 Acknowledgements

12 References

\section{Discovery of chlorogenic acids}

The term 'chlorogenic acids' (CGAs) encompasses a large group of naturally-occurring compounds of which the majority are synthesised in planta by esterification of a $\mathrm{C}_{6}-\mathrm{C}_{3}$ trans-hydroxycinnamic acid with $1 \mathrm{~L}-(-)$-quinic acid (1). The main hydroxycinnamates are $p$-coumaric (2), caffeic (3), ferulic (4) and sinapic acids (5).<smiles>O=C(O)C1(O)CC(O)C(O)C(O)C1</smiles><smiles>O=C(O)C=Cc1ccc(O)cc1</smiles><smiles>O=C(O)C=Cc1ccc(O)c(O)c1</smiles>

1L-(-)-Quinic acid (1) p-Coumaric acid (2)

Caffeic acid (3)<smiles>COc1cc(/C=C/C(=O)O)ccc1O</smiles>

Ferulic acid (4)<smiles>COc1cc(/C=C/C(=O)O)cc(OC)c1O</smiles>

Sinapic acid (5)
A wider definition of CGAs includes compounds formed with various quinic acid epimers, quinic acid methyl ethers, alkyl 
quinates, deoxyquinic acid, 2-hydroxyquinic acid and shikimic acid and its epimers, plus the analogous compounds that are esterified with a hydroxybenzoic acid (6), hydroxyphenylacetic acid (7) or 3-(4'-hydroxyphenyl)propionic acid (8). Aliphatic acid substituents may also be present, occasionally in the absence of an aromatic residue. A fuller account of these less common CGAs is available. ${ }^{1}$

The origin of 'chlorogenic acid' is probably related to the use of the term 'chlorogen acid' by Payen ${ }^{2,3}$ in 1846 (1846a, 1846b) who reported the isolation of a crystalline potassium caffeine chlorogenate that formed up to $5 \%$ of green coffee (Coffea

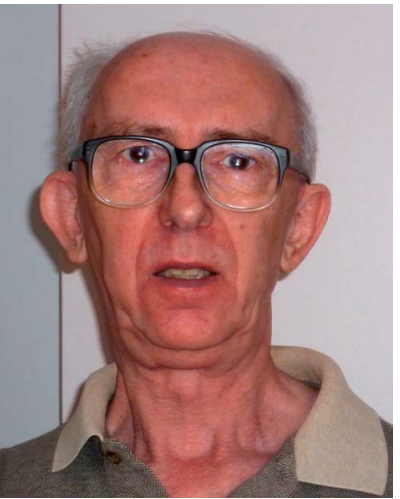

Mike Clifford is the Emeritus Professor of Food Safety at the University of Surrey and has investigated the analysis and characterisation, absorption and metabolism of phenols, polyphenols and tannins. He has published several books, including monographs on tea and coffee, over 250 research papers of which over 70 relate to chlorogenic acids. These latter include a new unambiguous nomenclature for the chlorogenic acids, plus several technical reports, citing in excess of 1500 references thereon, that are freely available on Researchgate. In 2009 he was awarded the Mars Prize for his research on "Polyphenol Analysis" at the Fourth International Conference on Polyphenols and Health, in Harrogate, UK.

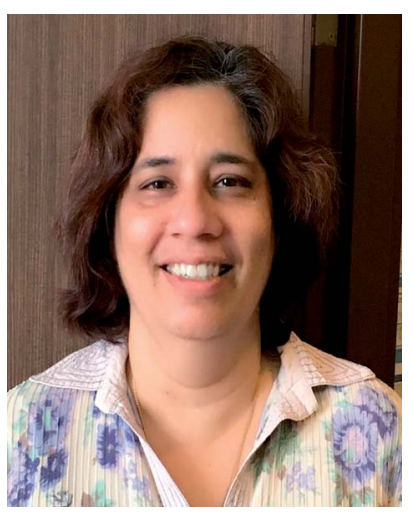

Indu Jaganath is a Principal Research Officer at the Malaysian Agricultural Research and Development Institute. She obtained her Master of Science from the University of California, Riverside and her PhD at University of Glasgow. Her research is focused on the discovery of chemically and biologically active natural compounds in tropical plants. Her main expertise lies in the area of metabolomics and nutrigenomics where she incorporates in multidisciplinary approach utilizing transcriptomics, metabolomics, pharmacokinetics and in vivo animal models to gain a holistic approach on how dietary compounds alters metabolism and affect various cellular pathways through gene regulation. arabica) beans. He proposed an empirical formula of $\mathrm{C}_{14} \mathrm{H}_{8} \mathrm{O}_{7}$ which is now known to be $\mathrm{C}_{16} \mathrm{H}_{18} \mathrm{O}_{9}$, and described its conversion to a green pigment on alkaline oxidation. In retrospect, one can deduce that there were a few earlier studies with the same or a very similar fraction prepared from green coffee beans. The earliest of these appears to be a paper by Robiquet and Boutron in $1837,{ }^{4}$ in which they reported the isolation of an acidic substance that turned green when treated with ferric chloride. Rochleder ${ }^{5}$ isolated an acidic substance from green coffee beans in 1844 that associated with caffeine and which precipitated as a lead salt. In 1846 Rochleder further reported that this fraction

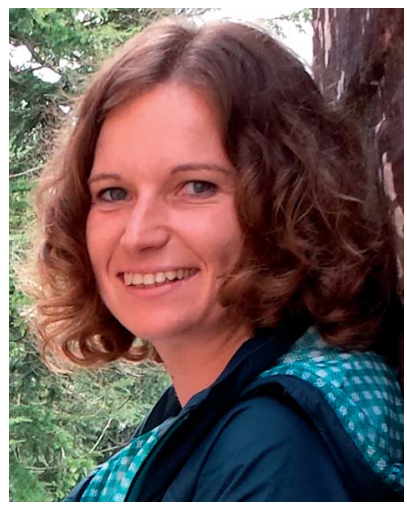

Iziar Ludwig obtained a bachelors degree in Food Science and Biotechnology at the University of Natural Resources and Life Sciences (BOKU, Vienna) in 2009 and her PhD in Physiology, Nutrition and Health at the University of Navarra (Pamplona) in 2013. She then work in Alan Crozier's group at the University of Glasgow and is currently a Research Associate at the Antioxidants Group, Department of Food Technology, at the University of Lleida. Her research is focussed on (poly)phenolic compounds in fruits and beverages, their metabolism, bioavailability and potential health effects.

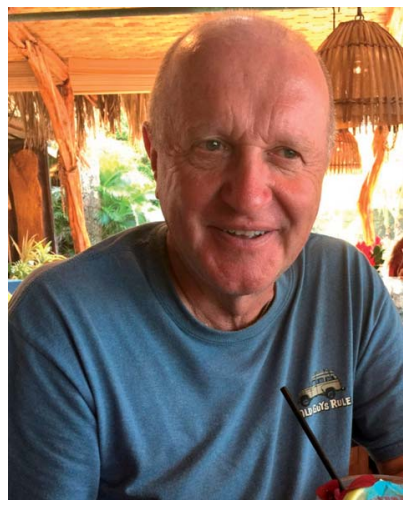

Alan Crozier is Senior Researcher in the Department of Nutrition at the University of California, Davis and a consultant for Mars Inc. He is also an Honorary Senior Research Fellow in the School of Medicine, Dentistry and Nursing at the University of Glasgow where he was previously Professor of Plant Biochemistry and Human Nutrition. He has published over 300 papers and edited nine books. While retaining an interest in purine alkaloids, his research has centred on dietary flavonoids and related phenolic compounds in fruits, vegetables and beverages and their bioavailability following ingestion. He was elected an Eminent Scientist of RIKEN, the Institute of Physical and Chemical Research in Japan, in 1999 for his achievements in the field of plant hormones and secondary metabolites. In 2013 he was awarded the Mars Prize for his research on "Flavonoid Metabolism/Chemistry" at the Sixth International Conference on Polyphenols and Health, in Buenos Aires, Argentina. He was a Thomson Reuters Highly Cited Researcher in 2014, 2015, 2016 and 2017. 


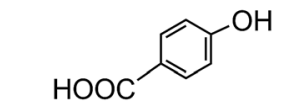

4-Hydroxybenzoic acid (6)

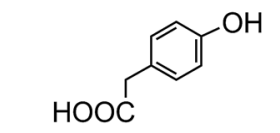

4'-Hydroxyphenylacetic acid (7)

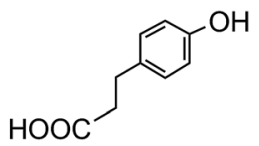

3-(4'-Hydroxyphenyl)propionic acid (8) was yellow in ammoniacal solution and became green on exposure to oxygen, and suggested $\mathrm{C}_{16} \mathrm{H}_{9} \mathrm{O}_{8}$ for the free acid. ${ }^{6}$ It was not until 1907 that pure white crystals were obtained which had a melting point of $206-207^{\circ} \mathrm{C}$, and from which quinic acid (1) and caffeic acid (3) were released by alkaline hydrolysis. An empirical formula of $\mathrm{C}_{32} \mathrm{H}_{38} \mathrm{O}_{19}$ was proposed in 1908 and to reconcile this with the evidence from hydrolysis Gorter $^{7}$ proposed that quinic acid combined with caffeic acid to form hemichlorogenic acid, two molecules of which condensed losing one molecule of water to produce chlorogenic acid. This would development of higher resolution NMR led to a steady increase in the number of CGAs and in the number of species in which they were found. ${ }^{21-29}$ With the arrival of the ion trap mass spectrometer coupled to HPLC in the first decade of the $21^{\text {st }}$ century the total number of identified naturally occurring CGAs has increased markedly. ${ }^{30-33}$ Taking the wider definition of CGAs, and including non-food sources, over 400 CGAs have been reported in over 400 genera embracing some 44 botanical orders. ${ }^{34}$ This review will focus on the acyl-quinic acids which are the most studied of the extended CGA family.<smiles>O=C(O)COC(=O)CCC1(O)CCC(O)(C(=O)O)CC1CO</smiles>

5-O-Caffeoylquinic acid (9) (chlorogenic acid)

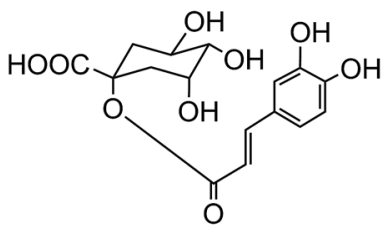

1-O-Caffeoylquinic acid (12)<smiles>O=C(C=Cc1ccc(O)c(O)c1)OC1C(O)CC(O)(C(=O)O)CC1O</smiles>

4-O-Caffeoylquinic acid (10) (cryptochlorogenic acid)<smiles></smiles>

3-O-Caffeoylquinic acid (11) (neochlorogenic acid)<smiles>O=C(O)C1C(O)C2C(COCc3ccc(O)c(O)c3)OCC1C(O)C2O</smiles>

5-O-Caffeoylshikimic acid (14)
1,3-O-Dicaffeoylquinic acid (13) (cynarin) correspond to an empirical formula of $\mathrm{C}_{16} \mathrm{H}_{20} \mathrm{O}_{10}$. Freudenberg ${ }^{8}$ reported in 1920 that chlorogenic acid was a substrate for the enzyme tannase and that hydrolysis released equimolar amounts of quinic acid and caffeic acid. In 1932 Fischer and Dangschat ${ }^{9}$ proposed that this substance was 3-O-caffeoylquinic acid (3-CQA).

In 1950 Barnes et al. ${ }^{10}$ reported the presence in coffee of 5-Ocaffeoylquinic acid (9) (5-CQA), and over the next 15 years other isomers $(\mathbf{1 0}, \mathbf{1 1}, \mathbf{1 2})$ and several related dicaffeoylquinic acids (diCQAs) were reported from various sources. Cynarin(e), now known to be (1,3-O-dicaffeoylquinic acid (13, 1,3-di-CQA)) from artichoke, characterised in 1954, was the first 1-acyl quinic acid to be reported..$^{11}$ The same period saw the first reports of galloyl, ${ }^{12,13} p$-coumaroyl, ${ }^{14,15}$ feruloyl, ${ }^{16}$ caffeoyl-feruloyl, ${ }^{17}$ caffeoylsuccinoyl $^{18}$ and sinapoyl ${ }^{19}$ esters of quinic acid. The first papers referring to caffeoylshikimic acids (14) were published by Maier et al. in $1964 .^{20}$ During the last quarter of the $20^{\text {th }}$ century, improvements in chromatographic procedures and the
Acyl-quinic acids are widespread dietary components being found, for instance, in coffee, cherries (Prunus avium), blueberries (Vaccinium spp.), aubergine (Solanum melongena), apples (Malus pumila) oregano (Origanum vulgare), spearmint (Mentha spicata), chicory (Cichorium intybus) and sunflower (Helianthus annus) seeds ${ }^{28,35-39}$ with high levels in globe artichoke. ${ }^{40,41}$ The herbal tea maté, made from infusion of dry leaves of Ilex paraguariensis, contains substantial amounts of CQAs and diCQAs (Table 1). ${ }^{42}$ Coffee beverage, rather than fruits and vegetables is probably the main dietary source of CQAs for many people with intakes in excess of $1 \mathrm{~g}$ per day being readily attained. ${ }^{43}$

The hydroxycinnamic acid moiety of acyl-quinic acids is predominantly in the trans form. Some cis isomers are known, with $c i s-5-O-p$-coumarylquinic acid (15) being detected in flower buds of herbal aster (Aster ageratoides Turcz). ${ }^{47}$ and a wide range of $c i s$-isomers have now been detected in other species. ${ }^{34}$ It has been suggested that the cis derivatives originate from plant 
Table 1 Acyl-quinic acid content of coffees, apples juices, globe artichoke and maté

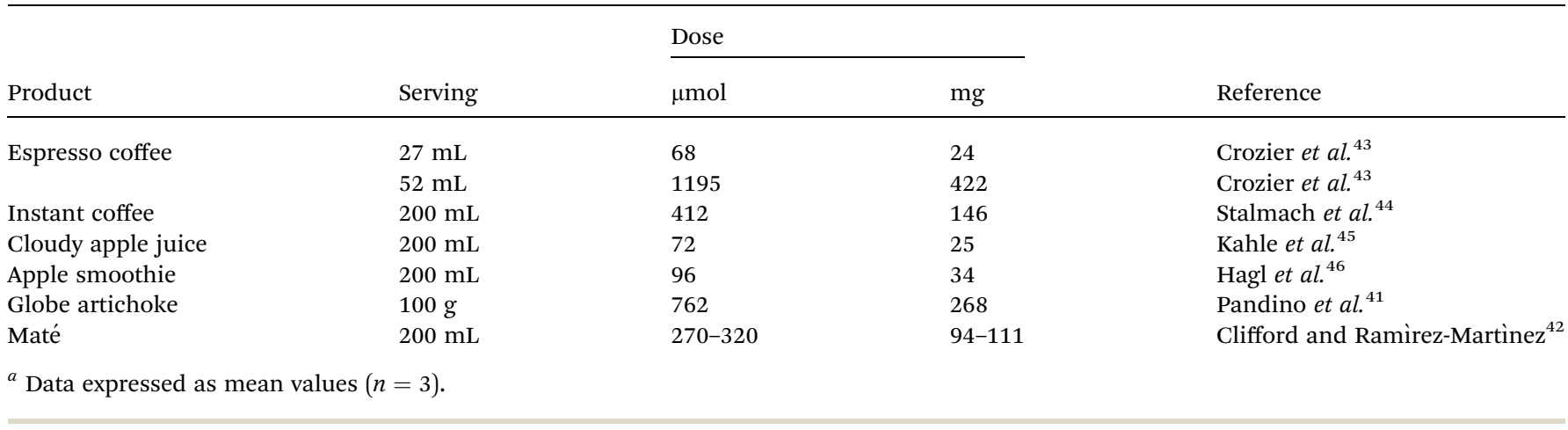

tissues where the trans isomer has been exposed to relatively strong UV-irradiation which induces geometric isomerisation. ${ }^{48}$ There is good experimental evidence to support this view. ${ }^{\mathbf{4 9}}$ However, direct synthesis cannot be ruled out, and there is some evidence from research with cell culture to suggest that UV-irradiation is not essential. ${ }^{50}$

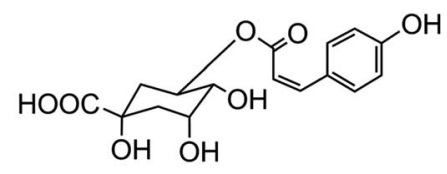

cis-5-O-p-Coumaroylquinic acid (15)

\section{Nomenclature}

Acyl-quinic acids exhibit configurational isomerism, conformational isomerism and regio-isomerism, plus geometric isomerism for those containing a cinnamic acid residue. Consequently, it is not easy to describe unambiguously the structures of acyl-quinic acids that may appear almost identical when drawn in $2 \mathrm{D}$ or projected in $3 \mathrm{D}$. Various systems for cyclitols were evaluated by IUPAC who recommended that the most common natural form of quinic acid be described as $1 \mathrm{~L}^{-}$ $1(\mathrm{OH}), 3,4 / 5$-tetrahydroxycyclohexanecarboxylic acid, with the trivial names (-)-quinic acid or L-quinic acid. ${ }^{51}$ In the IUPAC system, Fischer and Dangschatt's 3-CQA ${ }^{9}$ became 5-CQA (9).

Unfortunately, papers are still published in which nonIUPAC numbering is used, the numbering system used is not stated, or worse, the numbering is IUPAC but the structure shown is not, or vice versa. Kremr et al. ${ }^{52}$ commented that some published structures make no attempt to depict the spatial arrangement of the substituents, and Clifford recorded that some authors discuss previously published data unaware that different numbering systems have been used, for example 3CQA (non-IUPAC) and 3-CQA (IUPAC) are treated as the same compound..$^{3453}$ Note that Wikipedia and many other online sources, plus many catalogues listing acyl-quinic acid preparations, use non-IUPAC nomenclature. Many examples of misleading or incorrect descriptions have been compiled. ${ }^{\mathbf{1}, \mathbf{3 4}, 53}$ For the avoidance of doubt, the IUPAC and non-IUPAC structures are presented in Fig. 1. From this point onwards the

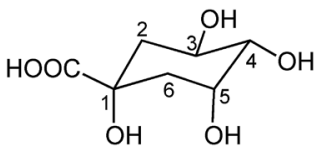

Non-IUPAC<smiles>O=C(O)C1(O)C[C@H](O)[C@@H](O)[C@H](O)C1</smiles>

IUPAC 1976
Fig. 1 Non-IUPAC and IUPAC numbering of $1\llcorner-(-)$-quinic acid.

IUPAC numbering system will be used in this review. Trivial names further complicate the literature but a glossary is available, ${ }^{1,54}$ and this is presented as Table S1 in the ESI. $\dagger$ To this must be added chrysanthemorimic acids, a series of recently discovered diCQAs, in which one caffeic acid residue has undergone a $[5+2]$ cycloaddition of D-glucose. ${ }^{55}$

The IUPAC system, however, has limitations when applied to acyl-quinic acids and Abrankó and Clifford ${ }^{54}$ have proposed a combination of IUPAC cyclitol numbering ${ }^{51}$ the Cahn-IngoldPrelog (CIP) sequence rules ${ }^{56}$ plus the use of $\alpha$ to define a hydroxyl trans to the quinic acid carboxyl (and $\beta$ to define a hydroxyl cis to the quinic acid carboxyl) to describe the orientation of a substituent on a carbon atom which is not a centre of chirality, as favoured by Eliel and Ramirez. ${ }^{57}$ This approach can accommodate all eight quinic acid stereo-isomers, with, for example, IUPAC (-)quinic acid described as $1 \mathrm{~L}-(-)$-quinic acid $3 R, 5 R-(1 \alpha, 3 \alpha, 4 \alpha, 5 \beta){ }^{54}$ ESI Table S2 $\uparrow$ provides a comprehensive set of structures for the various quinic acids, which in addition to using different styles of presentation (Fischer-Tollens, 2D, alternative chair conformations), also considers the perspective from which a structure is viewed.

\section{Characterisation and quantification of acyl-quinic acids}

This section of the review draws on three open-access documents which contain extensive tabulations and discussion of the topics presented here. .,53,56 $^{-1}$

\subsection{Extraction}

Extraction of acyl-quinic acids from plant material generally employs aqueous alcohol, usually $70 \% \mathrm{MeOH}$. Artefacts may 
arise from acyl migration, alkylation, hydrolysis, water addition across the cinnamic acid double bond and/or trans-cis isomerisation. ${ }^{59}$ Acyl migration is favoured by higher water content in the solvent and sample, and when extracting undried plant material $100 \% \mathrm{MeOH}$ is advisable for the first stage, especially if 1,5-diCQA might be present, as it rapidly converts to 1,3-diCQA. In contrast, controlled acyl migration and partial hydrolysis can usefully generate regio-isomers that are not otherwise conveniently available (e.g. 1,4-diCQA, 1-CQA), ${ }^{\mathbf{2 6 , 6 0 , 6 1}}$ as can UVirradiation for preparing cis-isomers. ${ }^{48}$ Any novel acyl-quinic acid should be examined by controlled acyl migration in order to access associated regio-isomers.

\section{$3.2{ }^{1} \mathrm{H}-\mathrm{NMR}$}

Acyl-quinic acids can be characterised by ${ }^{1} \mathrm{H}-\mathrm{NMR}$, but this has limitations. ${ }^{53,63-65}$ The definitive studies of Pauli et al., ${ }^{63,64}$ and the data tabulated by Clifford,$^{53}$ show that if best practice is followed, mono- and di-acyl-quinic acids can be successfully identified $-d_{4}-\mathrm{MeOH}$ is the preferred solvent, to which a small amount of $\mathrm{D}_{2} \mathrm{O}$ or $d_{6}$-DMSO (not exceeding $10 \%$ ) can be added, followed by analysis at not less than $500 \mathrm{MHz}$. Identification of the acyl residue(s) is straightforward, assignment of the quinic acid configuration and the position(s) of acylation less so, because signals for $\mathrm{H} 2$ and $\mathrm{H} 6$ methylenes and $\mathrm{H} 3$ and $\mathrm{H} 5$ methines often overlap, especially in tri- or tetra-acyl-quinic acids, and/or when an aliphatic substituent is present.

Temperature, analyte concentration, and especially solvent influence the proton chemical shifts, the order in which the shifts occur, and the conformation of the quinic acid moiety, and hence the coupling constants for the relevant protons. ${ }^{\mathbf{6 3 , 6 4 , 6 6}}$ Incomplete signal resolution, producing inaccurate coupling constants, has generated unconvincing structural assignments, notably reports of acyl-quinic acids containing a stereo-isomer of $1 \mathrm{~L}-(-)$-quinic acid. ${ }^{67-73}$

These novel compound(s) are rarely observed in company with a full set of the commoner $1 \mathrm{~L}-(-)$-quinic acid derivatives. This does not per se refute the claim, but might suggest that one of the commoner acyl-quinic acids has been wrongly identified. Reports by Wang et al. ${ }^{7,75}$ of an acyl-iso-quinic acid (=4,5-diCepi-QA IUPAC) are convincing because the quinic acid moiety released by saponification did not co-chromatograph with $1 \mathrm{~L}^{-}$ (-)-quinic acid, and subsequent 500 or $600 \mathrm{MHz} \mathrm{NMR}$ in $d_{4^{-}}$ $\mathrm{MeOH}$ is distinctive. ${ }^{75,76}$ The biosynthesis of $1 \mathrm{~L}-(-)$-epi-quinic acid requires only that $\mathrm{D}^{-}$threose-4-phosphate replace $\mathrm{D}^{-}$ erythrose-4-phosphate in the pathway to $1 \mathrm{~L}-(-)$-quinic acid. ${ }^{58}$ There are LC-MS data for four incompletely characterised $\mathrm{CQA},{ }^{32,77}$ which plausibly are derivatives of a quinic acid isomer. NMR data are available for 3-C-muco-QA and 3-F-muco-QA, ${ }^{78}$ plus $( \pm)$-epi-quinic acid and scyllo-quinic acid. ${ }^{79-81}$

\subsection{Chromatography}

A reverse-phase LC column packing and shallow linear solvent gradient providing structure-diagnostic relative capacity factors or relative retention times (RRTs) is the best strategy for characterising acyl-quinic acids. Once characterised, a revised gradient may speed up the separation for routine use. The behaviour of acyl-quinic acids is determined by (i) orientation of the free quinic acid hydroxyls, and (ii) number and hydrophobicity of the acyl moieties. For a given acyl moiety, 1-acyl and 3acyl regio-isomers (two free equatorial hydroxyls) are wellresolved from the 4-acyl and 5-acyl regio-isomers (two free axial hydroxyls). 1-Acyl regio-isomers almost always elute first, but 4-acyl and 5-acyl regio-isomers vary with column packing. Similarly 1,3-diacyl regio-isomers (two free equatorial hydroxyls) elute first and 4,5-diacyl regio-isomers elute last (two free axial hydroxyls). The other four diacyl regio-isomers elute close together just before the 4,5-diacyl isomer, but their sequence varies with column packing. ${ }^{31,82}$ For diacyl-quinic acids with different substituents, the isomer with the more hydrophilic substituent more equatorially positioned, elutes first. ${ }^{58}$

Relative to free quinic acid, acylation delays elution. Cinnamic and benzoic acids with more ring hydroxyls elute faster, and for a given number of ring substituents, methylation of the hydroxyl slows elution, i.e. for a given regio-isomer the sequence is CQA, $p$-coumaroylquinic acid ( $p$ CoQA), feruloylquinic acid (FQA), and $\left(3^{\prime}, 4^{\prime}\right.$-dimethoxycinnamoyl)quinic acid (DQA), etc. cis-3-Cinnamoyl and cis-4-cinnamoyl elute before their transcounterparts but cis-5-cinnamoyl elute later. The methyl esters of the mono-acyl-quinic acid regio-isomers, but not the diacylquinic acid regio-isomers, elute in the reverse order compared with the free acids. ${ }^{83}$ Glycosidation of the acyl moiety markedly speeds the elution. Although the presence of an aliphatic dicarboxylic acid, e.g. succinic acid, may speed elution the behaviour is less predictable because of internal hydrogen bonding in some regio-isomers. ${ }^{84}$

With that exception, these RRTs are sufficiently consistent to be used as a structure-diagnostic tool, easily locating cis-5-CQA which is often reported as trans-1-CQA, ${ }^{85-89}$ and early-eluting CQA-glycosides which are often reported as diCQA. ${ }^{\mathbf{9 0 9 1}}$ RRT values should always be considered when assigning the structure of a novel acyl-quinic acid.

\subsection{LC-MS}

Mass spectroscopy was long considered blind to isomers but the development of LC-ion trap-MS changed perceptions, ${ }^{92}$ especially with regard to acyl-quinic acids, ${ }^{58}$ for which negative ion MS is preferable. The methods and hierarchical keys developed by Clifford and Kuhnert using mild fragmentation conditions produce distinctive patterns at $\mathrm{MS}^{2}, \mathrm{MS}^{3}$ and $\mathrm{MS}^{4}$, allowing regioisomers to be assigned confidently. Critically, these methods have been applied successfully to previously unknown acyl-quinic acids. The geometric isomers of cinnamoyl-quinic acids fragment identically, ${ }^{48}$ but the cis-isomers can be distinguished by UVirradiation, ${ }^{62}$ sodium-adduct $\mathrm{MS},{ }^{93}$ and ion mobility-MS. ${ }^{94}$ Using the hierarchical keys it is possible to identify at regio-isomer level in excess of 20 acyl-quinic acids in a single run subject to adequate analyte concentration. ${ }^{31,77,78,83,95-115}$ It is false economy to characterise CGAs and flavonoids in a single run, because flavonoids require harsher MS conditions which mask the structure-diagnostic fragmentations of the acyl-quinic acids, and invalidate the hierarchical keys. 
The hydrogen-bonding networks responsible for these distinctive fragmentations have been deduced. ${ }^{58}$ For some regio-isomers the charge may be on a phenolic hydroxyl rather than the quinic acid carboxyl. ${ }^{116}$ Accurate mass may be helpful, but is not essential to distinguish diCQA from CQA-glycosides because the glycosides yield characteristic $\mathrm{MS}^{2}$ ions $(\mathrm{m} / \mathrm{z} 341$ and 323$)^{84}$ the latter as the base peak indicating a $3^{\prime}$-glycoside. ${ }^{103,107}$ TriCQA, diCQA-glycosides and CQA-biosides, as well as acylisocitric acids and acyl-quinic acids, can be distinguished similarly, but only fragmentation can distinguish between isobaric methyl-CQ, FQA and isoFQA, and acyl-quinides and acyl-shikimic acids. ${ }^{58}$ Methyl-CQ and methyl-diCQ fragment very differently from CQA and diCQA,${ }^{83}$ which coupled with the 'reversed' order of elution for the methyl CQ, necessitates care in regio-isomer assignment. Reports of FQA and caffeoyl-feruloylquinic acids (CFQA) producing fragments at $\mathrm{m} / \mathrm{z} 179$ or $\mathrm{m} / \mathrm{z} 161$, but not $\mathrm{m} / \mathrm{z}$ 193 or $m / z$ 367, might be methyl-CQ and methyl-diCQ. ${ }^{117-120}$

Full assignment of tri-acyl- and tetra-acyl-quinic acids requires $\mathrm{MS}^{4}$ and perhaps $\mathrm{MS}^{5}$ spectra, particularly where there are two or more different acyl moieties (e.g. dicaffeoylferuloylquinic acids or caffeoyl-sinapoyl-feruloylquinic acids). $\mathrm{MS}^{8}$ is required to characterise depsidic GQA bearing up to eight galloyl residues. ${ }^{98}$ Targeted rather than automated fragmentation may be essential with more complex structures such as 4-methoxyoxalyl-1,5-dicaffeoylquinic acid and 4methoxyoxalyl-3,5-dicaffeoylquinic acid, ${ }^{112}$ or when a 'dehydrated' base peak (e.g. $m / z 349$ rather than $m / z$ 367) occurs, more frequent with increasing methylation of the acyl moieties. ${ }^{\mathbf{5 8 , 1 0 2}}$

These structure-diagnostic protocols were developed using a ThermoFinnigan LCQ deca+ or a Bruker Daltronics HCT Ultra ion trap mass spectrometer, but should be easily transferred to similar instruments provided that the ionisation potential and fragmentation energy are appropriate. Even on the instruments originally used changes to the instrument parameters, such as increasing the ion spray voltage from $3.5 \mathrm{kV}$ to $4.5 \mathrm{kV}$, generates many additional fragments and invalidates the hierarchical keys as published. ${ }^{\mathbf{1 2 1 , 1 2 2}}$

Some investigators have reported that with QTOF-MS all CQA regio-isomers fragment identically. ${ }^{123,124}$ However, Madala and co-workers have demonstrated that with careful control of the collision energy it is possible to obtain the same $\mathrm{MS}^{2}$ and $\mathrm{MS}^{3}$ fragmentation data as an ion trap. ${ }^{\mathbf{1 2 5 , 1 2 6}}$ When adapting the ion trap-MS hierarchical key methods to a non-ion trap-MS, a surrogate standard, such as a green coffee extract, ${ }^{127}$ should be analysed and operating parameters adjusted until identical fragmentations are achieved. ${ }^{58}$ Whatever equipment is used there is scan-to-scan variation in fragment intensity, being most prominent for weak signals, i.e. low analyte concentrations, and higher order spectra, and for a reliable assignment at least 20 scans should be taken. If necessary use a more concentrated extract or larger injection.

Only limited success has been achieved with triple quadrupole instruments because of the much increased fragmentation energy employed. Matsui et al. successfully fingerprinted several CQA, FQA and diCQA regio-isomers using two different collision energies in positive ion mode (15 and $30 \mathrm{eV}$ ) and three different collision energies in negative ion mode (20, 40 and
$60 \mathrm{eV}),{ }^{128}$ but this is too cumbersome for routine use. Similar limitations are apparent in the methods reported by Lin and Harnly, ${ }^{129,130}$ and Willems et al. ${ }^{\mathbf{1 3 1}}$

Ion-trap-MS has its limitations, most apparent where there is an aliphatic dicarboxylic acid substituent (e.g. succinic acid) because the fragmentations can be driven also by the distal carboxyl of that substituent in addition to the quinic acid carboxyl. ${ }^{\mathbf{8 4 , 9 5 , 1 1 1 , 1 1 2}}$ Reproducible fingerprints are obtained, but even with targeted fragmentations, full regio-isomeric assignment is not always possible. ${ }^{58}$ Scopoletin (16) and the CQAs are indistinguishable by accurate mass, and there are currently insufficient fragmentation data for scopoletin to judge whether it could easily be distinguished. ${ }^{58}$

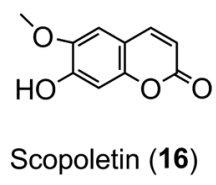

\subsection{Calibrants}

Quantification requires one or more pure calibrants. The molar absorbance of any set of acyl-quinic acid regio-isomers differs comparatively little, e.g. CQA $\pm 4 \%$ of mean (18 500), $p \mathrm{CoQA} \pm$ $2.5 \%$ of mean (20 400), FQA $\pm 2.5 \%$ of mean (19 000) and diCQA $\pm 6 \%$ of mean (33 300). A good quality 5-CQA (for which the molar absorbance should be quoted) can be used for all of the foregoing with arithmetic corrections for the subgroups if required, although this is only significant for the diCQA and other acyl-quinic acids with two or more aromatic substituents.

In contrast to molar absorbance values obtained after meticulous purification with corrections for ash content, water content, etc., published calibration curve response factors for acyl-quinic acids can vary by some $300 \%$, indicating that these commercial preparations are far from pure, containing non-UVabsorbing salts, solvents, etc. ${ }^{58}$ Such preparations are unsuitable for quantitative analysis. Some commercial standards are incorrectly described at regio-isomer level, ${ }^{1}$ and use of surrogate standards such as a green coffee extract, an alcoholic cider, or artichoke extract, characterised by LC-MS fragmentation and relative retention times should be considered. ${ }^{\mathbf{1 3 0}}$

\section{Biosynthesis of acyl-quinic acids}

The initial steps in the biosynthesis of CQAs are via the phenylpropanoid pathway and the enzymes catalysing the conversions that produce 5-CQA (9) are well established but there is less clarity about the later stages of the pathway leading from 5-CQA to other acyl-quinic acids.

The conversion of phenylalanine to $p$-coumaroyl-CoA, with cinnamic acid and $p$-coumaric acid acting as intermediates, is catalysed sequentially by phenylalanine ammonia lyase (PAL), cinnamate $4^{\prime}$-hydroxylase $(\mathrm{C} 4 \mathrm{H})$ and 4-cinnamoyl-CoA ligase (4CL) (Fig. 2). PAL is encoded by a multi-gene family and typically exists as multiple isoforms in plants, ranging from a few members, such as three in Arabica coffee (Coffea canephora), ${ }^{\mathbf{1 3 2}}$ four in Arabidopsis thaliana, and nine in rice (Oryza sativa $)^{133}$ to 


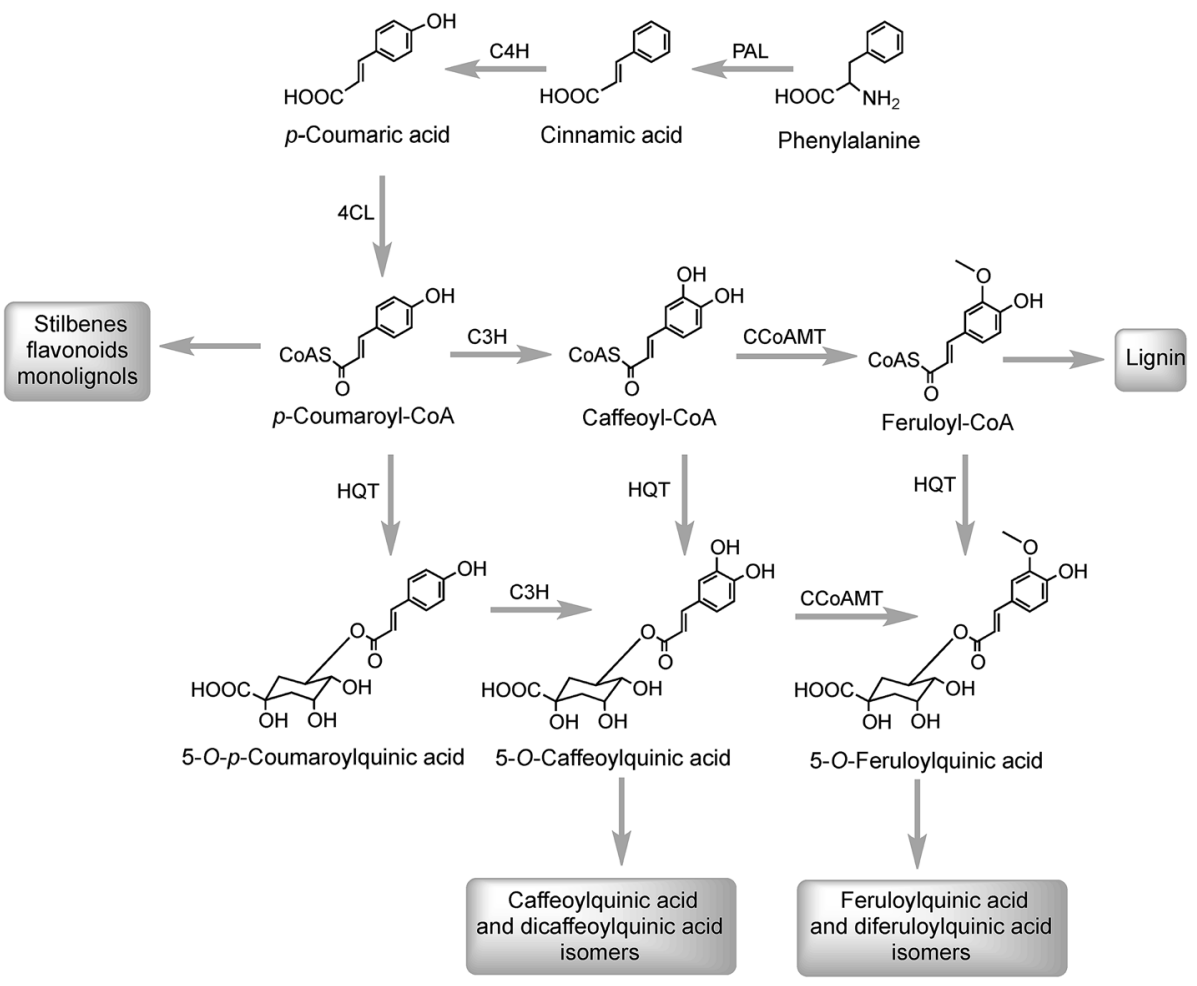

Fig. 2 5-O-Caffeoylquinic acid biosynthesis pathways. Enzymes: phenylalanine ammonia lyase (PAL), cinnamate 4'-hydroxylase (C4H), 4cinnamoyl CoA ligase (4CL), hydroxycinnamoyl CoA:quinate hydroxycinnamoyl transferase (HQT), $p$-coumaroyl-3'-hydroxylase (C3H), and caffeoyl-COA-3-O-methyltransferase (CCOAMT).

more than a dozen copies in tomato (Lycoperscion esculentum). ${ }^{134}$ Individual PAL isoforms might be associated with specific metabolic activity during plant growth and development, and in plant-environment interactions. ${ }^{135}$ In western balsam poplar (Populus trichocarpa), there are five genes (PtrPAL1-5) that are differentially expressed. PtrPAL2, 4 and 5 are mainly expressed in xylem and root tips, predominantly responsible for the production of lignin while PtrPAL1 and 3 are responsible principally for the production of condensed tannins. ${ }^{136}$ However, in plants such as tomato, most of the isoforms of PAL present are functionally redundant and underutilized. There are 20 PAL-encoding genes in tomato but only one is expressed strongly throughout the plant with others being silenced. ${ }^{134}$ Since PAL is the entry point enzyme, its control and regulation is crucial to mediate carbon flux from primary metabolism into biosynthesis of acyl-quinic acids. The regulation of PAL have been shown to occur at multiple levels, and has been reviewed in detail by Zhang and Liu. ${ }^{135}$

In Arabidopsis thalania the $\mathrm{C} 4 \mathrm{H}$ catalysing the $4^{\prime}$-hydroxylation of cinnamic acid to $p$-coumaric acid (Fig. 2 ) is encoded by a single gene, mutation of which causes a dwarf phenotype, male sterility and swellings at branch junctions, and also results in the accumulation of cinnamoylmalate (17), which is not found in wild-type plants. ${ }^{137}$ However, when the gene encoding $\mathrm{C} 4 \mathrm{H}$ in sweet sagewort (Artemisia annua) was silenced through RNAi technology, it caused accumulation of cinnamic acid accompanied with significant reductions in $p$-coumaric acid (1), total phenolics and anthocyanins, highlighting its role as a major flux controlling enzyme in the phenylpropanoid pathway (Kumar et al. 2016). ${ }^{138}$ The next step in the pathway is the conversion of $p$-coumaric acid to $p$-coumaroyl-CoA catalysed by a small gene family of $4 \mathrm{CL}$ ligases (Fig. 2). $p$-Coumaroyl-CoA is a key branch point in phenylpropanoid biosynthesis acting as the immediate precursor of flavonoids and stilbenes, as well as being channeled into the production of methoxy guaiacyl- and syringyl-monolignols. ${ }^{139}$ Four isoforms of $4 \mathrm{CL}$ have been identified in Morus notabilis (mulberry) ${ }^{140}$ and Arabidopsis. ${ }^{141}$ The subcellular localization of specific isoforms of 4CL plays a central role in redirecting the biosynthetic pathway either towards the $p$-coumaroyl-CoA or towards other branch points in the phenylpropanoid pathway. ${ }^{141}$<smiles>O=C(O)CC(OC(=O)C=Cc1ccccc1)C(=O)O</smiles>

Cinnamoylmalate (17)

The conversion of $p$-coumaroyl-CoA to 5-CQA involves the enzymes hydroxycinnamoyl CoA:quinate hydroxycinnamoyl transferase (HQT) and a cytochrome P450 oxidase $p$-coumaroyl3'-hydroxylase (C3H) (Fig. 2). The HQT-catalysed metabolism of $p$-coumaroyl-CoA produces 5-O- $p$-coumaroylquinic acid (5$p$ CoQA) which then undergoes C3H-mediated 3 -hydroxylation to yield 5-CQA. Alternatively, $\mathrm{C} 3 \mathrm{H}$-mediated hydroxylation of $p$ coumaroyl-CoA produces caffeoyl-CoA which is then converted 
to 5-CQA via the action of HQT (Fig. 2). Two HQT-encoding genes have been isolated from globe artichoke and when expressed in Escherichia coli each produced a recombinant protein, HQT1 and HQT2, with acyltransferase activity. Kinetic data and in silico homology modeling and docking analyses suggested that the two enzymes may be involved in different steps in the 5-CQA biosynthesis pathway with HQT1 catalysing the esterification of caffeoyl-CoA with quinic acid to produce 5CQA, and HQT2 being involved in the conversion of $p$ coumaroyl-CoA to 5-pCoQA (Fig. 2). ${ }^{\mathbf{1 4 2}}$ This esterification is reversible. However, as a result of the genome-wide identification of BAHD acyltransferases in globe artichoke, a third isoform of HQT enzyme was detected. ${ }^{\mathbf{1 4 3}}$ When HQT1 was subjected to virus-induced gene silencing, a marked reduction of both CQAs and diCQAs occurred. In contrast, transient overexpression of all three isoforms in leaves of Nicotiana benthamiana had the opposite effect, ${ }^{63}$ highlighting the role of all three isoforms in the production of acyl-quinic acids.

5-CQA (9) is the dominant regio-isomer in most plants. However, most species also contain 4-CQA (10) and 3-CQA (11), while 1-CQA (12) is present in a limited number of plants, and 3CQA is the dominant isomer in some species, most notably in plums (Prunus sp.) belonging to the Rosaceae family, ${ }^{27}$ and some Brassicaceae. ${ }^{\mathbf{1 4 4}}$ From an enzymic perspective information is available only on the biosynthesis of 5-CQA (9) and the perceived wisdom is that other CQAs are derived from 5-CQA although there are no data on the seemingly specific isomerases involved in such conversions. Little is also known about the biosynthesis of di- and triCQAs or acyl-quinic acids containing substituents other than caffeic acid (3), although the in vitro synthesis of diCQAs from 5-CQA and CoA, mediated by a recombinant HCT enzyme cloned from coffee, has been reported. ${ }^{145}$ In tomato, the enzyme HQT converted 5-CQA to diCQAs in vitro. It was proposed that the HQT enzyme has a dual role in vivo catalysing different reactions in two subcellular compartments: in the cytoplasm acting as a quinate transferase while in the vacuole favouring chlorogenate:chlorogenate transferase (acyl-quinate:acyl-quinate transferase) activity producing diCQA. ${ }^{\mathbf{1 4 6}}$

Research with globe artichoke, switchgrass (Panicum virgatum) and chicory has established a further route to acyl-quinic acids that contains a shikimic acid shunt ${ }^{\mathbf{1 4 2 , 1 4 7}}$ It involves an hydroxycinnamoyl-CoA:shikimate hydroxycinnamoyl transferase (HCT1; EC 2.3.1.133), or possibly two such enzymes in switchgrass ${ }^{\mathbf{1 4 8}}$ that catalyse the conversion of $p$-coumaroyl-CoA to 5-O-p-coumaroylshikimic acid, which is further converted to 5-O-caffeoylshikimic acid (dactylifric acid) by $p$-coumaroylshikimate-3'-hydroxylase (C3H) (Fig. 3). The caffeoylshikimate so generated could be converted to caffeoyl-CoA by an HCT acting in the reverse direction. In vivo functional analysis of the gene encoding HCT from chicory when transiently overexpressed in tobacco confirmed the involvement and the role of HCT in this step. ${ }^{147}$ Alternatively a caffeoylshikimate esterase could release caffeic acid which is converted to caffeoyl-CoA by a ligase. Conversion of caffeoyl-CoA to 5-CQA in globe artichoke and other dicots probably involves an HQT. ${ }^{\mathbf{1 4 3 , 1 4 7}}$ The gene encoding this enzyme is not present in switchgrass and phylogenetic analysis suggests that in monocots the conversion may be catalysed by enzymes more closely related to HCT than HQT (Fig. 3). ${ }^{148}$

As far as the production of FQAs, such as 5-FQA is concerned, cDNA encoding $S$-adenosyl-L-methionine:caffeoyl-CoA-3-Omethyltransferase (CCOAOMT) an enzyme which catalyses the conversion of caffeoyl-CoA to feruloyl-CoA (Fig. 2) has been
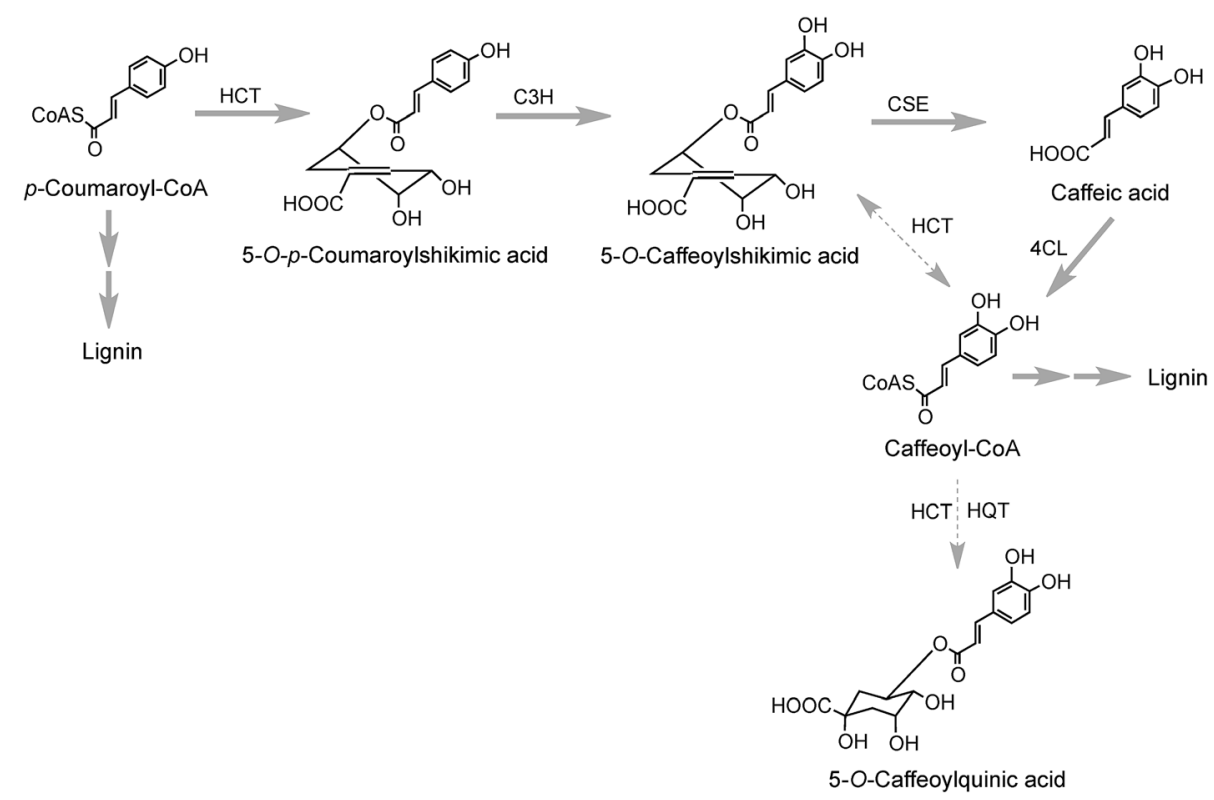

Fig. 3 5-O-Caffeoylquinic acid biosynthesis by a shikimate shunt. The likely main routes are indicated with bold arrows and minor routes with dotted arrows. Enzymes: hydroxycinnamoyl-CoA:shikimate hydroxycinnamoyl transferase (HCT), p-coumaroyl-3'-hydroxylase (C3H), caffeoylshikimate esterase (CSE), 4-cinnamoyl CoA ligase (4CL), hydroxycinnamoyl CoA:quinate hydroxycinnamoyl transferase (HQT). 
cloned from oats (Avena sativa) ${ }^{\mathbf{1 4 9}}$ and other plants, including Coffea species. ${ }^{150}$ Although the main role of the CCoAOMT family was initially ascribed to lignin biosynthesis, ${ }^{\mathbf{1 5 1}}$ other studies have indicated its multifunctional role in catalysing steps in other biosynthetic pathways including those producing the coumarin, scopoletin (16), ${ }^{152}$ anthocyanins ${ }^{153}$ and other flavonoids. ${ }^{154}$ In the scopoletin biosynthetic pathway, a recombinant CCOAOMT1 protein possessed methylating activity in vitro targeting caffeoyl-CoA and converting it to feruloyl-CoA. ${ }^{152}$

A third pathway to 5-CQA from cinnamic acid has been proposed on the basis of data obtained with tubers of sweet potato (Ipomoea batatas Lam.) which converted $\left[2-{ }^{14} \mathrm{C}\right]$ cinnamic acid to a radiolabeled intermediate that was metabolized to 5CQA and further converted to 3,5-diCQA ${ }^{155}$ both of which are major native acyl-quinic acids in sweet potato. ${ }^{156}$ The radiolabeled intermediate was identified as 1-O-cinnamoyl-glucose $\mathrm{e}^{157}$ and it was proposed that it was converted to 5-CQA via 1-O- $p$ coumaroyl-glucose and 1-O-caffeoyl-glucose as illustrated in Fig. 4. ${ }^{157,158}$ Enzymes which catalyse the first three steps in this postulated pathway, a UDP-glucose:cinnamate glucosyltransferase, ${ }^{159}$ a $p$-coumaroyl-glucose hydroxylase ${ }^{\mathbf{1 6 0}}$ and a hydroxycinnamoyl glucose:quinate hydroxycinnamoyltransferase have been detected in sweet potato roots. ${ }^{158,161}$ In addition, a partially purified enzyme has been isolated from sweet potato which catalyses the single step conversion of 5CQA to 3,5 -diCQA. ${ }^{162}$

The production of cinnamoyl-glucose has also been reported in strawberry (Fragaria $\times$ ananassa) where a cDNA encoding a UDP-glucose:cinnamate preferentially catalysed cinnamic acid in vitro. The cDNA transcript was found to accumulate during strawberry fruit ripening and this positively correlated with the in planta concentration of cinnamoyl, $p$-coumaroyl-, and caffeoyl-glucose. ${ }^{163}$ Similar results were obtained when the gene encoding this enzyme was overexpressed in transgenic Populus where it led to accumulation of hydroxycinnamate glucose esters which further increase under $\mathrm{N}$-limiting conditions. ${ }^{164}$
It has long been known that exposure of trans-cinnamoylquinic acids to UV light readily produces the associated cis isomers, and such isomers have been found in tissues, such as the leaves of tobacco and coffee, that are exposed to comparatively strong UV-irradiation, suggesting that such exposure might explain their presence. ${ }^{48} 3,5$-DiCQA has been shown to undergo isomerisation upon UV exposure where the naturally occurring 3-trans, 5-trans-diCQA isomer (18) gives rise to the 3-cis, 5-trans-diCQA (19), 3-trans, 5-cis-diCQA (20), and 3-cis, 5-cis-diCQA (21) isomers, allowing them to have a wider synergistic biological activity when present together. ${ }^{165}$ Recent studies of 120 samples of Stevia rebaudiana leaves have established a strong positive correlation between sunshine hours prior to harvesting and the content of $c$ is isomers in the harvested leaves, ${ }^{\mathbf{1 6 6}}$ effectively confirming this hypothesis. It has also been shown that treatment of cultured tobacco cells with several inducers of plant stress leads to an approximate doubling of cis 5-CQA (22) in the absence of UV irradiation..$^{50}$

There are many other details yet to be elucidated and several intriguing questions remain to be answered regarding the factors that control the biosynthesis of acyl-quinic acids and the significance of the observed variations.

\section{Role of acyl-quinic acids in planta}

With one or two notable exceptions, the in planta role(s) of acylquinic acids are not known with any certainty. It seems almost certain that their function in tissues containing $c a .100 \mathrm{~g} \mathrm{~kg}^{-1}$ is different to their function in tissues containing only $\mathrm{mg} \mathrm{kg} \mathrm{kg}^{-1}$ concentrations. Radiotracer studies have shown that 5-CQA (9) is incorporated into lignin in Xanthium ${ }^{\mathbf{1 6 7}}$ which suggests that 5CQA may accumulate as a store of cinnamic acid for lignin biosynthesis. It has also been proposed that FQAs are important indirect plant defence agents acting as lignin precursors, the lignin per se making tissues more resistant to attack or invasion. ${ }^{168}$

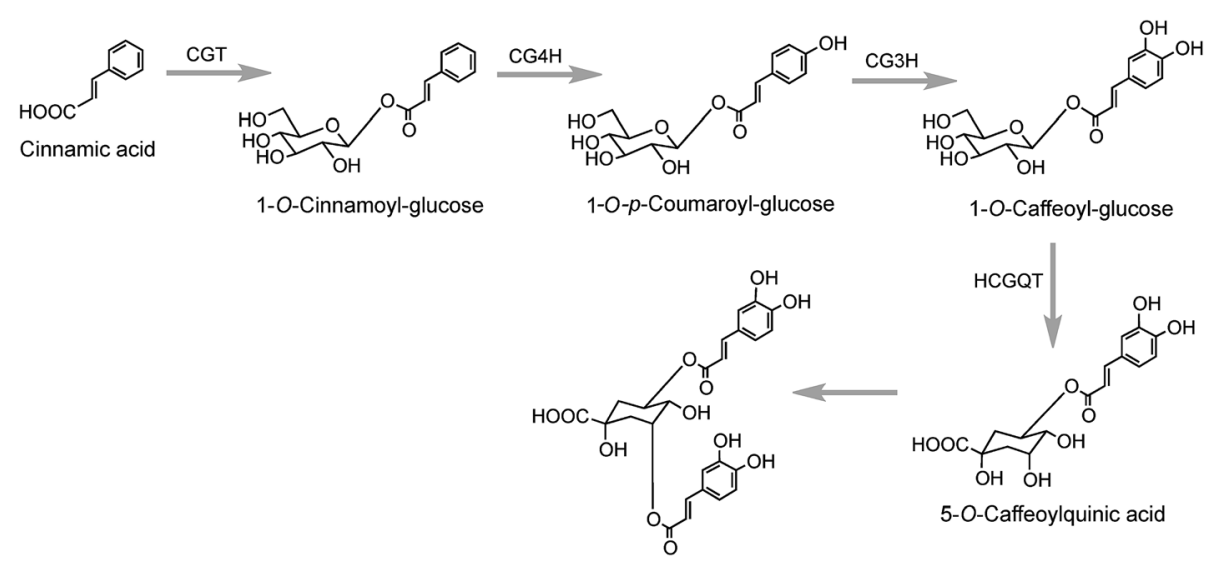

3,5-O-Dicaffeoylquinic acid

Fig. 4 Proposed pathway for the biosynthesis of 5-O-caffeoylquinic acid in sweet potato. Enzymes: UDP-glucose:cinnamate glucosyltransferase (CGT), cinnamate-glucose $4^{\prime}$-hydroxylase (CG4H), p-coumaroyl-glucose $3^{\prime}$-hydroxylase (CG3H) and hydroxycinnamoyl glucose:quinate hydroxycinnamoyltransferase (HCGQT). 
<smiles>O=C(/C=C/c1ccc(O)c(O)c1)OCC1CC(O)(C(=O)O)CC(O)C1OC(=O)/C=C/c1ccc(O)c(O)c1</smiles>

3-trans, 5-trans-O-Dicaffeoylquinic acid (18)<smiles>O=C(/C=C\c1ccc(O)c(O)c1)OC1CC(O)(C(=O)O)CCC1OC(=O)/C=C/c1ccc(O)c(O)c1</smiles>

3-cis, 5-trans-O-Dicaffeoylquinic acid (19)<smiles>O=C(/C=C/c1ccc(O)c(O)c1)OCC1CC(C(O)C(=O)/C=C\c2ccc(O)c(O)c2)CC(O)(C(=O)O)C1</smiles>

3-trans, 5-cis-O-Dicaffeoylquinic acid (20)<smiles>O=C(/C=C\c1ccc(O)c(O)c1)OC(O)C1CC(O)(C(=O)O)CCC1OC(=O)/C=C\c1ccc(O)c(O)c1</smiles>

3-cis, 5-cis-O-Dicaffeoylquinic acid (21)<smiles>O=C(/C=C\c1ccc(O)c(O)c1)OC(=O)C1CC(O)C(O)CCC1(O)C(=O)O</smiles>

5-cis-O-Caffeoylquinic acid (22)
A high acyl-quinic acid content has been linked to the allelopathic potential and resistance to root disease of some sweet potato clones, ${ }^{169}$ via an inhibition of fungal toxin production. ${ }^{170}$ An elevated 5-CQA content of transgenic tomato plants has been associated with enhanced tolerance to paraquat-induced oxidative stress and resistance to infection by the pathogen Pseudomonas syringae ${ }^{171}$ Acyl-quinic acids acting as defence metabolites may have possible links to phytohormone-activated defense signaling networks as implied in Nicotiana tabacum cells treated with salicylic acid (23) and methyl-jasmonate (24). ${ }^{172}$ The defense signaling networks produce a range of acyl-quinic acids to combat pathogens and some are capable of inhibiting cell wall degrading enzymes, such as polygalacturonase and cutinase, produced by the pathogens. ${ }^{173}$<smiles>O=C(O)c1ccccc1O</smiles>

Salicylic acid (23)

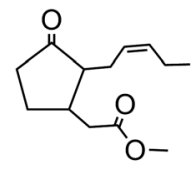

Methyl jasmonate (24)
In tomato plants CQA has been associated with a protective ability against oxidative damage when exposed to salinity or a combination of salinity and heat. ${ }^{174}$ Studies with transgenic tobacco plants have demonstrated that inhibition of acyl-quinic acid biosynthesis makes the plants more susceptible to oxidative damage and accelerated cell death, ${ }^{175}$ while in tomato, globe artichoke and chamomile (Matricaria chamomilla), acyl-quinic acids appear to protect against UV damage. ${ }^{\mathbf{1 7 6 - 1 7 8}}$ There is evidence that these compounds also protect against predators because those which are substrates for polyphenol oxidase and/ or peroxidase, are readily converted to quinones which react readily with nucleophiles and link covalently to protein. ${ }^{\mathbf{1 7 9 - 1 8 2}}$ This interaction is thought to have anti-feedant activity, for example, limiting the growth of herbivorous insect pests by impairing digestibility of the hosts' proteins. ${ }^{183-185}$

\section{Acyl-quinic acids in coffee}

Much of the literature on acyl-quinic acids focuses on coffee and green beans which contain substantial amounts. In addition to the major CQAs, FQAs, diCQAs and $p$-CoQAs (Fig. 5) many quantitatively minor acyl-quinic acids have also been

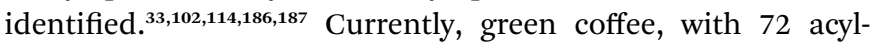
quinic acids, is second only to Lonicera japonica (Japanese honeysuckle) which contains a record 111 in the form of 35 trans-cinnamoyl-quinic acids, 17 cis isomers and 49 acyl-quinic acid glucosides. ${ }^{\mathbf{1 8 8}}$

The principal component in green coffee beans is always 5-CQA (9) and is accompanied by numerous diacyl-quinic acids and some triacyl-quinic acids. All the cinnamic acid derivatives so far characterised in green coffee have the cinnamate moiety in the trans configuration. To date, no 1-acyl-quinic acids have been found in the green coffee bean. The triacyl-quinic acids have so far been found only in Robusta coffee beans. ${ }^{33}$ Robustas usually have a greater content of any isomer but there are exceptions, the best known being a tendency for Arabicas to contain more 5- $p$-CoQA (25) than Robustas. From a chemotaxonomic standpoint it is interesting to note that acyl-quinic acids containing $3^{\prime}, 4^{\prime}$-dimethoxycinnamic acid (26), 3', $4^{\prime}, 5^{\prime}$-trimethoxycinnamic acid (27), 3'-methoxy-4', $5^{\prime}$-dihydroxycinnamic acid (5-hydroxyferulic 
<smiles>O=C(O)CC1(O)CC(O)C(OC(=O)C=Cc2ccc(O)c(O)c2)CO1</smiles>

3-O-Caffeoylquinic acid<smiles>COc1cc(/C=C/C(=O)OC2C(O)CC(O)(C(=O)O)CC(O)C2O)ccc1O</smiles>

3-O-Feruloylquinic acid<smiles>O=C(C=Cc1ccc(O)c(O)c1)OC1C(O)CC(O)(C(=O)O)CC1O</smiles>

4-O-Caffeoylquinic acid<smiles>COc1cc(CC(=O)OC2C(O)CC(O)(C(=O)O)CC(O)C2O)ccc1O</smiles>

4-O-Feruloylquinic acid<smiles>O=C(COC(O)C1CC(O)C(O)CCC1C(=O)O)c1ccc(O)c(O)c1</smiles>

5-O-Caffeoylquinic acid<smiles>COc1cc(C=COC(=O)CCC(O)C(O)CC(=O)O)ccc1O</smiles>

5-O-Feruloylquinic acid<smiles>O=C(COC(=O)COC(=O)c1ccc(O)c(O)c1)OCC1CC(O)CC(O)CC1C(=O)O</smiles>

3,4-O-Dicaffeoylquinic acid

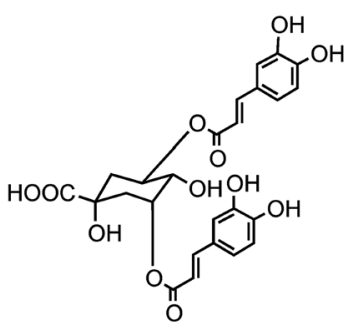

3,5-O-Dicaffeoylquinic acid

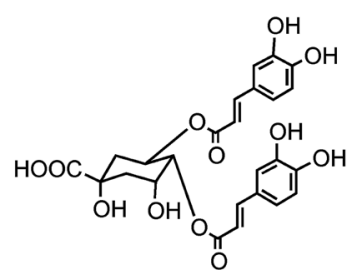

4,5-O-Dicaffeoylquinic acid<smiles>O=C(/C=C/c1ccc(O)cc1)OC1C(O)CC(O)(C(=O)O)CC1O</smiles>

4-O-p-Coumaroylquinic acid<smiles>O=C(O)CCC(O)C(O)CC(O)C(O)CC(=O)OCc1ccc(O)cc1</smiles>

5-O-p-Coumaroylquinic acid

Fig. 5 The main acyl-quinic acids in coffee beans.

acid) (28), and $3^{\prime}, 5^{\prime}$-dihydroxy-4'-methoxycinnamic acid (29) are scarce in nature and may be unique to coffee. Cinnamoyl-amino acid conjugates also have been characterised, ${ }^{26,187,189,190}$ and together with the acyl-quinic acids have been used as criteria in chemo-taxonomic studies ${ }^{191,192}$ for distinguishing Robustas from
Arabicas, ${ }^{193}$ and to some extent the profile can be used to define the geographic origin of green coffee beans, especially Robustas from Angola, ${ }^{25,197}$ Ethiopia, ${ }^{194}$ Uganda, Vietnam, Cameroun and Indonesia, and for distinguishing South American from African Arabicas. ${ }^{193}$

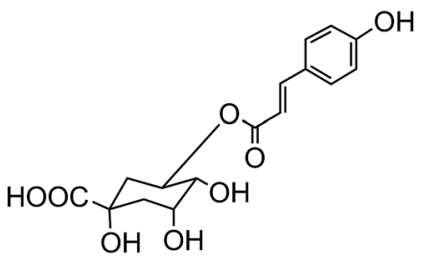

5-O-p-Coumaroylquinic acid (25)<smiles>COc1ccc(CC(=O)O)cc1OC</smiles>

3',4'-Dimethyoxycinnamic acid (26)<smiles>COc1cc(CC(=O)O)cc(OC)c1OC</smiles>

3', 4',5'-Trimethoxycinnamic acid (27)<smiles>COc1cc(C=CC(=O)O)cc(O)c1O</smiles>

3'-Methoxy-4',5'-dihydroxycinnamic acid

(5'-hydroxyferulic acid) (28)<smiles>COc1c(O)cc(CC(=O)O)cc1O</smiles>

3',5'-Dihydroxy-4'-methoxycinnamic acid (29) 
Table 2 Cinnamoyl-quinic acids and other cinnamic acid derivatives occurring in green coffee beans

Caffeic acid $^{114}$

Ferulic acid $^{114}$

3,4-Dimethoxycinnamic acid ${ }^{114}$

3-O-p-Coumaroylquinic acid $^{30}$

4-O-p-Coumaroylquinic acid ${ }^{30}$

5-O- $p$-Coumaroylquinic acid ${ }^{30}$

3-O-Feruloylquinic acid $^{29}$

4-O-Feruloylquinic acid $^{29}$

5-O-Feruloylquinic acid ${ }^{29}$

3-O-Sinapoylquinic acid ${ }^{101}$

4-O-Sinapoylquinic acid ${ }^{101}$

5-O-Sinapoylquinic acid ${ }^{101}$

3,4-O-Dicaffeoylquinic acid $^{30}$

3,5 -O-Dicaffeoylquinic acid ${ }^{30}$

4,5-O-Dicaffeoylquinic acid ${ }^{30}$

3-O-Caffeoyl-4-O-feruloylquinic acid $^{30}$

3-O-Feruloyl-4-O-caffeoylquinic acid ${ }^{30}$

3-O-Caffeoyl-5-O-feruloylquinic acid $^{30}$

3-O-Feruloyl-5-O-caffeoylquinic acid $^{30}$

4-O-Caffeoyl-5-O-feruloylquinic acid $^{30}$

4-O-Feruloyl-5-O-caffeoylquinic acid $^{30}$

3-O-Dimethoxycinnamoyl-4-O-caffeoylquinic acid ${ }^{102}$ 3-O-Caffeoyl-4-O-dimethoxycinnamoylquinic acid ${ }^{190}$ 3-O-Dimethoxycinnamoyl-5-O-caffeoylquinic acid $^{102}$ 3-O-Caffeoyl-5-O-dimethoxycinnamoylquinic acid ${ }^{190}$ 4-O-Dimethoxycinnamoyl-5-O-caffeoylquinic acid $^{102}$ 4-O-Caffeoyl-5-O-dimethoxycinnamoylquinic acid ${ }^{190}$

3-O-p-Coumaroyl-4-O-feruloylquinic acid ${ }^{101}$ 3-O- - -Coumaroyl-5-O-feruloylquinic acid ${ }^{101}$ 4-O-p-Coumaroyl-5-O-feruloylquinic acid ${ }^{101}$

3-O-p-Coumaroyl-4-O-dimethoxycinnamoylquinic acid ${ }^{33}$ 3-O- $p$-Coumaroyl-5-O-dimethoxycinnamoylquinic acid ${ }^{33}$

4-O-Dimethoxycinnamoyl-5-O- $p$-coumaroylquinic acid ${ }^{101}$

3-O-Trimethoxycinnamoyl-5-O-caffeoylquinic $\operatorname{acid}^{33}$

4-O-Trimethoxycinnamoyl-5-O-caffeoylquinic acid ${ }^{33}$

3-O-(3', $5^{\prime}$-dihydroxy-4'-methoxy)cinnamoyl-4-O-feruloylquinic $\operatorname{acid}^{33}$

3,4-O-Dicaffeoyl-5-O-feruloylquinic acid $^{33}$

3,5-O-Dicaffeoyl-4-O-feruloylquinic acid $^{33}$

3-O-Feruloyl-4,5-O-dicaffeoylquinic acid $^{33}$

3-O-Dimethoxycinnamoyl-4-O-feruloyl-5-O-caffeoylquinic acid $^{b 33}$
Caffeoyl-hexose conjugate ${ }^{a 114}$

Dicaffeoyl-hexose conjugate ${ }^{a 114}$

Dimethoxycinnamoyl-hexose conjugate $e^{a 114}$

3-O-Caffeoylquinic acid $^{30}$

4-O-Caffeoylquinic acid ${ }^{30}$

5-O-Caffeoylquinic acid $^{30}$

3-O-Dimethoxycinnamoylquinic acid $^{102}$ 4-O-Dimethoxycinnamoylquinic acid ${ }^{102}$ 5-O-Dimethoxycinnamoylquinic acid ${ }^{102}$

3,4-O-Di- $p$-coumaroylquinic acid ${ }^{111}$

$3,5-O$-Di- $p$-coumaroylquinic acid ${ }^{111}$

4,5-O-Di- $p$-coumaroylquinic acid ${ }^{111}$

3,4-O-Diferuloylquinic acid ${ }^{110}$

3,5-O-Diferuloylquinic acid ${ }^{110}$

4,5-O-Diferuloylquinic acid ${ }^{110}$

3-O-Caffeoyl-4-O- $p$-coumaroylquinic acid ${ }^{101}$

3 -O- $p$-Coumaroyl-4-O-caffeoylquinic acid ${ }^{101}$

3-O-Caffeoyl-5-O- - -coumaroylquinic acid ${ }^{101}$

3-O- - -Coumaroyl-5-O-caffeoylquinic acid ${ }^{101}$

4-O-Caffeoyl-5-O- - -coumaroylquinic acid ${ }^{101}$

4-O- $p$-Coumaroyl-5-O-caffeoylquinic acid ${ }^{101}$

3-O-Dimethoxycinnamoyl-4-O-feruloylquinic acid ${ }^{102}$ 3-O-Dimethoxycinnamoyl-5-O-feruloylquinic acid ${ }^{102}$ 4-O-Dimethoxycinnamoyl-5-O-feruloylquinic acid ${ }^{102}$

3-O-Caffeoyl-4-O-sinapoylquinic acid $^{33}$ 3-O-Sinapoyl-5-O-caffeoylquinic acid $^{33}$ 3-O-Sinapoyl-4-O-caffeoylquinic acid $^{33}$

3-O-Sinapoyl-5-O-feruloylquinic acid $^{33}$ 3-O-Feruloyl-4-O-sinapoylquinic acid ${ }^{b 33}$ 4-O-Sinapoyl-5-O-feruloylquinic acid ${ }^{33}$

3-O-Trimethoxycinnamoyl-4-O-feruloylquinic acid $^{33}$ 3-O-Trimethoxycinnamoyl-5-O-feruloyl-quinic acid $^{33}$ 4-O-Trimethoxycinnamoyl-5-O-feruloylquinic acid $^{33}$

3,4,5-O-Tricaffeoylquinic acid ${ }^{33}$

3,4-O-Dicaffeoyl-5-O-sinapoylquinic acid $^{33}$ 3-O-Sinapoyl-4,5-O-dicaffeoylquinic acid $^{33}$

3,4-O-Diferuloyl-5-O-caffeoylquinic $\operatorname{acid}^{33}$ 3-O-Caffeoyl-4,5-O-diferuloylquinic acid $^{33}$

${ }^{a}$ Tentative identification. ${ }^{b}$ Identification correct but structure as illustrated in original paper is incorrect.

Tables 2 and 3 provide a comprehensive list of the acylquinic acids and cinnamoyl-amino acid conjugates occurring in green coffee beans. Although Robusta coffees contain all six CFQA and all six $p$-coumaroyl-caffeoylquinic acids, intriguingly, they only contain three caffeoyl-( $3^{\prime}, 4^{\prime}$-dimethoxycinnamoyl)quinic acids, feruloyl-( $\left(3^{\prime}, 4^{\prime}\right.$-dimethoxycinnamoyl)quinic acids, $p$-coumaroyl-feruloylquinic acids and $p$-coumaroyl- $\left(3^{\prime}, 4^{\prime}\right.$ - dimethoxycinnamoyl)quinic acids highlighting some subtle control of biosynthesis.

Roasting of green coffee beans can result in acyl-quinic acid losses of $\sim 90 \% .^{43}$ Substantial transformations also occur and the number of acyl-quinic acids detected in the roasted bean increases to over 200 as judged by the number of characteristic fragments observed in tandem mass spectrometry-based 
Table 3 Cinnamoyl-amino acid conjugates in green and roasted coffee beans

Cinnamoyl-amino acid conjugates

$p$-Coumaroyl- $N$-tyrosine $\mathrm{e}^{186}$

Caffeoyl- $N$-tyrosine ${ }^{186}$

Feruloyl- $N$-tyrosine ${ }^{186}$

$p$-Coumaroyl- $N$-tryptophan ${ }^{186}$

Caffeoyl- $N$-tryptophan ${ }^{186}$

Feruloyl- $N$-tryptophan ${ }^{186}$

Caffeoyl- $N$-phenylalanine ${ }^{186}$

$p$-Coumaroyl- $N$-aspartic acid ${ }^{187}$

Caffeoyl- $N$-aspartic acid ${ }^{187}$

analyses, in comparison with the 72 derivatives detected in the green coffee bean..$^{30,31,33,102,114,115,186,187,190}$ Acyl migration and hydrolysis during coffee roasting changes the relative proportions of each subgroup, being most obvious within the CQAs, FQAs and diCQAs, with 3-CQA being very susceptible to hydrolysis. For example, it has been reported that after 5 min of roasting the content of 5-CQA (9) decreased substantially while the levels of 4-CQA (10) and 3-CQA (11) increased to twice their original values. The same behavior was observed for FQAs. It is also noted that partial hydrolysis of diCQAs to CQAs occurs in addition to isomerization. ${ }^{22,195}$ The triacyl-quinic acid derivatives of the green coffee bean have not been found in the roasted bean, and presumably are lost via partial hydrolysis. The clearest evidence for acyl migration during coffee roasting is the appearance of 1-acyl derivatives, absent from the green beans, ${ }^{196}$ either as the free acids or as the lactones 1-O-caffeoylquinic-1,5lactone (1-CQL) (30) and 1-O-feruloylquinic-1,5-lactone (1-FQL) (31) $)^{197}$ with similar transformations also occurring during brewing and instant coffee manufacture. ${ }^{198,199}$
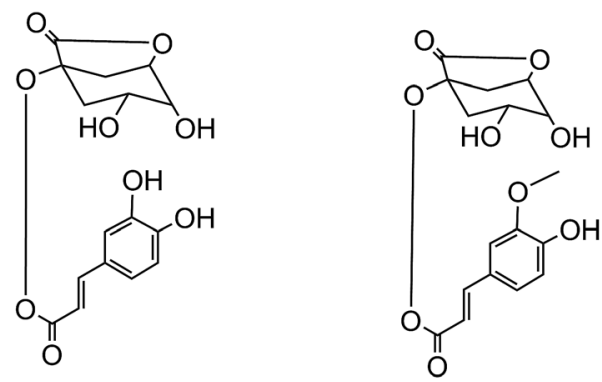

1-O-Caffeoyl-1,5,-lactone (30) 1-O-Feruloyl-1,5,-lactone (31)
Quantitatively, the main acyl-quinic acids in the roast bean and, instant coffee powder and beverage are CQAs, FQAs and diCQAs (Fig. 5). ${ }^{23}$ Despite the losses of acyl-quinic acids that occur during roasting, coffee beverage is still a rich, probably the richest, dietary source. ${ }^{200}$ However, because of the use of a diversity of roasting methods and infusion/manufacturing protocols, a 'cup of coffee' is an extremely variable commodity which is best illustrated by modern data for the acyl-quinic acids contents. Espresso coffees bought at 20 commercial outlets near the University of Glasgow in the UK delivered between $24 \mathrm{mg}$ and $423 \mathrm{mg}$ per serving (Table 4$) \cdot{ }^{43}$ A similar but more extensive study of coffees from 104 commercial outlets in Scotland, Italy and Spain observed that one cup delivered between $6 \mathrm{mg}$ and $188 \mathrm{mg}$ of acyl-quinic acids. ${ }^{201}$ Standardised brewing of eight commercial roast and ground coffees $(20 \mathrm{~g} / 900 \mathrm{~mL})$ delivered between 27 and $95 \mathrm{mg}$ of acyl-quinic acids per cup, whereas standardised preparation of ten commercial instant coffees available in the UK $(1.8 \mathrm{~g} / 200 \mathrm{~mL})$ delivered between 37 and $121 \mathrm{mg} .{ }^{202}$ An individual preferring weak instant coffee would likely consume rather less than these figures suggest. It is well known that coffee brews consumed on the American west coast are appreciably weaker than on the American east coast. This variation is such that, conceivably, a person consuming 10 cups per day might actually receive less acyl-quinic acids than another consuming only one cup per day. While this is undoubtedly an extreme and rare event, a four to five-fold variation can surely be expected. Under such circumstances data from epidemiological studies that link 'cups consumed' with an effect on health, whether advantageous or otherwise, can only be treated as a hypothesis until further investigations are performed under conditions that are as controlled as possible.

\section{Bioavailability and metabolism of acyl-quinic acids in humans}

Because of the dominance of coffee as the source of dietary acylquinic acids it has been used in most human studies on their absorption and metabolism, supported by in vitro investigations using cultured human cells. A study using cultured gastric epithelial cells established that CQAs, FQAs and CQLs cross the epithelium. The 3-acyl and 5-acyl regio-isomers probably cross by passive diffusion via the paracellular route, whereas facilitated transport might operate for 4-CQA and 4-FQA. ${ }^{203}$ DiCQAs crossed the membrane even more rapidly, a behaviour that could be attributable to their greater hydrophobicity, although in the case

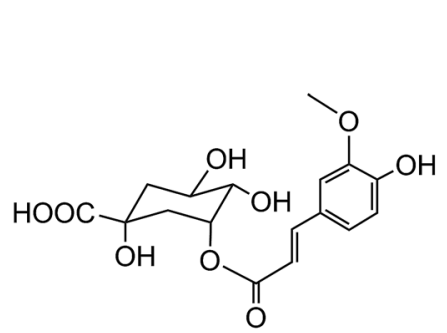

3-O-Feruloylquinic acid (32)

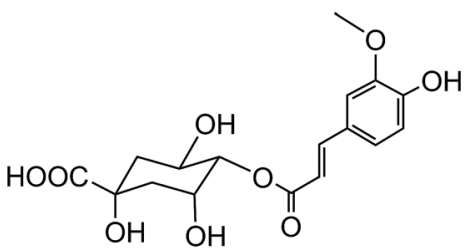

4-O-Feruloylquinic acid (33)

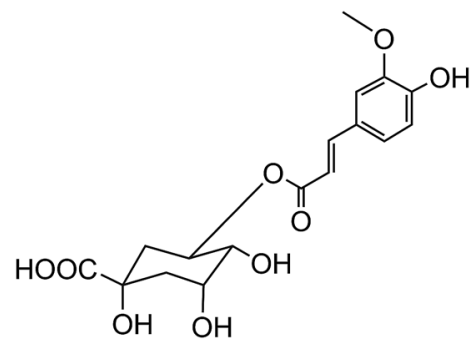

5-O-Feruloylquinic acid (34) 
Table 4 Levels of caffeoylquinic acids $(6,14,15)$ in espresso coffees purchased from 20 coffee shops in Glasgow, United Kingdom (after Crozier et $\left.\mathrm{al}^{43}\right)^{a}$

\begin{tabular}{|c|c|c|c|c|c|}
\hline Coffee shop & Volume of coffee (mL) & 3-CQA (mg) & 4-CQA (mg) & 5-CQA (mg) & $\begin{array}{l}\text { Total CQA per } \\
\text { serving (mg) }\end{array}$ \\
\hline Pattiserie Francoise & 52 & 95 & 112 & 216 & 423 \\
\hline Costa coffee & 25 & 48 & 61 & 118 & 227 \\
\hline Little Italy & 23 & 37 & 59 & 121 & 217 \\
\hline Paperino's & 50 & 65 & 52 & 99 & 216 \\
\hline University Cafe & 49 & 40 & 54 & 93 & 187 \\
\hline Baguette express & 45 & 30 & 40 & 74 & 144 \\
\hline Kember \& Jones & 43 & 37 & 46 & 92 & 141 \\
\hline Heart Buchanan & 24 & 22 & 37 & 67 & 126 \\
\hline Jellyhill & 63 & 26 & 29 & 56 & 111 \\
\hline Coffee @ 491 & 49 & 23 & 31 & 55 & 109 \\
\hline Morton's & 35 & 13 & 16 & 27 & 56 \\
\hline Antipasti & 36 & 8 & 15 & 21 & 44 \\
\hline Starbucks & 27 & 5 & 7 & 12 & 24 \\
\hline Range & $23-70$ & 5-95 & $7-112$ & $12-216$ & $24-423$ \\
\hline Median & 43 & 36 & 37 & 67 & 126 \\
\hline
\end{tabular}

of 3,5-diCQA (18) there was evidence for a carrier-mediated efflux. $^{203}$ These observations may help to explain the results of feeding studies, discussed below, where minor acyl-quinic acids in the coffee beverage had a higher peak plasma concentration $\left(C_{\max }\right)$ than the dominant regio-isomers. For example, Stalmach et $a .^{44}$ observed that 3-FQA (32) and 4-FQA (33) had $C_{\max }$ values of $16 \pm 2 \mathrm{nmol} \mathrm{L}^{-1}$ and $14 \pm 2 \mathrm{nmol} \mathrm{L}^{-1}$, respectively, while the beverage dominant 5-FQA (34) peaked at $6 \pm 2 \mathrm{nmol} \mathrm{L}^{-1}$.

In vitro studies have also shown that acyl-quinic acids differ in their susceptibility to intestinal chlorogenate esterase (acylquinate esterase), with 5-CQA (9) being hydrolysed more readily than 3-CQA (11), and 4-CQA (10) being particularly resistant to hydrolysis. ${ }^{204}$ Consistent with this enzymic hydrolysis occurring in the stomach or upper gastrointestinal (GI) tract, significant amounts of $1 \mathrm{~L}-(-)$-quinic acid, in excess of the amount consumed in the free form, were found in the ileostomy effluent of volunteers who consumed cloudy apple juice, apple smoothie, or coffee. ${ }^{205}$ Such in vivo resistance to enzymic and chemical hydrolysis postabsorption would also predispose to greater plasma concentrations of 4-acyl-quinic acids. It follows that commodities with acylquinic acid profiles substantially different from that of coffee beverage are likely to produce plasma profiles of acyl-quinic acid metabolites that differ quite markedly from those produced when coffee is consumed, as recently reported for mate which contains proportionately more 3-CQA (11) and diCQAs. ${ }^{206}$

The presence of low nmol $\mathrm{L}^{-1}$ concentrations of CQAs in plasma and their low level excretion in urine after oral intake of coffee, ${ }^{\mathbf{4 4 2 0 7 - 2 0 9}}$ artichoke, ${ }^{210}$ and 5-CQA (9) ${ }^{\mathbf{2 1 1}}$ suggest that the bioavailability of acyl-quinic acids per se is limited. In contrast, Monteiro et al. ${ }^{212}$ reported the presence of unmetabolised CQAs in the circulatory system with a $C_{\max }$ of $7.7 \mu \mathrm{mol} \mathrm{L}^{-1}, 2.3 \mathrm{~h}$ $\left(T_{\max }\right)$ after acute ingestion of a coffee containing $3395 \mu \mathrm{mol}$ of acyl-quinic acids. Despite the high $C_{\max }$ of the CQAs, CQAs were not detected in urine collected $0-24 \mathrm{~h}$ after coffee intake. In a subsequent study by the same group, in which volunteers consumed a green coffee extract containing a much lower 451 $\mu \mathrm{mol}$ of acyl-quinic acids, 5-CQA (9) and 4-CQA (10) were detected in urine from some, but not all, subjects. ${ }^{213}$ The CQAs were also detected in plasma although there were unusually marked variations in the plasma pharmacokinetic profiles of the individual subjects with, in two instances, an exceedingly high $C_{\max }$ of $>20 \mu \mathrm{mol} \mathrm{L}{ }^{-1}$ being recorded. The coffee used in this study contained $43.2 \mu \mathrm{mol}$ of diCQAs which after consump-

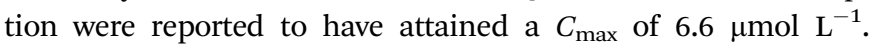
Assuming an average plasma volume of $3 \mathrm{~L}$ per person, this corresponds to $45.8 \%$ of intake. Despite there being some evidence from in vitro studies that diCQAs are more rapidly absorbed than monoacyl-quinic acids. ${ }^{203}$ It is difficult to reconcile these studies with the results obtained by other investigators. After volunteers consumed maté delivering 210 $\mu \mathrm{mol}$ of diCQAs no diacyl-quinic acids were detect in plasma. ${ }^{206}$

Stalmach et al. ${ }^{\mathbf{4 4 2 1 4}}$ carried out coffee feeding studies with healthy humans and ileostomists who have had their colon removed surgically for medical reasons, typically Crohn's disease or ulcerated colitis. In these investigations, samples were analysed using HPLC-MS ${ }^{2}$ without recourse to the use of 
the more typical glucuronidase/sulfatase treatments prior to analysis. It was observed that during passage through the body extensive metabolism of acyl-quinic acids occurs, with some compounds being absorbed in the stomach and/or small intestine and others in the colon. Studies with ileostomists have made a major contribution to our understanding of colonic (poly)phenol metabolism in humans with an intact colon. Viewed simply, a transformation associated with the colonic gut microflora will not be seen in ileostomists. In reality, it is important to recognise some colonisation of the upper GIT can occur in ileostomists and, as a consequence, some limited microbial transformations may persist. An ileostomy involves major surgery and is likely to have some patho-physiological

Table 5 Quantities of acyl-quinic acids in a $200 \mathrm{~mL}$ serving of instant coffee fed to volunteers (after Stalmach et al. $\left.{ }^{44}\right)^{a}$

\begin{tabular}{lr}
\hline Chlorogenic acids & \multicolumn{1}{c}{$\mu \mathrm{mol}$} \\
\hline 3-O-Caffeoylquinic acid & $72 \pm 1.3$ \\
4-O-Caffeoylquinic acid & $78 \pm 1.5$ \\
5-O-Caffeoylquinic acid & $119 \pm 2.1$ \\
Total caffeoylquinic acids & $269 \pm 4.9$ \\
3-O-Feruloylquinic acid & $20 \pm 1.6$ \\
4-O-Feruloylquinic acid & $22 \pm 1.8$ \\
5-O-Feruloylquinic acid & $25 \pm 1.9$ \\
Total feruloylquinic acids & $67 \pm 5.3$ \\
3-O-Caffeoylquinic acid lactone & $34 \pm 2.9$ \\
4-O-Caffeoylquinic acid lactone & $23 \pm 2.0$ \\
Total caffeoylquinic acid lactones & $57 \pm 4.9$ \\
3,4-O-Dicaffeoylquinic acid & $5.8 \pm 0.6$ \\
3,5-O-Dicaffeoylquinic acid & $2.8 \pm 0.3$ \\
4,5-O-Dicaffeoylquinic acid & $4.0 \pm 0.4$ \\
Total dicaffeoylquinic acids & $12.6 \pm 1.2$ \\
4-O-p-Coumaroylquinic acid & $3.8 \pm 0.1$ \\
5-O-p-Coumaroylquinic acid & $3.1 \pm 0.1$ \\
Total $p$-coumaroylquinic acids & $6.8 \pm 0.1$ \\
Total acyl-quinic acids & $\mathbf{4 1 2} \pm \mathbf{9 . 3}$ \\
a Data expressed as mean values \pm SEM $(n=3)$. & \\
&
\end{tabular}

effects on other organs and tissues, and although the consequences have barely been studied, it would not be surprising if there were some alteration to (poly)phenol metabolism in, for example, the upper GIT, liver and kidney of ileostomists.

\subsection{Studies involving volunteers with and without a functioning colon}

Stalmach et $a .^{\mathbf{4 4}}$ carried out a study in which healthy humans with an intact colon consumed a $200 \mathrm{~mL}$ serving of instant coffee, containing $412 \mu \mathrm{mol}(146 \mathrm{mg}$ ) of acyl-quinic acids, with CQAs comprising $65 \%$ of the total (Table 5), after which plasma and urine samples were collected over a $24 \mathrm{~h}$ period. A total of 12 hydroxycinnamate derivatives, of which four were unchanged acyl-quinic acids and eight were metabolites, two of which were unconjugated, were identified and quantified in plasma. Their pharmacokinetic parameters are summarized in Table 6 and pharmacokinetic profiles are illustrated in Fig. 6.

A similar array of metabolites has been detected in plasma after the consumption of coffee by Scherbl et al. ${ }^{209}$ Postingestion $C_{\max }$ values in the Stalmach study ranged from $2.2 \mathrm{nM}$ for 5-CQA (9) to $385 \mathrm{nM}$ for dihydroferulic acid (35) ${ }^{44}$ with the duration for $T_{\max }$ extending from $0.6 \mathrm{~h}$ (ferulic acid- $4^{\prime}$ sulfate [36] and a 3-CQL-sulfate) to $5.2 \mathrm{~h}$ (dihydroferulic acid [35]). The compounds detected in highest concentrations in plasma were free and sulfated conjugates of dihydroferulic acid (35) and dihydrocaffeic acid (37) with $C_{\max }$ values ranging from 41 to $385 \mathrm{nmol} \mathrm{L}^{-1}$. The $T_{\max }$ for these compounds was in a narrow range from 4.7 to $5.2 \mathrm{~h}$, implying absorption in the large intestine. Much shorter $T_{\max }$ values of 0.6 to $1.0 \mathrm{~h}$, indicative of stomach and/or small intestine absorption, were obtained with 5-CQA (9) and three FQAs (32-34) which had not been subject to phase II metabolism, plus ferulic acid-4'-sulfate (36), caffeic acid-3'-sulfate (38), and two CQL-sulfates, and all of which had relatively low $C_{\max }$ values (Fig. 6 and Table 6).

As noted by Stalmach et ll. $^{\mathbf{4 4}}$ most of the acyl-quinic acidderived compounds were rapidly removed from the circulatory

Table 6 Pharmacokinetic parameters of acyl-quinic acid derivatives and metabolites circulating in plasma of healthy volunteers, $0-24 \mathrm{~h}$ following the ingestion of $412 \mu \mathrm{mol}$ of acyl-quinic acids and derivatives contained in a $200 \mathrm{~mL}$ serving of instant coffee (after Stalmach et al. $\left.{ }^{44}\right)^{a}$

\begin{tabular}{|c|c|c|c|}
\hline Chlorogenic acids and metabolites & $C_{\max }\left(\mathrm{nmol} \mathrm{L}^{-1}\right)$ & $T_{\max }(\mathrm{h})$ & $T_{1 / 2}^{c}(\mathrm{~h})$ \\
\hline 5-O-Caffeoylquinic acid & $2.2 \pm 1.0$ & $1.0 \pm 0.2$ & $0.3 \pm 0.3$ \\
\hline 3-O-Caffeoylquinic lactone-sulfate & $27 \pm 3$ & $0.6 \pm 0.1$ & $0.5 \pm 0.1$ \\
\hline 4-O-Caffeoylquinic lactone-sulfate & $21 \pm 4$ & $0.7 \pm 0.1$ & $0.4 \pm 0.1$ \\
\hline 3-O-Feruloylquinic acid & $16 \pm 2$ & $0.7 \pm 0.1$ & $0.9 \pm 0.1$ \\
\hline 4-O-Feruloylquinic acid & $14 \pm 2$ & $0.8 \pm 0.1$ & $0.9 \pm 0.1$ \\
\hline 5-O-Feruloylquinic acid & $6.0 \pm 1.5$ & $0.9 \pm 0.1$ & $0.8 \pm 0.1$ \\
\hline Caffeic acid- $3^{\prime}$-sulfate & $92 \pm 11$ & $1.0 \pm 0.2$ & $1.9 \pm 0.4$ \\
\hline \multirow[t]{2}{*}{ Ferulic acid- $4^{\prime}$-sulfate ${ }^{b}$} & $76 \pm 9$ & $0.6 \pm 0.1$ & $4.9 \pm 1.0$ \\
\hline & $46 \pm 13$ & $4.3 \pm 0.3$ & \\
\hline Dihydroferulic acid & $385 \pm 86$ & $4.7 \pm 0.3$ & $1.4 \pm 0.4$ \\
\hline Dihydroferulic acid- $4^{\prime}$-sulfate & $145 \pm 53$ & $4.8 \pm 0.5$ & $4.7 \pm 0.8$ \\
\hline Dihydrocaffeic acid & $41 \pm 10$ & $5.2 \pm 0.5$ & $1.0 \pm 0.4$ \\
\hline Dihydrocaffeic acid- $3^{\prime}$-sulfate & $325 \pm 99$ & $4.8 \pm 0.6$ & $3.1 \pm 0.3$ \\
\hline
\end{tabular}

${ }^{a}$ Data expressed as mean values $\pm \operatorname{SEM}(n=11) .{ }^{b}$ Double $C_{\max }$ and $T_{\max }$ values are due to the biphasic absorption profile of ferulic acid-4'-sulfate (see Fig. 4). ${ }^{c}$ Apparent $T_{1 / 2}$ estimated after oral intake rather than intravenous dosing. 

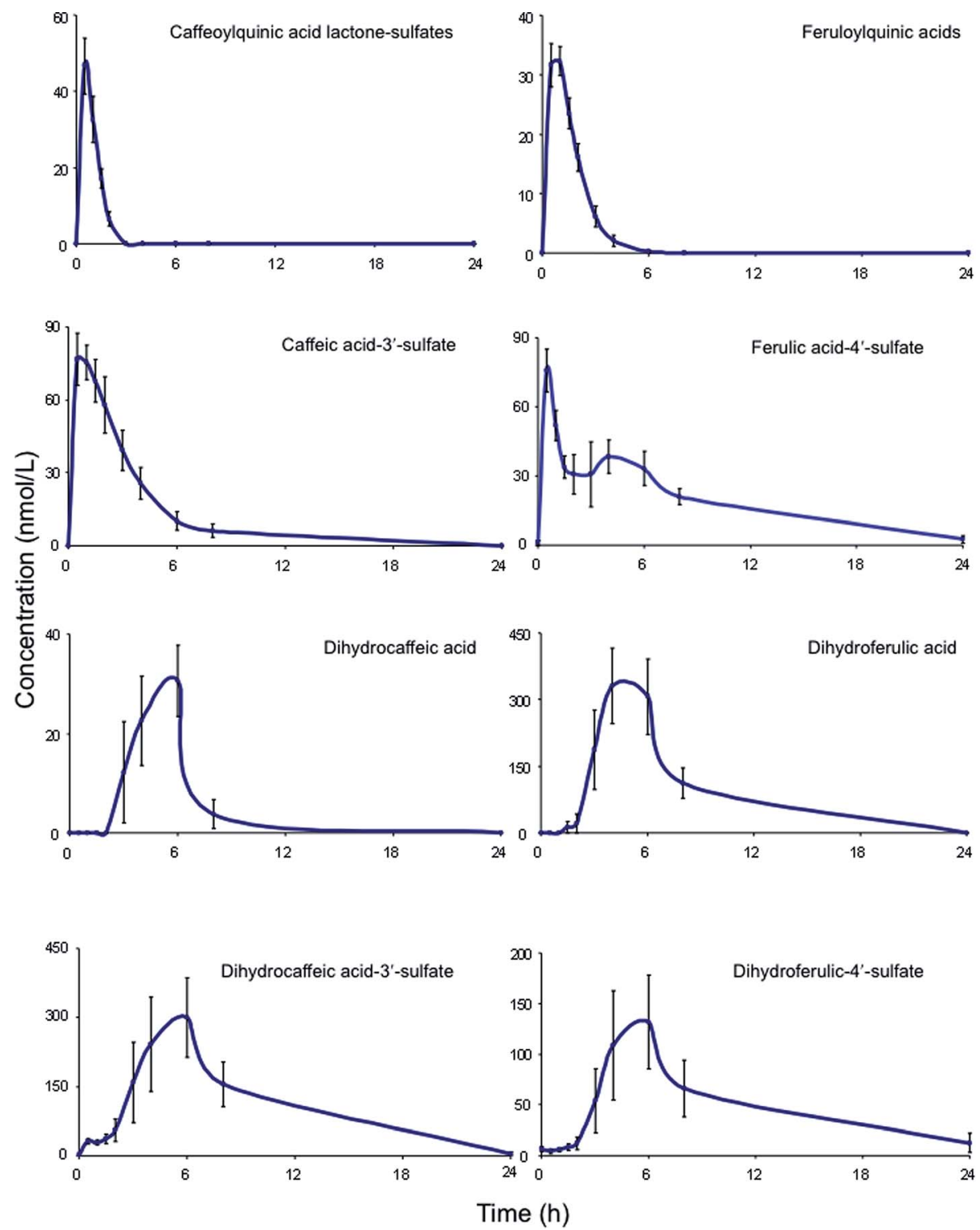

Fig. 6 Plasma pharmacokinetic profiles of circulating acyl-quinic acids and metabolites, following the ingestion of $200 \mathrm{~mL}$ of coffee by healthy human subjects (based on Stalmach et al. ${ }^{44}$ ).<smiles>COc1cc(CCC(=O)O)ccc1O</smiles>

Dihydroferulic acid (35)<smiles>O=C(O)CCc1ccc(O)c(O)c1</smiles>

Dihydrocaffeic acid (37)<smiles>COc1cc(/C=C/C(=O)O)ccc1OS(=O)(=O)O[Na]</smiles>

Ferulic acid-4'-sulfate (36)<smiles>O=C(O)C=Cc1ccc(O)c(O[Na])c1</smiles>

Caffeic acid-3'-sulfate (38)

system with apparent elimination half-life $\left(T_{1 / 2}\right)$ values of 0.3 to $1.9 \mathrm{~h}$ (Table 6). The only compounds with an extended $T_{1 / 2}$ were dihydroferulic acid- $4^{\prime}$-sulfate (39) (4.7 h), dihydrocaffeic acid-3'sulfate (40) (3.1 h) and ferulic acid- $4^{\prime}$-sulfate (36) which had an unusual biphasic plasma profile with dual $T_{\max }$ values at $0.6 \mathrm{~h}$ and $4.3 \mathrm{~h}$. It is of note that the free acid, dihydroferulic acid (35), as opposed to the more typical glucuronide and sulfate metabolites, was the principal component to accumulate in plasma which also contained dihydrocaffeic acid (38) in a lower concentration.

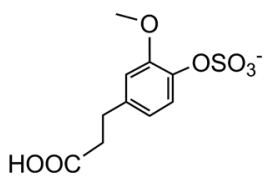

Dihydroferulic acid-4'-sulfate (39)<smiles>O=C(O)CCc1ccc(O)c(OS(=O)(=O)O[Na])c1</smiles>

Dihydrocaffeic acid-3'-sulfate (40) 
The true $T_{1 / 2}$ values can be determined only by intravenous dosing of the metabolite. Estimates based on elimination after oral intake overestimate the true $T_{\max }$ because the metabolite is still entering the plasma when the elimination is being estimated. A further complication arising with gut flora metabolites for which absorption, and hence elimination, cannot commence until several hours after substrate ingestion, is the lack of sufficient data points in the declining period between 8 and 24 hours. The lack of a reliable value for the true $T_{\max }$ effectively precludes modelling of multiple doses at say three hour intervals, i.e. the manner in which many people drink coffee. Nevertheless, with such a pattern of repeat consumption

Table 7 Quantities of acyl-quinic acids and metabolites recovered in ileal fluid collected $0-24 \mathrm{~h}$ after the consumption of $200 \mathrm{~mL}$ of instant coffee containing $385 \mu \mathrm{mol}$ of acyl-quinic acids by humans with an ileostomy (after Stalmach et al. $\left.{ }^{214}\right)^{a}$

\begin{tabular}{|c|c|c|}
\hline Acyl-quinic acids and metabolites & $\begin{array}{l}\text { Ileal fluid } \\
(\mu \mathrm{mol})\end{array}$ & $\begin{array}{l}\text { Recovery } \\
\text { of amount } \\
\text { ingested (\%) }\end{array}$ \\
\hline 3-O-Caffeoylquinic acid & $55 \pm 6$ & \\
\hline 4-O-Caffeoylquinic acid & $45 \pm 6$ & \\
\hline 5-O-Caffeoylquinic acid & $64 \pm 10$ & \\
\hline Total caffeoylquinic acids & $164 \pm 22$ & $59 \pm 8$ \\
\hline 3-O-Caffeoylquinic acid-sulfate & $3.5 \pm 0.5$ & \\
\hline 4-O-Caffeoylquinic acid-sulfate & $5.1 \pm 0.6$ & \\
\hline 5-O-Caffeoylquinic acid-sulfate & $0.7 \pm 0.2$ & \\
\hline 3-O-Caffeoylquinic acid-O-glucuronide & $0.7 \pm 0.2$ & \\
\hline 4-O-Caffeoylquinic acid-O-glucuronide & $0.4 \pm 0.2$ & \\
\hline Total caffeoylquinic acid metabolites & $10 \pm 1$ & $3.6 \pm 0.4$ \\
\hline 3-O-Feruloylquinic acid & $12 \pm 1$ & \\
\hline 4-O-Feruloylquinic acid & $12 \pm 1$ & \\
\hline 5-O-Feruloylquinic acid & $13 \pm 1$ & \\
\hline Total feruloylquinic acids & $37 \pm 4$ & $77 \pm 8$ \\
\hline 3-O-Feruloylquinic acid-sulfate & $0.7 \pm 0.2$ & \\
\hline 4-O-Feruloylquinic acid-sulfate & $0.8 \pm 0.2$ & \\
\hline 5-O-Feruloylquinic acid-sulfate & $0.3 \pm 0.1$ & \\
\hline 3-O-Feruloylquinic acid-O-glucuronide & $0.4 \pm 0.1$ & \\
\hline 4-O-Feruloylquinic acid-O-glucuronide & $2.0 \pm 0.3$ & \\
\hline Total feruloylquinic acid metabolites & $4.2 \pm 0.6$ & $8.8 \pm 1.3$ \\
\hline 3-O-Caffeoylquinic lactone & $1.0 \pm 0.3$ & \\
\hline 4-O-Caffeoylquinic lactone & $1.5 \pm 0.1$ & \\
\hline Total caffeoylquinic lactones & $2.5 \pm 0.3$ & $6.4 \pm 0.8$ \\
\hline 3-O-Caffeoylquinic lactone-sulfate & $13 \pm 2.4$ & \\
\hline 4-O-Caffeoylquinic lactone-sulfate & $8.2 \pm 1.7$ & \\
\hline 3-O-Caffeoylquinic lactone- $O$-glucuronide & $0.6 \pm 0.2$ & \\
\hline 4-O-Caffeoylquinic lactone- $O$-glucuronide & $0.4 \pm 0.1$ & \\
\hline Total caffeoylquinic lactone metabolites & $22 \pm 4.4$ & $56 \pm 11$ \\
\hline $4-O-p$-Coumaroylquinic acid & $1.1 \pm 0.3$ & \\
\hline 5-O-p-Coumaroylquinic acid & $1.9 \pm 0.2$ & \\
\hline Total p-coumaroylquinic acids & $3.0 \pm 0.2$ & $46 \pm 3$ \\
\hline 3,4-O-Dicaffeoylquinic acid & $3.0 \pm 0.3$ & \\
\hline 3,5-O-Dicaffeoylquinic acid & $1.3 \pm 0.2$ & \\
\hline 4,5-O-Dicaffeoylquinic acid & $2.2 \pm 0.2$ & \\
\hline Total dicaffeoylquinic acids & $6.5 \pm 0.7$ & $46 \pm 5$ \\
\hline Caffeic acid & $9.0 \pm 3.1$ & \\
\hline Caffeic acid-3'- and $4^{\prime}$-sulfates & $11 \pm 2$ & \\
\hline Ferulic acid & $0.8 \pm 0.3$ & \\
\hline Ferulic acid- $4^{\prime}$-sulfate & $4.2 \pm 1.0$ & \\
\hline Total caffeic and ferulic acids & $25 \pm 5$ & - \\
\hline Total acyl-quinic acids and metabolites & $274 \pm 28$ & $71 \pm 7$ \\
\hline
\end{tabular}

${ }^{a}$ Data presented as mean values \pm standard error $(n=5)$. n.d - not detected. there is clearly a potential for a sizable accumulation of gut flora metabolites in the plasma because a subsequent dose of substrate will have entered the colon before the previous intake has been eliminated.

In a further study, ileostomists drank an instant coffee with a very similar $385 \mu \mathrm{mol}(136 \mathrm{mg})$ acyl-quinic acid content and profile to that ingested by the healthy subjects. ${ }^{214}$ Plasma metabolites were not investigated, but data on the amounts of acylquinic acids and their metabolites in ileal fluid collected over a $0-24 \mathrm{~h}$ period after the ingestion of coffee are presented in Table 7 . The highest recovery of unmetabolised acyl-quinic acids compared to their intake was FQAs (77\%), followed by CQAs (59\%) and $p$-CoQAs and diCQAs (46\%). The recoveries of acyl-quinic acid metabolites were much lower, ranging from 3.6 to $8.8 \%$, except for CQL metabolites which corresponds to $56 \%$ of CQL intake.

Of the $385 \mu \mathrm{mol}$ of acyl-quinic acids ingested by the ileostomists, $274 \mu \mathrm{mol}(71 \%)$ was recovered in the $0-24 \mathrm{~h}$ ileal fluid as the parent compounds and metabolites (Table 7). This indicates that $\sim 30 \%$ of intake is absorbed in the stomach and/or small intestine, and that in subjects with a functioning colon $\sim 70 \%$ of the ingested acyl-quinic acids pass from the small to the large intestine where they will be subjected to the action of the colonic microflora. These observations are in line with the findings of Olthof et al. ${ }^{211}$ who fed $2.8 \mathrm{mmol}$ of 5-CQA (9) to humans with an ileostomy and recovered $\sim 70 \%$ of the CQA intake in ileal fluid. The data from both studies, albeit at substantially different doses, imply that around one third of ingested 5-CQA is absorbed and enters the bloodstream from the small intestine. In vitro studies support this conclusion as 5-CQA is not extensively degraded when incubated with gastric juice, duodenal fluid and ileostomy effluent $^{211,215}$ although as noted below interesterification can occur. ${ }^{205}$ In keeping with these findings, when 3,5-, 3,4-, and 4,5diCQAs $(\mathbf{1 8}, \mathbf{4 1}, \mathbf{4 2})$ from Ilex kudingcha were incubated with artificial saliva, gastric and pancreatic fluids, they were not degraded. When incubated with a human fecal slurry under anaerobic conditions, the diCQAs were hydrolysed to CQAs and caffeic acid, which was then further catabolised to dihydrocaffeic acid. ${ }^{216}$

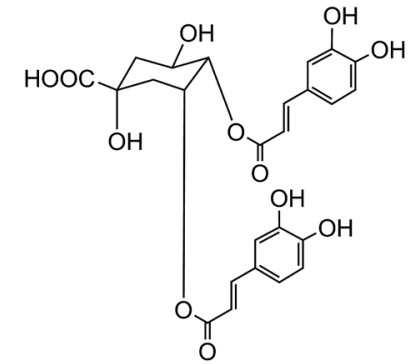

3,4-O-Dicaffeoylquinic acid (41)

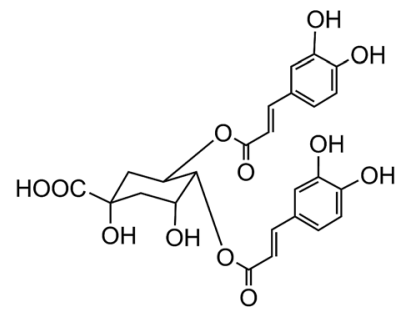

4,5-O-Dicaffeoylquinic acid (42)
Animal and in vitro cell culture studies indicate that postabsorption acyl-quinic acids are subjected to the action of epithelial esterases in the stomach and small intestine. ${ }^{204,217,218}$ In incubations with cultured gastric epithelial cells, there is some release of caffeic acid (3), ferulic acid (4) and 3',4'-dimethoxycinnamic acid (26) from CQAs, FQAs and dimethoxycinnamoylquinic acids (DQAs). Caffeic acid is metabolised primarily to isoferulic acid (43) and a lesser amount of ferulic acid but is not transported 
unchanged to the basal side. In contrast, ferulic, isoferulic and dimethoxycinnamic acids are transported, and this must be the primary source of these substrates in ileostomists. ${ }^{219,220}$<smiles>COc1ccc(/C=C/C(=O)O)cc1O</smiles>

Isoferulic acid (43)

The absorption of ferulic acid and subsequent conjugation in the liver ${ }^{221}$ is consistent with the early plasma $T_{\max }(0.6 \mathrm{~h})$ for ferulic acid-4'-sulfate (36) observed in feeding studies ${ }^{\mathbf{4 4}}$ while the later secondary $T_{\max }(4.3 \mathrm{~h})$ (Fig. 6 and Table 6) plausibly reflects the absorption and sulfation of ferulic acid released by

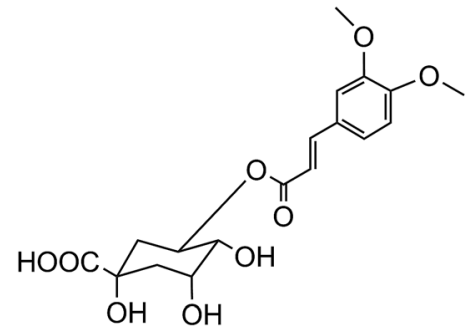

5-O-3', 4'-Dimethoxycinnamoylquinic acid (44)

gut microflora-mediated hydrolysis of unabsorbed FQA. Escherichia coli, Bifidobacterium lactis and Lactobacillus gasseri have the requisite cinnamoyl esterase activity. ${ }^{222}$ The plasma profile was not recorded for the ileostomists and, thus, it is not known whether that too was biphasic, but because ileostomists could not be absorbing ferulic acid released in the colon there would have to be another compensatory source to maintain ferulic acid-4'-sulfate excretion. The plasma profile (Fig. 6) and the excretion of substantial amounts of dihydroferulic acid (35) by volunteers with an intact colon continues until at least $8 \mathrm{~h}$ after coffee consumption, ${ }^{44}$ indicating that a significant part of this is derived from $77 \%$ of FQA intake that reaches the colon
(Table 7). The necessary hydrolysis of FQAs and hydrogenation of ferulic acid to dihydroferulic acid could involve either microbial and/or human enzymes post absorption. ${ }^{223}$

$3^{\prime}, 4^{\prime}$-Dimethoxycinnamic acid (26) and $3^{\prime}, 4^{\prime}$-dimethoxycinnamoylquinic acid (44) are minor components in coffee. However, when a coffee containing $\sim 400 \mathrm{nmol}$ of these compounds was ingested by volunteers free $3^{\prime}, 4^{\prime}$-dimethoxycinnamic acid was detected in plasma with a $500 \mathrm{nmol} \mathrm{L}{ }^{-1} C_{\max }$ and a $T_{\max }$ of $\sim 0.5 \mathrm{~h}^{219}$ The $C_{\max }$ is higher than that of the metabolites derived from CQAs that occur in coffee in much higher quantities (see Fig. 6). 3-( $3^{\prime}, 4^{\prime}$-Dimethoxyphenyl)propionic acid (45) appeared later, predominantly 8-12 h after coffee intake with a $C_{\max }$ of $97 \mathrm{nmol} \mathrm{L}^{-1}$. The high $C_{\max }$ relative to dose probably reflects the comparatively high hydrophobicity of dimethoxycinnamic acid derivatives facilitating passive absorption. ${ }^{225}$<smiles>COc1ccc(CCC(=O)O)cc1OC</smiles>

3-(3',4'-Dimethoxyphenyl)propionic acid (45)

In contrast to the behaviour of ferulic acid and dimethoxycinnamic acid, the failure of cultured gastric cells to transport caffeic acid (3) 3$)^{219}$ seemingly conflicts with the $\sim 1 \mathrm{~h}$ plasma $T_{\max }$ for caffeic acid-3'-sulfate (39) (Table 6). ${ }^{44}$ The most plausible explanation is that absorbed CQAs may be hydrolysed and the caffeic acid conjugated in hepatocytes.

The quantities of acyl-quinic acids and their metabolites excreted in urine by healthy subjects and ileostomists over a $24 \mathrm{~h}$ period after ingestion of coffee are summarised in Table 8. It is apparent that absence of a colon had minimal impact on urinary excretion of CQL-sulfates and FQAs, as well as caffeic, ferulic and isoferulic acid sulfates. The ileostomists<smiles>O=C(O)Cc1ccc(O)c(O)c1</smiles><smiles>COc1cc(CC(=O)O)ccc1O</smiles><smiles>O=C(O)c1cccc(O)c1</smiles>

3-Hydroxybenzoic acid (48)<smiles>O=C(O)CNC(=O)c1ccccc1</smiles>

Hippuric acid (49)<smiles>O=C(O)CNC(=O)c1cccc(O)c1</smiles>

3'-Hydroxy-hippuric acid (50) 
Table 8 Urinary excretion of acyl-quinic acids and their conjugated metabolites in $0-24$ h urine of healthy subjects $(n=11)$ and ileostomists $(n=$ 5) following the ingestion of $200 \mathrm{~mL}$ of coffee (after Stalmach et al. $\left.{ }^{44,214}\right)^{a}$

\begin{tabular}{|c|c|c|}
\hline Chlorogenic acid and metabolites & $\begin{array}{l}\text { Subjects without a colon } \\
\text { (385 } \mu \mathrm{mol} \text { ingested) }\end{array}$ & $\begin{array}{l}\text { Subjects with a colon } \\
(412 \mu \mathrm{mol} \text { ingested })\end{array}$ \\
\hline 3-O-Caffeoylquinic lactone-sulfate & $0.6 \pm 0.1$ & $1.1 \pm 0.1$ \\
\hline 3-O-Feruloylquinic acid & $0.9 \pm 0.2$ & $1.2 \pm 0.1$ \\
\hline 4-O-Feruloylquinic acid & $0.9 \pm 0.2$ & $1.1 \pm 0.1$ \\
\hline 5-O-Feruloylquinic acid & $1.1 \pm 0.2$ & $1.0 \pm 0.2$ \\
\hline Dihydroferulic acid & n.d. ${ }^{a}$ & $9.7 \pm 2.0^{b}$ \\
\hline Dihydroferulic acid- $4^{\prime}$-sulfate & $0.8 \pm 0.2^{a}$ & $12.4 \pm 3.4^{b}$ \\
\hline Dihydroferulic acid-4'-O-glucuronide & n.d. ${ }^{a}$ & $8.4 \pm 1.9^{b}$ \\
\hline Isoferulic acid-3'-sulfate & $0.2 \pm 0.0$ & $0.4 \pm 0.1$ \\
\hline Isoferulic acid-3'-O-glucuronide & $3.9 \pm 0.8$ & $4.8 \pm 0.5$ \\
\hline Dihydroisoferulic acid-3'-O-glucuronide & n.d. ${ }^{\bar{a}}$ & $2.5 \pm 0.4^{b}$ \\
\hline Total & $30.8 \pm 4.3(8.0 \%)^{a}$ & $120.2 \pm 17.0(29.2 \%)^{b}$ \\
\hline
\end{tabular}

${ }^{a}$ Data represent mean values in $\mu \mathrm{mol} \pm$ standard error. n.d. not detected. Different superscripts within rows indicate a statistical difference between the two sets of volunteers (two-sample $t$-test, $P$-value $<0.05$ ). ${ }^{b}$ Figures in bold italicised parentheses indicate excretion as a percentage of acyl-quinic acids intake.

excreted in urine $30.8 \mu \mathrm{mol}$ of acyl-quinic acid metabolites equivalent to $8.0 \%$ of the amount ingested. In contrast, the volunteers with an intact colon excreted a total of $120.2 \mu \mathrm{mol}$ which corresponds to $29.2 \%$ of intake. This is almost certainly an under estimate of acyl-quinic acid bioavailability because in this study phenolic catabolites, such as $\mathrm{C}_{6}-\mathrm{C}_{2}$ hydroxy- and methoxy-phenylacetic acids $(46,47), \mathrm{C}_{6}-\mathrm{C}_{1}$ benzoic acids (48) and hippuric acids $(\mathbf{4 9}, \mathbf{5 0})$ were not quantified. As well as these phenolics being catabolites of caffeic acid, ${ }^{215,224-226}$ there is growing evidence that they are also a feature of the catabolism of many flavonoids including flavonols, ${ }^{224,227,228}$ anthocyanins, ${ }^{229-231}$ flavanones ${ }^{232-234}$ and flavan-3-ols. ${ }^{224,235,236}$

The data in Table 7 show that after coffee consumption a total of $46.2 \mu \mathrm{mol}$ of ferulic acid-based compounds (ferulic acid [3], FQAs [32-34], ferulic acid-4'-sulfate [36], FQA-O-glucuronides FQAsulfates) were present in the $0-24 \mathrm{~h}$ ileal fluid. In healthy subjects these compounds would pass to the large intestine and the quantity of ferulic acid metabolites excreted in the urine of volunteers with a functioning colon (feruloylglycine [51], and dihydroferulic acid [35] and its $4^{\prime}$-sulfate [39] and $4^{\prime}$-O-glucuronide [52]) totalled $51.2 \mu \mathrm{mol}$ (Table 8). This is not greatly in excess of the $46.2 \mu \mathrm{mol}$ of ferulic acid-based compounds entering the large intestine (Table 8). In contrast to in vitro cell culture studies, ${ }^{203}$ arguably, this suggests that in vivo the ferulic acid metabolites may be derived principally from the ingested FQAs rather than via 3'methylation of caffeic acid derivatives, formed from CQAs, diCQAs and CQLs. However, the presence of isoferulic acid [43] and dihydroisoferulic acid [53] metabolites in urine signifies that caffeic acid undergoes $4^{\prime}$-methylation. Excretion of these metabolites by subjects with and without a colon (Table 9) points to $4^{\prime}$-methylation of caffeic acid [3] producing isoferulic acid [43] occurring in the upper GI tract. The human gastric epithelium is capable of such a methylation, ${ }^{203}$ while formation of dihydroisoferulic acid (54) takes place in the distal GI tract.

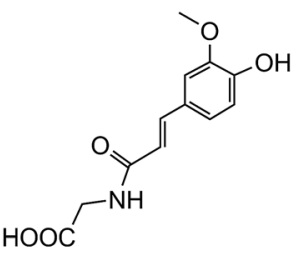

Feruloylglycine (51)<smiles>COc1ccc(CCC(=O)O)cc1O</smiles>

Dihydroisoferulic acid (53)

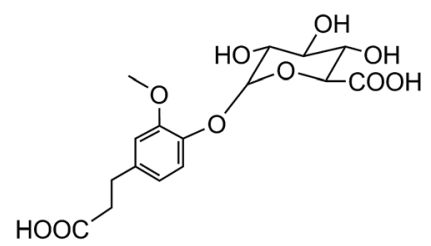

Dihydroferulic acid-4'-O-glucuronide (52)<smiles>O=C(O)c1ccc(O)c(O)c1</smiles>

Protocatechuic acid (54) (3,4-Dihydroxybenzoic acid)
On the basis of coffee feeding studies with healthy volunteers and ileostomists, Stalmach et al. ${ }^{44,214}$ proposed a series of metabolic pathways. These have been extended to incorporate data obtained when coffee was incubated with fecal slurries and the breakdown of acyl-quinic acids monitored. ${ }^{226}$ The proposed pathways are illustrated in Fig. 7 and 8. In the preparation of these pathways the following points were taken into consideration. Some, but not complete hydrolysis of CQAs and CQLs can occur in the small intestine, catalysed by mammalian esterases 
Table 9 Impact of acyl-quinic acid dose on ileal and urinary excretion of acyl-quinic acids and conjugated metabolites as a percentage of intake, and on metabolite sulfate : glucuronide (S : GlcUA) ratio, after ingestion of coffees and a fruit drink containing apple juice by ileostomists ${ }^{a}$ (after Stalmach et al. ${ }^{214}$ and Erk et al. ${ }^{205}$ )

\begin{tabular}{|c|c|c|c|c|c|c|}
\hline \multirow[b]{2}{*}{$\begin{array}{l}\text { Acyl-quinic acids } \\
\text { intake }\end{array}$} & \multicolumn{3}{|c|}{ Ileal excretion } & \multicolumn{3}{|c|}{ Urinary excretion } \\
\hline & $\%$ of intake & $\begin{array}{l}\% \text { conjugated } \\
\text { metabolites }\end{array}$ & $\begin{array}{l}\mathrm{S}: \text { GlcUA } \\
\text { ratio }\end{array}$ & $\%$ of intake & $\begin{array}{l}\% \text { conjugated } \\
\text { metabolites }\end{array}$ & S : GlcUA ratio \\
\hline $385 \mu \mathrm{mol}$ & $71 \pm 7$ & 22.3 & 15.5 & $8.0 \pm 1.1$ & 90 & 5.6 \\
\hline $1053 \mu \mathrm{mol}$ & $77 \pm 2$ & 8.9 & 13.4 & $14.6 \pm 3.0$ & 70 & 1.3 \\
\hline $2219 \mu \mathrm{mol}$ & $72 \pm 2$ & 7.7 & 10.4 & $12.1 \pm 3.0$ & 69 & 1.1 \\
\hline
\end{tabular}

releasing caffeic acid. ${ }^{237}$ Further, hydrolysis in the colon is probably due to the action of bacterial esterases. Small amounts of CQAs and more substantial amounts of FQAs and CQLs are absorbed in the small intestine with the CQLs appearing in the circulatory system as sulfates (Fig. 6). The released caffeic acid is subjected to sulfation forming caffeic acid- $4^{\prime}$-sulfate and smaller quantities of caffeic acid-3'-sulfate. Caffeic acid is also methylated producing isoferulic acid, but also possibly ferulic acid, both of which in turn form glucuronide and sulfate derivatives.

FQAs are absorbed in the small intestine and are also hydrolysed to some degree with ferulic acid-4'-sulfate [36] appearing in the bloodstream with an initial $C_{\max }$ of $0.6 \pm 0.1 \mathrm{~h}$.
Ferulic acid (4) undergoes glycination forming feruloylglycine (51) and although this involves mammalian enzymes the conversion is reduced by $90 \%$ in ileostomists indicating that it is primarily colonic in origin. Methyl, glucuronyl, sulfate and glycine conjugation steps involve mammalian enzymes. Dehydroxylation and demethoxylation are almost certainly mediated by the gut microflora while demethylation and hydrogenation steps can be mediated by both microbial and mammalian enzymes. For convenience, the pathways in Fig. 7 and 8 show $\mathrm{C}_{6}-\mathrm{C}_{3}$ catabolites being converted by two $\alpha$-oxidations to $\mathrm{C}_{6}-\mathrm{C}_{1}$ compounds by microflora and/or mammalian enzymes. However, it is possible the $\mathrm{C}_{6}-\mathrm{C}_{3}$ catabolites progress directly to

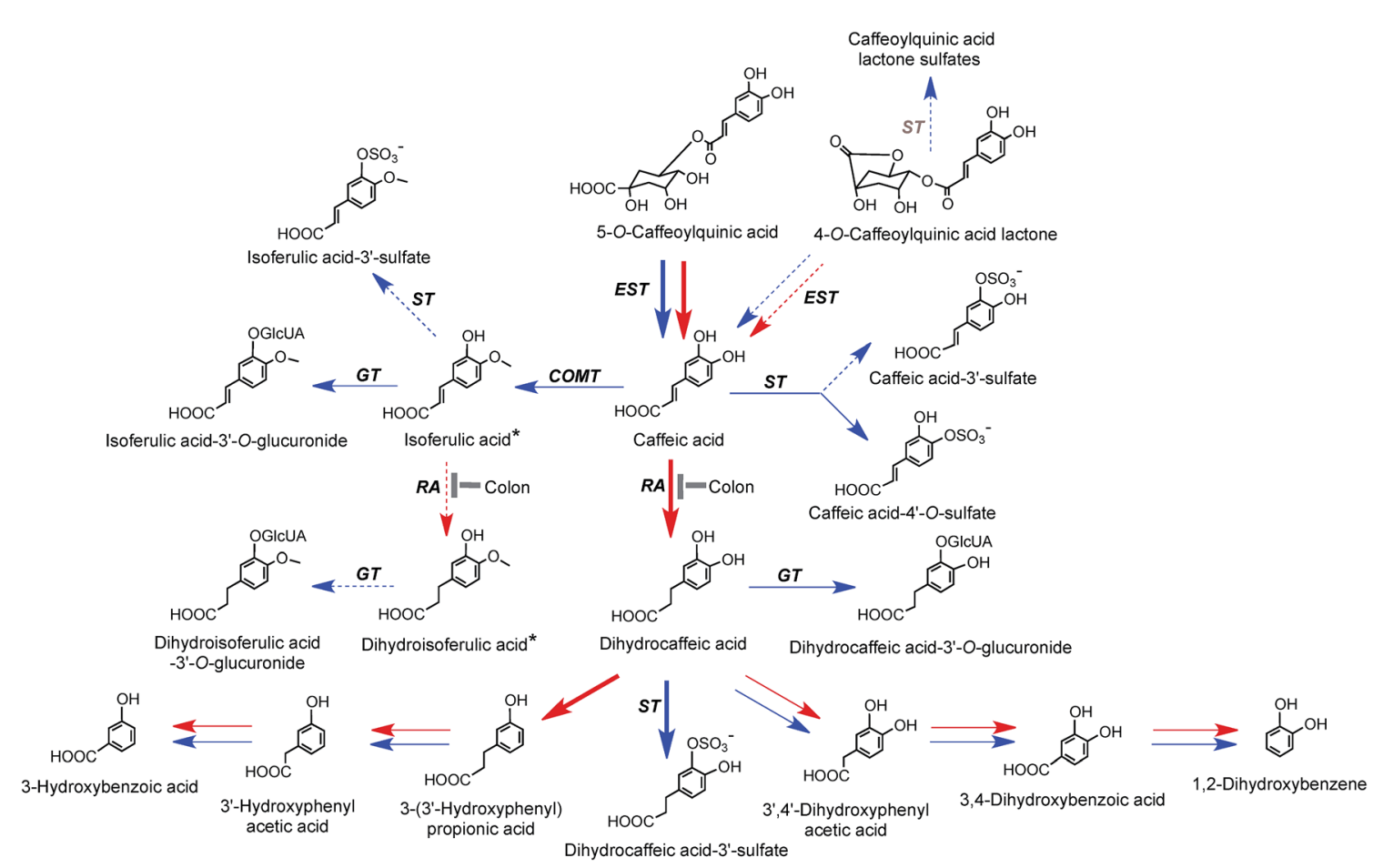

Fig. 7 Proposed metabolism of caffeoylquinic acids and caffeoylquinic lactones following the ingestion of coffee by volunteers. 5-CQA is the illustrated structure but the respective $3^{\prime}$ - and $4^{\prime}$-isomers and diCQAs would be metabolized in a similar manner. Likewise 4-CQAL is the illustrated lactone but 3-CQAL would be metabolised in a similar manner. COMT, catechol-O-methyltransferase; ET, esterase; RA, reductase; GT, UDP-glucuronyltransferase; ST, sulfuryltransferase; Co-A, co-enzyme A. Arrows: bold - major routes, dotted - minor pathways; red microbial enzymes, blue - mammalian enzymes. Steps blocked in subjects with an ileostomy and hence occurring principally, but not necessarily exclusively, in the colon are indicated. * Intermediates that did not accumulate in detectable amounts (based on data of Stalmach et al. ${ }^{44,139}$ and Ludwig et al. $\left.{ }^{226}\right)$. 


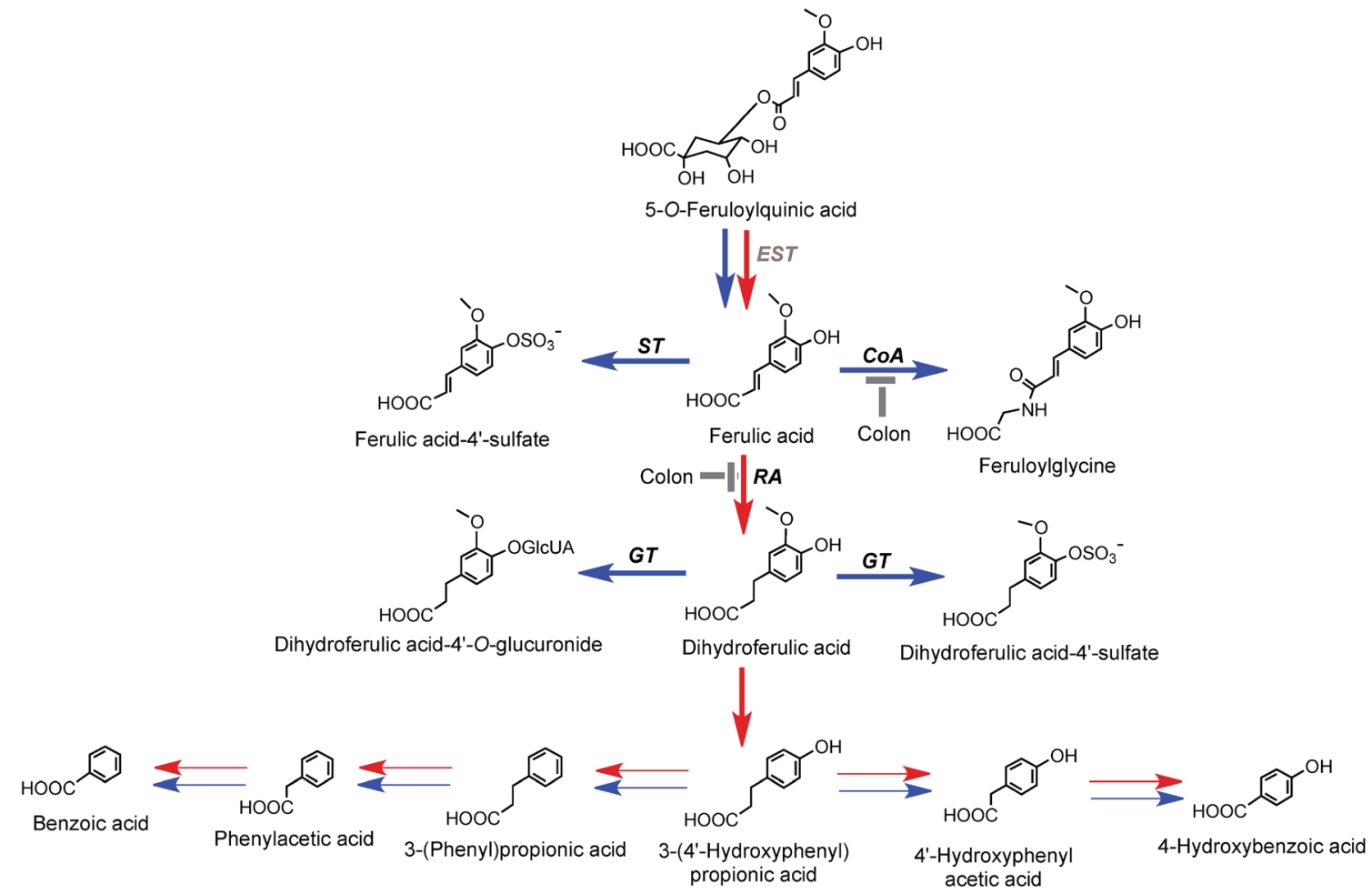

Fig. 8 Proposed metabolism of feruloylquinic acids following the ingestion of coffee by volunteers. 5-FQA is the illustrated structure but the respective $3^{\prime}$ - and $4^{\prime}$-isomers would be metabolized in a similar manner. EST, esterase; RA, reductase; GT, UDP-glucuronyltransferase; ST, sulfuryltransferase; Co-A, co-enzyme A. Arrows: bold - major routes; red - microbial enzymes, blue - mammalian enzymes. Steps blocked in subjects with an ileostomy and hence occurring principally, but not exclusively, in the colon are indicated (based on data of Stalmach et al. ${ }^{44,139}$ and Ludwig et al. $\left.{ }^{226}\right)$.

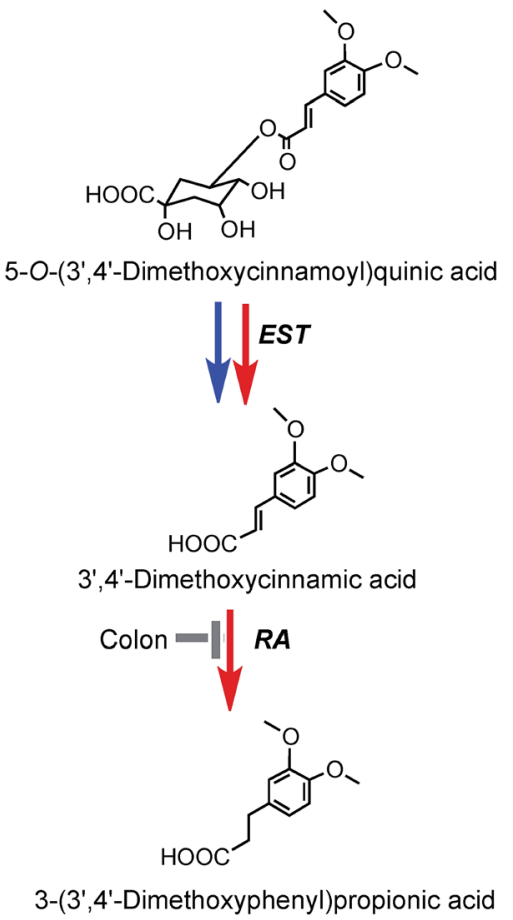

Fig. 9 Potential metabolism of 5-O- $\left(3^{\prime}, 4^{\prime}\right.$-dimethoxycinnamoyl) quinic acid following the ingestion of coffee by volunteers. The 5-Oester is the illustrated structure but the respective 3-O- and 4-Oisomers would be metabolized in a similar manner. EST, esterase; RA, reductase. Blue arrows mammalian enzymes, red arrow - microbial enzymes (based on data of Farrell et al. ${ }^{144}$ ).
$\mathrm{C}_{6}-\mathrm{C}_{1}$ structures via a mammalian catalysed $\beta$-oxidation and that $\mathrm{C}_{6}-\mathrm{C}_{2}$ catabolites arise independently. In reality, further complexity is introduced as there are multiple points at which catabolites might be absorbed. For example, a percentage of some $\mathrm{C}_{6}-\mathrm{C}_{3}$ catabolites could be absorbed and undergo $\beta$ oxidation and/or mammalian phase II conjugation while the balance is subjected to microbial hydrogenation and/or $\alpha$ oxidation prior to absorption and mammalian conjugation. Also for some catabolites mammalian conjugation either does not occur or is incomplete.

As noted above, after feeding coffee containing trace levels of $3^{\prime}, 4^{\prime}$-dimethoxycinnamic acid (26) and dimethoxycinnamoylquinic acids to volunteers with a functioning colon, $3^{\prime}, 4^{\prime}$-dimethoxycinnamic acid appears rapidly in plasma and this is followed by a delayed appearance of a smaller amounts of 3 -( $3^{\prime}, 4^{\prime}$-dimethoxyphenyl)propionic acid (45). ${ }^{219}$ These observations are in keeping with esterases in the small intestine hydrolysing the dimethoxycinnamoylquinic acids releasing free dimethoxycinnamic acid which is readily absorbed in the upper GI tract, while the unabsorbed methoxy acid reaching the colon it is converted to 3 -( $3^{\prime}, 4^{\prime}$-dimethoxyphenyl)propionic acid. A potential pathway involved in such conversions is illustrated in Fig. 9. Currently there is no evidence for further phase II metabolism of these products.

Sulfates are the main acyl-quinic acid metabolites and glucuronides are relatively minor components (Fig. 6 and Table 
9). Transformations that occur in the colon facilitate the absorption, as microbial catabolites, of $70 \%$ or more of the acylquinic acids consumed, clearly highlighting the importance of the colon in their bioavailability. It is also apparent that ileostomists are less able to utilise acyl-quinic acids and other dietary phenolics and are, thus, less able to access any benefits that might otherwise accrue.

Further clarification of the proposed pathways in Fig. 7-9 will require feeding studies, not with coffee, but with substrates such as 5-CQA (9) and 5-FQA (34) in which the hydroxycinnamate moiety is labelled with ${ }^{13} \mathrm{C}$. This approach has been used successfully with $\left[{ }^{13} \mathrm{C}_{5}\right]$ cyanidin-3-O-glucoside to obtain detailed profiles of the metabolism and catabolism of the anthocyanin in the small and large intestine and in the process provided novel details of involvement of the microbiota in the lower bowel. ${ }^{229,230}$ Human feeding studies are the gold standard and while animal studies can be helpful, because of species differences in gut microbiota and endogenous metabolism, they can produce data that are difficult to apply to human studies as has recently been shown with the radiolabelled flavan-3-ol $\left[2-{ }^{14} \mathrm{C}\right](-)$-epicatchin. ${ }^{236}$ Likewise, data obtained in vitro with isolated cells and tissue extracts should be treated with caution as substrates can come into contact with enzymes and conditions to which they would not be exposed in vivo when cellular compartmentation is maintained.

\subsection{Impact of dose on acyl-quinic acid bioavailability}

The impact of dose on acyl-quinic acid absorption in the small intestine has been assessed in a study by Erk et al. on coffee consumption by ileostomists where acyl-quinic acid-derived compounds were analysed in plasma, urine and ileal fluid after the ingestion of coffees containing 1053, 2219 and $4525 \mu$ mole of CQAs, diCQAs and FQAs. ${ }^{238}$ The profile of acyl-quinic acids and their metabolites identified in ileal fluid and urine by HPLC-MS was very similar to that detected by Stalmach et al. ${ }^{\mathbf{2 1 4}}$ after the ingestion of a coffee containing $385 \mu \mathrm{mol}$ of acyl-quinic acids. Ileal excretion reported by Erk et $a l^{238}$ was $\sim 70 \%$ of intake irrespective of dose (Table 9), which was also the level reported by Stalmach et $a .^{2 \mathbf{1 4}}$ In keeping with these observations the $\sim 3: 1$ ratio of urinary excretion of metabolites absorbed in the distal and proximal GI tract was not influenced to any extent by dose following coffee acyl-quinic acid intakes of 412-795 $\mu \mathrm{mol}$ (Table 10). ${ }^{239}$ Dose did, however, have a noticeable impact on the amount of conjugated metabolites appearing in ileal fluid where they were equivalent to $22.3 \%$ of the acyl-quinic acids at the lowest dose and $6.7-8.9 \%$ at the three higher intakes. ${ }^{238}$ Sulfated metabolites were

Table 10 Urinary excretion of acyl-quinic acid metabolites absorbed in the upper and lower gastrointestinal tract by volunteers with a functioning colon after the consumption of $200 \mathrm{~mL}$ of coffee beverage containing 412, 635 and $795 \mu$ mol of acyl-quinic acids. (after Stalmach et al. $\left.{ }^{239}\right)^{a}$

\begin{tabular}{llll}
\hline & Acyl-quinic acids intake & & \\
\cline { 2 - 4 } & $412 \mu \mathrm{mol}$ & $635 \mu \mathrm{mol}$ & $795 \mu \mathrm{mol}$ \\
\hline Upper gastrointestinal tract & $29 \pm 2(27 \%)$ & $37 \pm 4(24 \%)$ & $37 \pm 4(21 \%)$ \\
Lower gastrointestinal tract & $80 \pm 14(73 \%)$ & $119 \pm 21(76 \%)$ & $137 \pm 23(79 \%)$
\end{tabular}

${ }^{a}$ Data expressed as mean values in $\mu \mathrm{mol} \pm \mathrm{SE}(n=11)$. Italicised figures in parentheses represent the percentage absorption taking place in the upper and lower gastrointestinal tract.

Table 11 Impact of acyl-quinic acid dose on plasma $C_{\max }$ of acyl-quinic acids and metabolites absorbed in the small intestine after ingestion of coffees by healthy volunteers with a colon (lowest dose) (Stalmach et al. ${ }^{44}$ ) and ileostomists (three higher doses) (after Erk et al. $\left.{ }^{238}\right)^{a}$

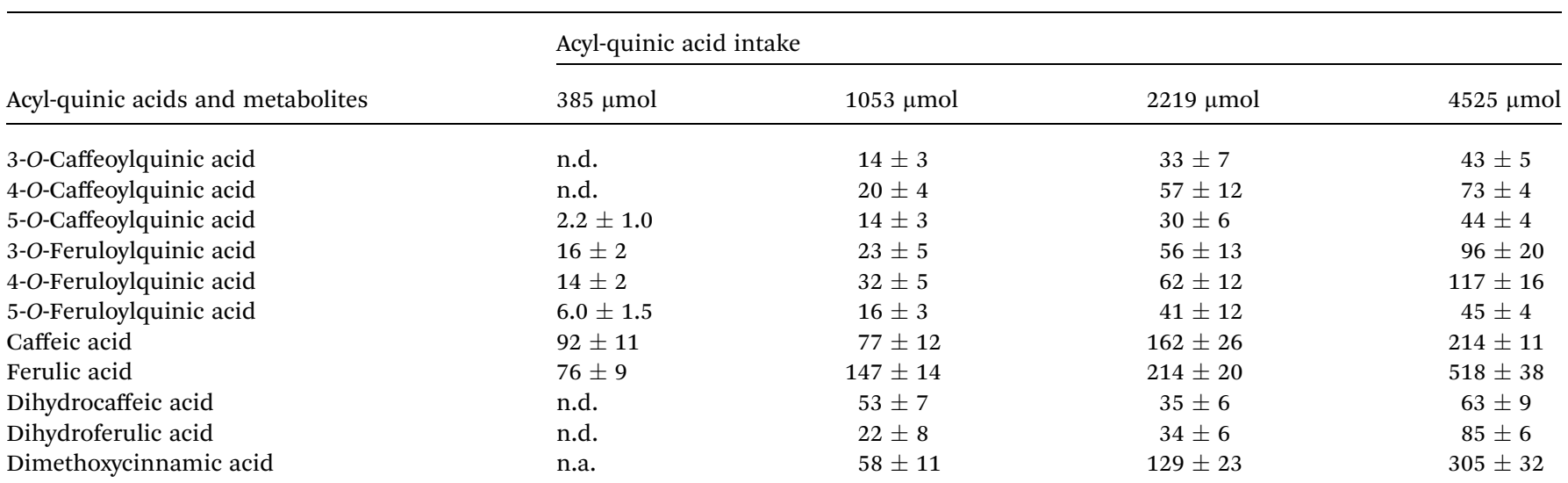

${ }^{a}$ Data in $\mathrm{nM} \pm$ standard error. Analysis of acyl-quinic acids at the three higher doses was after enzyme hydrolysis ${ }^{162}$ and without enzyme hydrolysis for the lowest dose. ${ }^{139}$ n.d., not detected; n.a., not analysed. 
15.5 times more prevalent than glucuronides at the lowest dose but as intake increased this changed and with the ingestion of $4525 \mu \mathrm{mol}$ of acyl-quinic acids the ratio of sulfated metabolites to glucuronides in ileal fluid fell to 8.2 (Table 10). In keeping with these observations, in a further study in which ileostomists consumed a (poly)phenol-rich drink containing $46 \mu \mathrm{mol}$ of 5-CQA derived from apples, only sulfate metabolites of caffeic acid, dihydrocaffeic acid and ferulic acid were detected in urine $0-24 \mathrm{~h}$ after intake. ${ }^{240}$

These dose-related changes presumably reflect enzyme saturation, limited transport capacities into and out of the enterocyte in the small intestine and/or differences in GI tract transit times. The increasing proportion of glucuronidation with increasing acyl-quinic acid dose was even more marked in urine (Table 9), arguably indicative of phase II UDPglucuronyltransferase activity in the small intestine epithelium and/or in the liver and kidneys.

Data on the effect of dose on plasma $C_{\max }$ of acyl-quinic acids and metabolites absorbed in the small intestine after ingestion of coffee by healthy subjects with a colon (lowest dose) and ileostomists are presented in Table 11. This reveals a clear trend towards higher $C_{\max }$ values with increasing acyl-quinic acids intakes.

\subsection{Matrix effects and acyl-quinic acid bioavailability}

There is one report on the consumption by humans of black coffee and black coffee made with milk rather than water in which urinary excretion of acyl-quinic acids and metabolites was $68 \%$ of intake with the black coffee and $40 \%$ after ingestion of coffee with milk. The two figures were not statistically different but it was hypothesized that milk may have impaired the absorption of coffee acyl-quinic acids. ${ }^{241}$ Although an in vitro investigation suggests that the addition of milk fat to coffee may increase acyl-quinic acids bioavailability, ${ }^{242}$ a feeding study by Renouf et al. ${ }^{243}$ revealed no difference in the pharmacokinetic profiles of plasma acyl-quinic acid metabolites after drinking black coffee with or without $10 \%$ whole milk. Thus, although 5CQA has been reported to bind to certain proteins in vitro, such as albumin and casein, ${ }^{244,245}$ milk would appear not to have a significant impact on the overall absorption of coffee acylquinic acids. However, adding a mixture of sugar and nondairy creamer to the black coffee resulted in lower $C_{\max }$ values for caffeic acid (3) and isoferulic acid (43) accompanied by longer $T_{\max }$ times for ferulic acid (4) and isoferulic acid. ${ }^{243}$ Sugar $^{\mathbf{2 4 6}}$ and lipids ${ }^{\mathbf{2 4 7}}$ are known to delay gastric emptying and this may have delayed absorption of the coffee acyl-quinic acids resulting in an extended $T_{\max }$ for two of the three metabolites.

Changes in the CQA profile in the upper GI tract have been monitored by feeding ileostomists coffee, cloudy apple juice and an apple smoothie and analysing the CQAs excreted in ileal fluid over an $8 \mathrm{~h}$ period. ${ }^{205}$ The data obtained are summarised in Table 12. With coffee, in keeping with other investigations, there was an overall recovery of $76 \%$ of intake and the ratios of the individual CQA isomers were not affected by interesterification reactions during passage through the proximal GI tract. ${ }^{214,238}$ There was a similar $77 \%$ recovery of apple smoothie CQAs but whereas the drink contained only 5-CQA (9) and 4-CQA (10) while the ileal fluid also contained 3-CQA (11) and 1-CQA (12). The same occurred following consumption of cloudy apple juice but in this instance the overall recovery of CQAs was only $26 \%$.

The matrix in which the CQAs were ingested, therefore, appears to have had an impact on their fate as they pass through the proximal GI tract with interesterification of CQAs occurring with the apple products but not coffee. Such reactions have been reported previously ${ }^{\mathbf{2 4 8 , 2 4 9}}$ and seemingly are caused by the $\mathrm{pH}$ increasing to above $\mathrm{pH} 6$ during passage through the small intestine. Erk et al. ${ }^{238}$ suggest that the CQA profile of the coffee was closer to the interesterification equilibrium reported by Trugo and Macrae ${ }^{250}$ and so did not alter substantially during gastric transport (Table 12). The susceptibility of individual acyl-quinic acids to inter-esterification and hydrolysis was discussed in Section 3.1.

There was also a $\sim 3$-fold lower recovery of CQAs in ileal fluid after cloudy apple juice consumption compared with the apple smoothie (Table 12). ${ }^{205}$ The CQA content of the two beverages was similar and the drinks differed only in that cloudy apple juice was pressed and unfiltered whereas the smoothie comprised $60 \%$ cloudy juice and $40 \%$ apple purée which contains a much higher proportion of cell wall constituents. How this resulted in the enhanced ileal recovery of CQAs from the apple smoothie is unclear. Although neither plasma nor urine were analysed in this study to confirm the point, it appears unlikely that it is a consequence of enhanced absorption in the small intestine of the cloudy apple juice CQAs. It is also unclear as to what constituents

Table 12 Summary of caffeoylquinic acid intake by ileostomists and 0-8 h CQA ileal excretion after the ingestion of coffee, apple smoothie and cloudy apple juice. (after Erk et al. $\left.{ }^{205}\right)^{a}$

\begin{tabular}{|c|c|c|c|c|c|c|}
\hline Caffeoylquinic acids & \multicolumn{2}{|l|}{ Coffee } & \multicolumn{2}{|c|}{ Apple smoothie } & \multicolumn{2}{|c|}{ Cloudy apple juice } \\
\hline 3-O-Caffeoylquinic acid & 231 & 179 & n.d. & 14 & n.d. & 34 \\
\hline 4-O-Caffeoylquinic acid & 209 & 157 & 26 & 27 & 40 & 9.2 \\
\hline 5-O-Caffeoylquinic acid & 298 & $227(76 \%)$ & 309 & $216(77 \%)$ & 318 & $32(26 \%)$ \\
\hline
\end{tabular}

${ }^{a}$ Data presented in $\mu$ moles as mean values. Bold figures in parentheses represent total caffeoylquinic acid recovery in ileal fluid as a percentage of intake. n.d., not detected. 
Table 13 Summary of the quantities of total acyl-quinic acids and their metabolites, excreted in urine $0-24 \mathrm{~h}$ after the consumption of $200 \mathrm{~mL}$ of coffee beverage containing 412, 635 and $795 \mu \mathrm{mol}$ of acyl-quinic acids by 11 volunteers with an intact functioning colon (based on unpublished data of Stalmach et al. $\left.{ }^{239}\right)^{a}$

\begin{tabular}{|c|c|c|c|c|c|c|c|c|c|c|c|c|c|}
\hline \multirow{2}{*}{$\begin{array}{l}\text { Acyl-quinic acid } \\
\text { intake }\end{array}$} & \multicolumn{11}{|c|}{ Volunteers } & \multirow[b]{2}{*}{ Mean $\pm \mathrm{SE}$} & \multirow[b]{2}{*}{ Rang } \\
\hline & 1 & 2 & 3 & 4 & 5 & 6 & 7 & 8 & 9 & 10 & 11 & & \\
\hline $635 \mu \mathrm{mol}$ & 10 & 12 & 11 & 35 & 25 & 17 & 52 & 29 & 36 & 19 & 31 & $25 \pm 4$ & $10-52$ \\
\hline $795 \mu \mathrm{mol}$ & 18 & 14 & 15 & 47 & 19 & 16 & 48 & 20 & 28 & 25 & 50 & $27 \pm 4$ & $14-48$ \\
\hline
\end{tabular}

in the smoothie result in the CQAs being less prone to degradation and/or irreversible binding in the apple matrix.

Scherbl et al. reported on a study in which volunteers consumed (i) black coffee, (ii) a carbohydrate-rich black coffee and two bread rolls and honey $(\sim 626 \mathrm{kcal})$ and (iii) a fatrich black coffee and one bread roll and peanut butter $(\sim 626 \mathrm{kcal}) .{ }^{209}$ Plasma and urine collected $0-24 \mathrm{~h}$ postingestion were analysed and a detailed spectrum of acylquinic acid metabolites was obtained. The fat-and carbohydrate-rich supplements resulted in a statistically significant, but relatively small, reduction in the levels of acylquinic acid metabolites. This contrast with more marked effects obtained in an anthocyanin study in which a strawberry drink was ingested either $2 \mathrm{~h}$ before or $2 \mathrm{~h}$ after a breakfast meal which comprised a croissant with butter and apple jelly, cereal, whole milk and sausages ( $838 \mathrm{kcal}){ }^{251} \mathrm{Co}-$ ingestion of the drink with the meal resulted in the $C_{\max }$ of the main anthocyanin, a pelargonidin- $O$-glucuronide, falling significantly to $12.8 \pm 2.1 \mathrm{nmol} \mathrm{L}^{-1}$ compared to $38.0 \pm 6.6$ and $35.5 \pm 2.1 \mathrm{nmol} \mathrm{L}^{-1}$ when the drink was ingested, respectively, before and after the meal. Co-ingestion with the meal also extended the $T_{\max }$ from $\sim 1.8 \mathrm{~h}$ to $2.9 \mathrm{~h}$.

\subsection{Inter-individual variations in acyl-quinic acids excretion after coffee intake}

Data obtained on urinary excretion of acyl-quinic acids and their metabolites following coffee consumption showed substantial inter-individual variation. With a $412 \mu$ mole intake by 11 volunteers the mean excretion was equivalent to $26 \pm 4 \%$ of intake while individual values ranged from 12 to 58\% urinary recoveries. Similar figures were obtained with intakes of 635 and $793 \mu$ mole (Table 13). It is noteworthy that while there was some variation, high excretors such as volunteer 4, maintained the condition at all three doses as did low excretors such as volunteers 1-3. Much of this person-to-person variation probably reflects variation in the composition and biochemical competence of the gut microbiota. ${ }^{239}$ The inter-individual variation in the bioavailability of dietary (poly)phenols in general, is an area of increasing interest because the knowledge of the variation in the capacity to absorb and metabolize these compounds is thought to be a key factor in obtaining a better knowledge of the beneficial effects of plant bioactive compounds against diseases, and particularly, an understanding of their role in healthy ageing and cardiometabolic risk reduction. ${ }^{252}$

\section{Biomarkers of acyl-quinic acids intake}

The data presented in Table 8, and that of Gomez-Juaristi et al. ${ }^{206}$ on urinary excretion of hydroxycinnamate metabolites after the respective ingestion of coffee and maté by healthy volunteers clearly show that dihydrocaffeic acid-3'-sulfate (40) and feruloylglycine (51) would serve as very sensitive biomarkers for the consumption of relatively small amounts of acyl-quinic acids. A more detailed fingerprint for coffee could be obtained by the additional analysis of $3^{\prime}, 4^{\prime}$-dimethoxycinnamic acid (26), dihydroferulic acid (35), dihydroferulic acid-4' -sulfate (39), ferulic acid$4^{\prime}$-sulfate (36) and dihydroferulic acid-4'-O-glucuronide (52). However, whether coffee and/or maté consumption can be accurately assessed in population studies from measurements of urinary biomarkers is doubtful. These colonic catabolites are not unique to acyl-quinic acids as some can be derived from other (poly)phenols including orange juice flavanones and berry anthocyanins. Intake of CQAs from coffee or mate is, however, likely to yield much higher levels of the catabolites than consumption from alternative sources. Of more importance, is the 4-5-fold inter-individual variation in the quantity of acyl-quinic acids metabolites excreted by volunteers who consume the same coffee (Table 13) which is further compounded by the large variations in the acyl-quinic acids content of seemingly similar coffees consumed by the general public, as noted in Section $6 .^{43,201,202}$

\section{Bioactivity}

Potential health benefits have been associated with coffee consumption, including a reduced incidence of several chronic and degenerative diseases, such as cancer, cardiovascular disorders, diabetes, and Parkinson's disease and the protective effects have been ascribed, at least in part, to the acyl-quinic acids present in the brew. ${ }^{\mathbf{2 5 3 - 2 5 5}}$ However, relatively little information exists about their mechanisms of action. For many years, mechanistic studies linked the protective effects of dietary (poly)phenols to their antioxidant activity. Acyl-quinic acids, particularly the dominating CQAs, are frequently referred to as powerful antioxidants, and this might be true in 
vitro. After coffee consumption by humans, unmetabolised CQAs achieve transient and very low nmol $\mathrm{L}^{-1}$ peak plasma concentrations (Table 6), thus, they cannot realistically compete with the much more substantial concentrations of other dietary antioxidants, such as the far more powerful ascorbate and $\alpha$ tocopherol. ${ }^{256}$ As discussed in Section 7.1, after ingestion acylquinic acids are extensively metabolised and the concept that health benefits might arise from direct-antioxidant activity has been challenged repeatedly, ${ }^{256-258}$ and it has now been discarded and alternative mechanisms are being investigated.

(Poly)phenols have been found to exert modulatory effects in cells through selective action on multiple cell-signalling pathways involved in the pathogenesis of degenerative diseases, indicating that the health effects go beyond simple antioxidant activity. ${ }^{259,260}$ However, most in vitro studies investigating the biological activity of acyl-quinic acids have used the unmetabolised parent compounds present in foods and beverages and, in many cases, at supra-physiological concentrations that are never attained in the circulatory system, and organs or tissues, except perhaps in the GI tract. This section will, therefore, cover studies using catabolites of acyl-quinic acids and their phase II metabolites that have been tested at physiologically relevant sub- and low $\mu \mathrm{mol} \mathrm{L}^{-1}$ concentrations. As noted in Section 8 , the relevant catabolites are not unique to acyl-quinic acids so studies that originally focussed on other dietary polyphenols are included.

Several such studies have investigated beneficial effects, on markers of cardiovascular diseases and the possible molecular mechanisms involved., Van Rymenant et al. ${ }^{\mathbf{2 6 1}}$ compared the effects of ferulic acid (4) and ferulic acid-4'-sulfate (36) on vasorelaxation ex vivo using mice saphenous artery, femoral artery and aorta. While ferulic acid was inactive, its ferulic acid$4^{\prime}$-sulfate, caused a concentration-dependent relaxation in all three tissues that were significant at sub- $\mu \mathrm{mol} \mathrm{L}^{-1}$ concentrations. Further analyses demonstrated that soluble guanylate cyclase (sGC) and voltage-gated $\mathrm{K}^{+}$-channels, are involved in the ferulic acid-4'-sulfate-dependent vasorelaxation. Whether these effects also occur with human test systems remains to be determined. It is of interest, however, that following human consumption of coffee containing $412 \mu \mathrm{mol}$ of acyl-quinic acids, ferulic acid- $4^{\prime}$-sulfate, but not ferulic acid, appears in the circulatory system with a dual $C_{\max }$ of $76 \mathrm{nmol} \mathrm{L}^{-1}$ after $0.6 \mathrm{~h}$ and $46 \mathrm{nmol} \mathrm{L}^{-1}$ after $4.3 \mathrm{~h}$ (Fig. 6 and Table 6). ${ }^{44}$

Amin et $a .^{262}$ studied the anti-inflammatory effects of ferulic acid, and protocatechuic acid (3,4-dihydroxybenzoic acid) (54) and its glucuronide and sulfate conjugates in human umbilical vein endothelial cells (HUVECs) stimulated with either oxidized LDL or a cluster of differentiation 40 ligand. Protocatechuic acid and its phase II metabolites were effective in modulating the production of key inflammatory mediators IL-6 and vascular cell adhesion molecule-1 (VCAM-1) at dietary relevant concentrations as low as $100 \mathrm{nmol} \mathrm{L}^{-1}$, with maximum reduction observed for the sulfate conjugates. In keeping with the data of Van Rymenant et $a .^{\mathbf{2 6 1}}$ these results indicate that phase II conjugation may unexpectedly increase bioactivity. However, in a similar study by Warner et al. ${ }^{\mathbf{2 6 3}}$ that analysed the effects of phenolic catabolites on secretion of VCAM-1 in HUVEC- stimulated with tumor necrosis factor alpha (TNF- $\alpha$ ), a statistically significant reduction of $17.2 \%$ was observed with $1 \mu \mathrm{mol}$ $\mathrm{L}^{-1}$ protocatechuic acid, but not its phase II metabolites. Protocatechuic acid at $0.5 \mu \mathrm{mol} \mathrm{\textrm {L } ^ { - 1 }}$ has also been shown to significantly reduce adhesion of monocytes to HUVECs by $28.7 \%$. Protocatechuic acid-3-sulfate (55) and protocatechuic acid-4-sulfate (56) also significantly reduced VCAM-1 secretion but at the much higher concentrations of 10 and $100 \mu \mathrm{mol} \mathrm{L}^{-1}$, respectively. ${ }^{264}$ In the same study, $1 \mu \mathrm{mol} \mathrm{L}{ }^{-1}$ ferulic acid (4) significantly reduced monocyte adhesion by $21.3 \%$. Adhesion of monocytes to endothelial cells and their subsequent transendothelial migration into the vascular wall initiate the atheroma formation which leads to cardiovascular diseases.

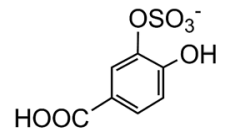

Protocatechuic acid-3-sulfate (55)

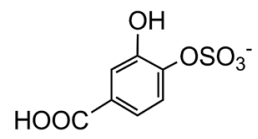

Protocatechuic acid-4-sulfate (56)
A study using lipopolysaccharide (LPS)-stimulated human peripheral blood mononuclear cells, demonstrated that dihydrocaffeic acid (37) and $3^{\prime}, 4^{\prime}$-dihydroxyphenylacetic acid (48) at $1 \mu \mathrm{mol} \mathrm{L}{ }^{-1}$ significantly reduced secretion of the main proinflammatory cytokines TNF- $\alpha$, IL-1 $\beta$ and IL-6 by $84.9-97.9 \%$ compared to control cells. ${ }^{265}$ In a study in which $300 \mathrm{~g}$ of raspberries were consumed by volunteers, after 6 h, 3' $4^{\prime}$-dihydroxyphenylacetic acid (46) attained a plasma $C_{\max }$ of $180 \mathrm{nmol} \mathrm{L}{ }^{-1}$, while after consuming coffee, dihydrocaffeic acid (37) reached a $C_{\max }$ of $41 \mathrm{nmol} \mathrm{L}^{-1}$ (Table 6).

Baeza et al. ${ }^{266}$ studied the inhibitory effects of caffeic acid (3), ferulic acid (4), dihydrocaffeic acid (37), and dihydroferulic acid (35) on platelet activation in human blood samples by measuring ADP-induced P-selectin expression. Excessive platelet activation has been associated with development of chronic inflammation and has, therefore, been proposed as a risk factor for cardiovascular diseases. ${ }^{267}$ A significant decrease in P-selectin expression was observed with dihydrocaffeic acid at $1 \mu \mathrm{mol} \mathrm{L^{-1 }}$ while ferulic acid and dihydroferulic acid were without effect at concentrations up to 10 and $20 \mu \mathrm{mol} \mathrm{L}^{-1}$, respectively.

González-Sarrías et al. $^{268}$ evaluated the potential neuroprotective effects of 19 (poly)phenol-derived metabolites, including dihydrocaffeic acid (37) and $3^{\prime}, 4^{\prime}$-dihydroxyphenylacetic acid (46). At $1 \mu \mathrm{mol} \mathrm{\textrm {L } ^ { - 1 }}$ no protective effects were observed but at $5 \mu \mathrm{mol} \mathrm{L}{ }^{-1}$ both CQA catabolites significantly attenuated the $\mathrm{H}_{2} \mathrm{O}_{2}$-induced cytotoxicity in SH-SYS neuroblastoma cells. The strongest neuroprotective effects occurred at 10 $\mu \mathrm{mol} \mathrm{L}^{-1}$ and at this concentration they were also able to significantly reduce ROS levels in the SH-SY5Y cells and decrease oxidative stress-induced apoptosis by preventing caspase 3-activation via mitochondrial apoptotic pathway.

In a similar study Verzelloni et al. ${ }^{269}$ investigated the ability of an array of (poly)phenol catabolites generated in vivo from different food sources, including coffee, to counteract neurotoxicity linked to oxidative stress in human SK-N-MC neuroblastoma cells. The compounds were tested at concentrations ranging from 0.1 to $20 \mu \mathrm{mol} \mathrm{L}^{-1}$. Dihydrocaffeic acid (37) 
exhibited significant protective effects at $0.5 \mu \mathrm{mol} \mathrm{L}{ }^{-1}$, while at the highest tested concentration dihydroferulic acid (35) and feruloylglycine (51) also protected neurons against 2,3dimethoxy-1,4-naphthoquinone-induced toxicity, with increased survival after oxidative stress ranging from 6.5 to $17.0 \%$. The possible synergistic effects were investigated by evaluating the neuroprotective effects of different combinations of catabolites. When assayed in this manner at concentrations of $0.5 \mu \mathrm{mol} \mathrm{L}{ }^{-1}$, the three acyl-quinic acids catabolites induced a statistically significant $16 \%$ increase in cell viability.

It is unfortunate that there are still comparatively few studies of relevant in vitro metabolites and catabolites at concentrations close to those known to occur in humans consuming real-world diets. Nevertheless, the results summarised here suggest that at least some gut flora catabolites and their phase II metabolites may indeed have anti-inflammatory and neuroprotective effects at such concentrations. Although the consumption of acylquinic acids is not an absolute pre-requisite for the production of these catabolites and metabolites, the fact that acylquinic acids-rich beverages such as coffee and maté are typically consumed repeatedly at short intervals throughout the day, day after day, makes the acyl-quinic acids particularly important. This frequent and long term consumption results in several bolus doses being available simultaneously to the gut microbiota and greatly increasing the period of time during which catabolite absorption can occur. Accordingly there is a potential for a somewhat higher plasma $C_{\max }$ than would be achieved by a single bolus dose, but more importantly, a significant concentration is achieved for several hours rather than a few minutes. ${ }^{270}$ For these reasons plasma AUC values and 24 hour urinary excretion values are better indicators of physiological relevance than $C_{\max }$ values per se. Such data for freeliving healthy and clinically compromised volunteers, in addition to volunteers given defined supplements, would be a valuable adjunct to epidemiological and in vitro studies.

\section{Conflicts of interest}

There are no conflicts to declare.

\section{Acknowledgements}

IAL was supported by a postdoctoral research contract "Juan de la Cierva-Formación" funded by the Spanish Ministry of Economy and Competitiveness (FJCI-2014-20689).

\section{References}

1 M. N. Clifford and L. Abranko, Researchgate, 2017, https:// www.researchgate.net/publication/312647842.

$2 \mathrm{~S}$. Payen, Comptes rendus hebdomadaires des séances de l'Académie des Sciences, 1846, 23, 244-251.

3 S. Payen, Ann. Chem. Pharm., 1846, 60, 286-294.

4 P.-J. Robiquet and A. Boutron-Charlard, Justus Liebigs Ann. Chem., 1837, 23, 93-95.

5 F. Rochleder, Justus Liebigs Ann. Chem., 1844, 50, 224-234.

6 F. Rochleder, Justus Liebigs Ann. Chem., 1846, 59, 300-310.
7 K. Gorter, Justus Liebigs Ann. Chem., 1908, 358, 327-348.

8 K. Freudenberg, Ber. Dtsch. Chem. Ges. A, 1920, 53, 232-239.

9 H. O. L. Fischer and G. Dangschat, Ber. Dtsch. Chem. Ges. A, 1932, 65, 1037-1040.

10 H. M. Barnes, J. R. Feldman and W. V. White, J. Am. Chem. Soc., 1950, 72, 4178-4182.

11 L. Panizzi and M. l. Scarpati, Nature, 1954, 174, 1062-1063.

12 R. A. Cartwright and E. A. H. Roberts, J. Sci. Food Agric., 1954, 5, 593-597.

13 R. A. Cartwright and E. A. H. Roberts, Chem. Ind., 1955, 230231.

14 R. A. Cartwright, E. A. H. Roberts and E. A. Flood, Chem. Ind., 1955, 1062-1063.

15 E. A. H. Roberts, J. Sci. Food Agric., 1958, 9, 381-390.

16 J. Corse, R. Lundin and E. Sondheimer, Tetrahedron, 1962, 18, 2107-2108.

17 J. Corse, R. E. Lundin and A. C. Waiss, Phytochemistry, 1965, 4, 527-529.

18 T. Tsuchida, M. Suzuki and M. Kurogi, J. Jpn. Soc. Food Sci. Technol., 1968, 13, 199-206.

19 J. Corse and D. C. Patterson, Phytochemistry, 1969, 8, 203205.

20 V. P. Maier, D. M. Metzler and A. F. Huber, Biochem. Biophys. Res. Commun., 1964, 14, 124-128.

21 G. G. Gross, in The Biochemistry of Plants Volume 7, ed. E. E. Conn, Academic Press, London, 1981, pp. 301-316.

22 M. N. Clifford, in Coffee 1. Chemistry, ed. R. J. Clarke and R. Macrae, Elsevier Applied Science, London, 1985, pp. 153-202.

23 M. N. Clifford, in Coffee: Botany, Biochemistry and Production of Beans and Beverage, ed. M. N. Clifford and K. C. Willson, Croom Helm, London, 1985, pp. 305-374.

24 P. Mølgaard and H. Ravn, Phytochemistry, 1988, 27, 24112421.

25 M. N. Clifford, B. Kellard and E. Ah-Sing, Phytochemistry, 1989, 28, 1989-1990.

26 M. N. Clifford, B. Kellard and G. G. Birch, Food Chem., 1989, 33, 115-123.

27 M. N. Clifford, J. Sci. Food Agric., 1999, 79, 362-372.

28 M. N. Clifford, J. Sci. Food Agric., 2000, 80, 1033-1043.

29 M. N. Clifford, in Methods in Polyphenol Analysis, ed. C. Santos-Buelga and G. Williamson, Royal Society of Chemistry, Cambridge, 2003, pp. 314-337.

30 M. N. Clifford, K. L. Johnston, S. Knight and N. Kuhnert, J. Agric. Food Chem., 2003, 51, 2900-2911.

31 M. N. Clifford, S. Knight and N. Kuhnert, J. Agric. Food Chem., 2005, 53, 3821-3832.

32 R. Jaiswal, T. Sovdat, F. Vivan and N. Kuhnert, J. Agric. Food Chem., 2010, 58, 5471-5484.

33 R. Jaiswal and N. Kuhnert, Rapid Commun. Mass Spectrom., 2010, 24, 2283-2294.

34 M. N. Clifford, Researchgate, 2017, https://www.researchgate. net/publication/312591202.

$35 \mathrm{~K}$. Hermann, Occurrence and content of hydroxycinnamic and hydroxybenzoic acid compounds in foods, Crit. Rev. Food Sci. Nutr., 1989, 28, 315-347.

36 C. Manach, A. Scalbert and G. Williamson, Am. J. Clin. Nutr., 2004, 79, 727-747. 
37 A. Crozier, T. Yokota, I. B. Jaganath, S. C. Marks, M. Saltmarsh and M. N. Clifford, in Plant Secondary Metabolites. Occurrence, Structure and Role in the Human Diet, ed. A. Crozier, M. N. Clifford and H. Ashihara, Blackwell Publishing, Oxford, UK, 2006, pp. 208-302.

38 A. Crozier, I. B. Jaganath and M. N. Clifford, Nat. Prod. Rep., 2009, 26, 1001-1043.

39 Phenol-Explorer, Database on polyphenol content of foods (phenol-explorer.eu), 2015.

40 K. Schütz, D. Kammerer, R. Carle and A. Schieber, J. Agric. Food Chem., 2004, 52, 4090-4096.

41 G. Pandino, F. L. Courts, S. Lombado, S. Lombardo, G. Mauromicale and G. Williamson, J. Agric. Food Chem., 2010, 58, 1026-1031.

42 M. N. Clifford and J. R. Ramirez-Martinez, Food Chem., 1990, 35, 13-21.

43 T. W. M. Crozier, A. Stalmach, M. E. J. Lean and A. Crozier, Food Funct., 2012, 3, 30-33.

44 A. Stalmach, W. Mullen, D. Barron, K. Uchida, T. Yokota, C. Cavin, H. Steiling, G. Williamson and A. Crozier, Drug Metab. Dispos., 2009, 37, 1749-1758.

45 K. Kahle, W. Huemmer, W. Scheppach, T. Erk and E. Richling, J. Agric. Food Chem., 2007, 55, 10605-10614.

46 S. Hagl, H. Deusser, B. Soyalan, C. Janzowski, F. Will, H. Dietrich, F. W. Albert, S. Rohner and E. Richling, Mol. Nutr. Food Res., 55, 368-377.

47 M. N. Clifford, W. Zheng and N. Kuhnert, Phytochem. Anal., 2006, 7, 384-393.

48 M. N. Clifford, J. Kirkpatrick, N. Kuhnert, H. Roozendaal and P. R. Salgado, Food Chem., 2008, 106, 379-385.

49 H. Karaköse, R. Jaiswal, S. Deshpande and N. Kuhnert, J. Agric. Food Chem., 2015, 63, 3338-3347.

50 M. I. Mhlongo, L. A. Piater, P. A. Steenkamp, N. E. Madala and I. A. Dubery, Biotechnol. Lett., 2015, 37, 205-209.

51 IUPAC, Biochem. J., 1976, 153, 23-31.

52 D. Kremr, T. Bajer, P. Bajerova, S. Surmova and K. Ventura, Quim. Nova, 2016, 39, 530-533.

53 M. N. Clifford, Researchgate, 2017, https:// www.researchgate.net/publication/312590923.

54 L. Abrankó and M. N. Clifford, J. Agric. Food Chem., 2017, 65, 3602-3608.

55 P. F. Yang, Z. M. Feng, Y. N. Yang, J. S. Jiang and P. C. Zhang, J. Nat. Prod., 2017, 80, 1028-1033.

56 R. S. Cahn, J. Chem. Educ., 1964, 41, 116-125.

57 E. L. Eliel and M. B. Ramirez, Tetrahedron: Asymmetry, 1997, 8, 3551-3554.

58 M. N. Clifford, Researchgate, 2017, https:// www.researchgate.net/publication/312590947.

59 D. Wianowska, R. Typek and A. L. Dawidowicz, Phytochemistry, 2015, 117, 489-499.

60 M. N. Clifford, B. Kellard and G. G. Birch, Food Chem., 1989, 34, 81-88.

61 M. N. Clifford, B. Kellard and G. G. Birch, Food Chem., 1989, 33, 115-123.

62 M. N. Clifford, J. Kirkpatrick, N. Kuhnert, H. Roozendaal and P. R. Salgado, Food Chem., 2008, 106, 379-385.
63 G. F. Pauli, U. Kuczkowiak and A. Nahrstedt, Magn. Reson. Chem., 1999, 37, 827-836.

64 G. F. Pauli, F. Poetsch and A. Nahrstedt, Phytochem. Anal,, 1998, 9, 177-185.

65 A. Könczöl, Z. Beni, M. M. Sipos, A. Rill, V. Hada, J. Hohmann, I. Mathe, C. Szantay Jr, G. M. Keseru and G. T. Balogh, J. Pharm. Biomed. Anal., 2012, 59, 83-89.

66 N. Armesto, S. Ferrera and M. Ferrero, Tetrahedron, 2006, 62, 5401-5410.

67 M. Haribal, P. Feeny and C. C. Lester, Phytochemistry, 1998, 49, 103-108.

68 H. C. Kwon, C. M. Jung, C. G. Shin, J. K. Lee, S. U. Choi, S. Y. Kim and K. R. Lee, Chem. Pharm. Bull., 2000, 48, 1796-1798.

69 J. Y. Hur, P. Lee, H. Kim, I. Kang, K. R. Lee and S. Y. Kim, Biochem. Biophys. Res. Commun., 2004, 313, 948-953.

70 K. H. Kim, Y. Kim and K. R. Lee, Bioorg. Med. Chem. Lett., 2007, 17, 6739-6743.

71 A. Nugroho, K. H. Kim, K. R. Lee, M. B. Alam, J. S. Choi, W. B. Kim and H. J. Park, Arch. Pharmacal Res., 2009, 32, 1361-1367.

72 A. Nugroho, K. R. Lee, M. B. Alam, J. S. Choi and H. J. Park, Arch. Pharmacal Res., 2010, 33, 703-708.

73 H. J. Park, Arch. Pharmacal Res., 2010, 33, 1703-1720.

74 Y. Wang, M. Hamburger, J. Gueho and K. Hostettmann, Helv. Chim. Acta, 1992, 75, 269-275.

75 Y. Wang, V. Wray, N. Tsevegsuren, W. Lin and P. Proksch, Z. Naturforsch., C: J. Biosci., 2012, 67, 135-143.

76 M. Ono, C. Masuoka, Y. Odake, S. Ikegashira, Y. Ito and T. Nohara, Food Sci. Technol. Res., 2000, 6, 106-114.

77 R. Jaiswal, S. Deshpande and N. Kuhnert, Phytochem. Anal., 2011, 22, 432-441.

78 R. Jaiswal, M. F. Matei, A. Golon, M. Witt and N. Kuhnert, Food Funct., 2012, 3, 976-984.

79 S. Deshpande, Ph.D. thesis, Jacobs University Bremen, Germany, 2014.

80 B. M. Scholz and H. G. Maier, Z. Lebensm.-Unters. Forsch., 1990, 190, 132-134.

81 B. M. Scholz-Böttcher, E. Ludger and H. G. Maier, Liebigs Ann. Chem., 1991, 1029-1036.

82 L. Z. Lin and J. M. Harnly, J. Agric. Food Chem., 2008, 56, 10105-10114.

83 R. Jaiswal and N. Kuhnert, J. Mass Spectrom., 2011, 46, 269281.

84 M. N. Clifford, W. Wu, J. Kirkpatrick and N. Kuhnert, J. Agric. Food Chem., 2007, 55, 929-936.

85 L. Siracusa, T. Kulisic-Bilusic, O. Politeo, I. Krause, B. Dejanovic and G. Ruberto, J. Agric. Food Chem., 2011, 59, 12453-12459.

86 L. Zhang, Z. C. Tu, H. Wang, Z. F. Fu, Q. H. Wen and D. Fan, Food Chem., 2015, 186, 123-132.

87 D. X. Zhao, B. Q. Hu, M. Zhang, C. F. Zhang and H. X. Xu, J. Sep. Sci., 2015, 38, 571-575.

88 E. M. Sanchez-Salcedo, P. Mena, C. Garcia-Viguera, F. Hernandez and J. Jose Martinez, J. Funct. Foods, 2015, 18, 1039-1046. 
89 P. Dugo, F. Cacciola, P. Donato, R. A. Jacques, E. B. Caramao and L. Mondello, J. Chromatogr. A, 2009, 1216, 7213-7221.

90 F. J. Herraiz, D. Villano, M. Plazas, S. Vilanova, F. Ferreres, J. Prohens and D. A. Moreno, Int. J. Mol. Sci., 2016, 17(3), 394, DOI: 10.3390/ijms17030394.

91 B. Abdennacer, M. Karim, M. Yassine, R. Nesrine, D. Mouna and B. Mohamed, Food Chem., 2015, 174, 577-584.

92 N. Kuhnert, I. Hakeem Said and R. Jaiswal, in Studies in Natural Products Chemistry, ed. U. R. Atta, Elsevier, Amsterdam, 2014, vol. 42, pp. 305-339.

93 M. M. Makola, P. Steenkamp, I. A. Dubery, M. M. Kabanda and N. E. Madala, Rapid Commun. Mass Spectrom., 2016, 30, 1011-1018.

94 X. Y. Zheng, R. S. Renslow, M. M. Makola, I. K. Webb, L. L. Deng, D. G. Thomas, N. Govind, Y. M. Ibrahim, M. M. Kabanda, I. A. Dubery, H. M. Heyman, R. D. Smith, N. E. Madala and E. S. Baker, J. Phys. Chem. Lett., 2017, 8, 1381-1388.

95 M. N. Clifford, W. Wu, J. Kirkpatrick, R. Jaiswal and N. Kuhnert, Rapid Commun. Mass Spectrom., 2010, 24, 3109-3120.

96 Z. Wang, M. N. Clifford and P. Sharp, Food Chem., 2008, 108, 379-383.

97 Z. Wang and M. N. Clifford, Food Chem., 2008, 106, 147152.

98 M. N. Clifford, S. Stoupi and N. Kuhnert, J. Agric. Food Chem., 2007, 55, 2797-2807.

99 M. N. Clifford, W. Zheng and N. Kuhnert, Phytochem. Anal., 2006, 17, 384-393.

100 M. N. Clifford, W. Wu and N. Kuhnert, Food Chem., 2006, 95, 574-578.

101 M. N. Clifford, S. Marks, S. Knight and N. Kuhnert, J. Agric. Food Chem., 2006, 54, 4095-4101.

102 M. N. Clifford, S. Knight, B. Surucu and N. Kuhnert, J. Agric. Food Chem., 2006, 54, 1957-1969.

103 R. Jaiswal, H. Müller, A. Müller, M. G. E. Karar and N. Kuhnert, Phytochemistry, 2014, 108, 252-263.

104 R. Jaiswal, M. F. Matei, P. Subedi and N. Kuhnert, Food Res. Int., 2014, 61, 214-227.

105 R. Jaiswal, M. F. Matei, S. Deshpande and N. Kuhnert, in Handbook of Chemical and Biological Plant Analytical Methods Volume 2, ed. K. Hostettmann, S. Chen, A. Marston and H. Stuppner, Wiley, Oxford, 2014, pp. 505524.

106 R. Jaiswal, M. G. E. Karar, H. A. Gadir and N. Kuhnert, Phytochem. Anal., 2014, 25, 567-576.

107 R. Jaiswal, E. A. Halabi, M. G. Karar and N. Kuhnert, Phytochemistry, 2014, 106, 141-155.

108 R. Jaiswal, H. Karakose, S. Ruhmann, K. Goldner, M. Neumuller, D. Treutter and N. Kuhnert, J. Agric. Food Chem., 2013, 61, 12020-12031.

109 M. F. Matei, R. Jaiswal and N. Kuhnert, J. Agric. Food Chem., 2012, 60, 12105-12115.

110 H. Karaköse, R. Jaiswal and N. Kuhnert, Characterization and quantification of hydroxycinnamate derivatives in
Stevia rebaudiana leaves by $\mathrm{LC}-\mathrm{MS}^{\mathrm{n}}, \mathrm{J}$. Agric. Food Chem., 2011, 59, 10143-10150.

111 R. Jaiswal and N. Kuhnert, Food Funct., 2011, 2, 63-71.

112 R. Jaiswal, J. Kiprotich and N. Kuhnert, Phytochemistry, 2011, 72, 781-790.

113 N. Kuhnert, R. Jaiswal, M. F. Matei, T. Sovdat and S. Deshpande, Rapid Commun. Mass Spectrom., 2010, 24, 1575-1582.

114 R. Jaiswal, M. A. Patras, P. J. Eravuchira and N. Kuhnert, J. Agric. Food Chem., 2010, 58, 8722-8737.

115 R. Jaiswal and N. Kuhnert, Rapid Commun. Mass Spectrom., 2010, 24, 2283-2294.

116 N. Kuhnert, G. H. Yassin, R. Jaiswal, M. F. Matei and C. H. Grun, Rapid Commun. Mass Spectrom., 2015, 29, 675-680.

117 R. Li, S. K. Liu, W. Song, Y. Wang, Y. J. Li, X. Qiao, H. Liang and M. Ye, Anal. Methods, 2014, 6, 7181-7189.

118 F. Ferreres, D. M. Pereira, P. Valentao, P. B. Andrade, R. M. Seabra and M. Sottomayor, J. Agric. Food Chem., 2008, 56, 9967-9974.

119 G. Stefkov, S. Hristovski, J. Petreska Stanoeva, M. Stefova, L. Melovski and S. Kulevanova, Ind. Crops Prod., 2014, 61, 145-150.

120 V. M. Jimenez, M. Gruschwitz, R. M. Schweiggert, R. Carle and P. Esquivel, Food Res. Int., 2014, 65, 42-46.

121 J. Han, M. Ye, X. Qiao, M. Xu, B. R. Wang and D. A. Guo, J. Pharm. Biomed. Anal., 2008, 47, 516-525.

122 Y. Y. Xie, J. L. Qu, Q. L. Wang, Y. Wang, M. Yoshikawa and D. Yuan, J. Agric. Food Chem., 2012, 60, 12574-12583.

123 M. Ramirez-Ambrosi, B. Abad-Garcia, M. Viloria-Bernal, S. Garmon-Lobato, L. A. Berrueta and B. A. Gallo, J. Chromatogr. A, 2013, 1316, 78-91.

124 L. W. Qi, C. Y. Chen and P. Li, Rapid Commun. Mass Spectrom., 2009, 23, 3227-3242.

125 E. N. Ncube, M. I. Mhlongo, L. A. Piater, P. A. Steenkamp, I. A. Dubery and N. E. Madala, Chem. Cent. J., 2014, 8, 6675.

126 N. E. Madala, F. Tugizimana and P. Steenkamp, J. Anal. Methods Chem., 2014, 2014, 650879.

127 M. N. Clifford and N. E. Madala, J. Agric. Food Chem., 2017, 65, 3589-3590.

128 Y. Matsui, S. Nakamura, N. Kondou, Y. Takasu, R. Ochiai and Y. Masukawa, J. Chromatogr. B: Anal. Technol. Biomed. Life Sci., 2007, 858, 96-105.

129 L. Z. Lin and J. M. Harnly, J. Agric. Food Chem., 2008, 56, 10105-10114.

130 L. Z. Lin and J. M. Harnly, J. Agric. Food Chem., 2007, 55, 1084-1096.

131 J. Willems, M. M. Khamis, W. Mohammed Saeid, R. W. Purves, G. Katselis, N. Low and A. El-Aneed, Anal. Chim. Acta, 2016, 933, 164-174.

132 M. Lepelley, V. Mahesh, J. McCarthy, M. Rigoreau, D. Crouzillat, N. K. A. de Chabrillange and C. Campa, Planta, 2012, 236, 313-326.

133 B. Hamberger, M. Ellis, M. Friedman, C. de Azevedo Sousa, B. Barbasuk and C. Douglas, Can. J. Bot., 2007, 85, 11821201. 
134 A. Chang, M. H. Lim, S. W. Lee, E. J. Robb and R. N. Nazar, J. Biol. Chem., 2008, 283, 33591-33601.

135 X. Zhang and C.-J. Liu, Mol. Plant, 2015, 8, 17-27.

136 R. Shi, C. M. Shuford, J. P.Wang, Y. H. Sun, Z. Yang, H. C. Chen, S. Tunlaya-Anukit, Q. Li, J. Liu, D. C. Muddiman, R. R. Sederoff and V. L. Chiang, Planta, 2013, 238, 487-497.

137 A. L. Schilmiller, J. Stout, J. K. Weng, J. Humphreys, M. O. Rueger and C. C. S. Chapple, Plant J., 2009, 60, 771-782.

138 R. Kumar, D. Vashisth, A. Misra, M. Q. Akhtar, S. U. Jalil, K. Shanker, M. M. Gupta, P. K. Rout, A. K. Gupta and A. K. Shasany, Sci. Rep., 2016, 6, 26458.

139 T. Vogt, Mol. Plant, 2010, 3, 2-20.

140 C.-H. Wang, J. Yu, Y.-X. Cai, P.-P. Zhu, C.-Y. Liu, A.-C. Zhao, R.-H. Lu, M. J. Li, F. X. Xu and M.-D. Yu, PLoS One, 2016, 11(5), e0155814.

141 M. M. Rigano, A. Raiola, T. Docimo, V. Ruggieri, R. Calafiore, P. Vitaglione, R. Ferracane, L. Frusciante and A. Barone, Front. Plant Sci., 2016, 7, 1484, DOI: 10.3389/ fpls.2016.01484.

142 G. Sonannte, R. d'Amore, E. Blanco, C. L. Pierri, M. de Palma, J. Luo, M. Tucci and C. Martin, Plant Physiol., 2010, 153, 1224-1238.

143 A. Moglia, A. Acquadro, K. Eljounaidi, A. M. Milani, C. Cagliero, P. Rubiolo, A. Genre, K. Cankar, J. Beekwilder and C. Comino, Front. Plant Sci., 2016, 2, 1424.

144 L. Z. Lin and J. M. Harnly, J. Agric. Food Chem., 2009, 57, 7401-7408.

145 L. A. Lallemand, C. Zubieta, S. G. Lee, Y. Wang, S. Acajjaoui, J. Timmins, S. McSweeney, J. M. Jez, J. G. McCarthy and A. A. A. McCarthy, Plant Physiol., 2012, 160, 249-260.

146 A. Moglia, S. Lanteri, C. Comino, L. Hill, D. Knevitt, C. Cagliero, P. Rubiolo, S. Bornemann and C. Martin, Plant Physiol., 2014, 166, 1777-1787.

147 G. Legrand, M. Delporte, C. Khelif, A. Harant, C. Vuylsteker, M. Mörchen, P. Hance, J.-L. Hilbert and D. Gagneul, Front. Plant Sci., 2016, 7, 741, DOI: 10.3389/fpls.2016.00741.

148 L. L. Escamilla-Trevino, H. Shen, T. Hernandez, Y. Yin, Y. Xu and R. A. Dixon, Plant Mol. Biol., 2014, 84, 565-576.

149 Q. Yang, H. X. Trinh, S. Imai, A. Ishihara, L. Zhang, H. Nakayashiki, Y. Tosa and S. Mayama, Mol. PlantMicrobe Interact., 2004, 7, 81-89.

150 C. Campa, M. Noirot, M. Bourgeois, M. Pervent, C. L. Ky, H. Chrestin, S. Hamon and A. De Kochko, Theor. Appl. Genet., 2003, 107, 751-757.

151 T. Joet, J. Salmona, A. Laffargue, F. Descroix and S. Dussert, Plant, Cell Environ., 2010, 33, 1220-1233.

152 K. Kai, M. Mizutani, N. Kawamura, R. Yamamoto, M. Tamai, H. Yamaguchi, K. Sakata and B. Shimizu, Plant J., 2008, 55, 989-999.

153 D. Giordano, S. Provenzano, A. Ferrandino, M. Vitali, C. Pagliarani, F. Roman, F. Cardinale, S. D. Castellarin and A. Schubert, Plant Physiol. Biochem., 2016, 101, 23-32.

154 N. Itoh, C. Iwata and H. Toda, BMC Plant Biol., 2016, 16, 180, DOI: 10.1186/s12870-016-0870-9.
155 M. Kojima and I. Uritani, Plant Cell Physiol., 1972, 13, 10751084.

156 M. Takenaka, K. Nanayama, S. Isobe and M. Murata, Biosci., Biotechnol., Biochem., 2006, 70, 172-177.

157 M. Kojima and I. Uritani, Plant Physiol., 1973, 51, 768-771.

158 R. J. A. Villegas and M. Kojima, J. Biol. Chem., 1986, 261, 8729-8733.

159 T. Shimizu and M. Kojima, J. Biochem., 1984, 95, 205-212.

160 M. Tanaka and M. Kojima, Arch. Biochem. Biophys., 1991, 284, 151-157.

161 M. Kojima and R. J. A. Villegas, Agric. Biol. Chem., 1984, 48, 2397-2399.

162 M. Kojima and T. Kondo, Agric. Biol. Chem., 1985, 49, 24672469.

163 S. Lunkenbein, M. Bellido, A. Aharoni, E. M. Salentijn, R. Kaldenhoff, H. A. Coiner, J. Muñoz-Blanco and W. Schwabe, Plant Physiol., 2006, 140, 1047-1058.

164 B. A. Babst, H. Y. Chen, H. Q. Wang, R. S. Payyavula, T. P. Thomas, S. A. Harding and C. J. Tsai, J. Exp. Bot., 2014, 65, 4191-4200.

165 M. M. Makola, I. A. Dubery, G. Koorsen, P. A. Steenkamp, M. M. Kabanda, L. L. du Preez and N. E. Madala, Evid. base. Compl. Alternative Med., 2016, 4138263, DOI: 10:1155/2016/4138263.

166 H. Karaköse, R. Jaiswal, S. Deshpande and N. Kuhnert, J. Agric. Food Chem., 2015, 63, 3338-3347.

167 A. O. Taylor, Phytochemistry, 1968, 7, 63-71.

168 T. R. Nuringtyas, Y. H. Choi, R. Verpoorte, P. G. Klinkhammer and K. A. Leiss, Phytochemistry, 2012, 78, 89-97.

169 H. F. Harrison, T. R. Mitchell, J. K. Petersen, W. P. Wechter, G. F. Majetich and M. E. Smook, J. Am. Soc. Hort. Res., 2008, 113, 492-500.

170 E. Wojciechowska, C. H. Weinert, B. Egert, B. Trierweiler, M. Schmidt-Heydt, B. Horneburg, S. Graeff-Hönninger, S. E. Kulling and R. Geisen, Eur. J. Plant Pathol., 2014, 139, 735-747.

171 R. Niggeweg, A. J. Michael and C. Martin, Nat. Biotechnol., 2004, 22, 746-754.

172 M. I. Mhlongo, P. A. Steenkamp, L. A. Piater, N. E. Madala and I. A. Dubery, Front. Plant Sci., 2016, 7, 1527.

173 M.-H. Lee and R. M. Bostock, Phytopathology, 2007, 3, 269277.

174 V. Martinez, T. C. Mestre, F. Rubio, A. Girones-Vilaplana, D. A. Moreno, R. Mittler and R. M. Rivero, Front. Plant Sci., 2016, 7, 838, DOI: 10.3389/fpls.2016.00838.

175 L. Tamagnone, A. Merida, N. Stacey, K. Plaskitt, A. Parr, C. F. Chang, D. Lynn, J. M. Dow, K. Roberts and C. Martin, Plant Cell, 1998, 10, 1801-1816.

176 C. Cle, L. M. Hill, R. Niggeweg, C. R. Martin, Y. Guisez, E. Prinsen and M. A. Jansen, Phytochemistry, 2008, 69, 2149-2156.

177 A. Moglia, S. Lanteri, C. Comino, A. de Acquadro, R. de Vos and J. Beekwilder, J. Agric. Food Chem., 2008, 56, 8641-8649.

178 V. Petrulova, Z. Ducaiova and M. Repcak, Photochem. Photobiol., 2014, 90, 1061-1068.

179 W. S. Pierpoint, Biochem. J., 1969, 112, 619-629. 
180 R. F. Hurrell, P. A. Finot and J. L. Cuq, Br. J. Nutr., 1982, 47, 91-211.

181 T. F. Kuijpers, C. E. Narvaez-Cuenca, J. P. Vincken, A. J. Verloop, W. J. van Berkel and H. Gruppen, J. Agric. Food Chem., 2012, 60, 3507-3514.

182 C. E. Narvaez-Cuenca, J. P. Vincken and H. Gruppen, J. Agric. Food Chem., 2013, 61, 1563-1572.

183 G. W. Felton, K. Donato, R. J. Del Vecchio and S. S. Duffey, J. Chem. Ecol., 1989, 15, 2667-2694.

184 G. W. Felton and S. S. Duffey, J. Chem. Ecol., 16, 1221-1236. 185 G. W. Felton, J. Workman and S. S. Duffey, J. Chem. Ecol., 1992, 18, 571-583.

186 M. N. Clifford, S. Marks, S. Knight and N. Kuhnert, J. Agric. Food Chem., 2006, 54, 4095-4101.

187 M. N. Clifford and S. Knight, Food Chem., 2004, 87, 457463.

188 J. Y. Zhang, Z. J. Wang, Y. Li, Y. Li, W. Cai, C. Li, J. Q. Lu and Y. J. Qiao, Talanta, 2016, 47, 16-27.

189 T. Stark, H. Justus and T. Hofmann, J. Agric. Food Chem., 2006, 54, 2859-2867.

190 R. M. Alonso-Salces, C. Guillou and L. A. Berrueta, Rapid Commun. Mass Spectrom., 2009, 23, 363-383.

191 M. N. Clifford and T. Jarvis, Food Chem., 1988, 9, 291-298. 192 F. Anthony, M. N. Clifford and M. Noirot, Genet. Resour. Crop Evol., 1993, 40, 61-70.

193 R. M. Alonso-Salces, F. Serra, F. Reniero and K. Héberger, J. Agric. Food Chem., 2009, 57, 4224-4235.

194 B. Mehari, M. Redi-Abshiro, B. S. Chandravanshi, S. Combrinck, M. Atlabachew and R. McCrindle, J. Food Comp. Anal., 2016, 45, 16-25.

195 L. C. Trugo and R. Macrae, Food Chem., 1984, 15, 219-227.

196 R. Jaiswal, M. F. Matei, A. Golon, M. Witt and N. Kuhnert, Food Funct., 2012, 3, 976-984.

197 R. Jaiswal, M. F. Matei, P. Subedi and N. Kuhnert, Food Res. Int., 2014, 61, 214-227.

198 M. F. Matei, R. Jaiswal and N. Kuhnert, J. Agric. Food Chem., 2012, 60, 12105-12115.

199 S. Deshpande, R. Jaiswal, M. F. Matei and N. Kuhnert, J. Agric. Food Chem., 2014, 62, 9160-9170.

200 A. Stalmach, M. N. Clifford, G. Williamson and A. Crozier, in Tea, Cocoa and Coffee. Secondary Plant Metabolites and Health, ed. A. Crozier, H. Ashihara and F. TomásBarbéran, Wiley-Blackwell, Chichester, UK, 2012, pp. 169192.

201 I. A. Ludwig, P. Mena, L. Calani, C. Cid, D. Del Rio, M. E. J. Lean and A. Crozier, Food Funct., 2014, 5, 17181726.

202 C. E. Mills, M. J. Oruna-Concha, D. S. Mottram, G. R. Gibson and J. P. Spencer, The effect of processing on chlorogenic acid content of commercially available coffee, Food Chem., 2013, 141, 3335-3340.

203 T. L. Farrell, T. P. Dew, L. Poquet, P. Hanson and G. Williamson, Drug Metab. Dispos., 2011, 39, 2338-2346.

204 P. A. Guy, M. Renouf, D. Barron, C. Cavin, F. Dionisi, S. Kochhar, S. Rezzi, G. Williamson and H. Steiling, J. Chromatogr. B: Anal. Technol. Biomed. Life Sci., 2009, 877, 3965-3974.
205 T. Erk, M. Renouf, G. Williamson, R. Melcher, H. Steiling and E. Richling, Eur. J. Nutr., 2014, 53, 159-166.

206 M. Gomez-Juaristi, S. Martinez-Lopez, B. Sarria, L. Bravo and R. Mateos, Food Chem., 2018, 240, 1028-1038.

207 H. Ito, M. P. Gonthier, C. Manach, C. Morand, L. Mennen, C. Rémésy and A. Scalbert, Br. J. Nutr., 2005, 94, 500-509.

208 Y. Matsui, S. Nakamura, N. Kondou, Y. Takasu, R. Ochiai and Y. Masukawa, J. Chromatogr. B: Anal. Technol. Biomed. Life Sci., 2007, 858, 96-105.

209 D. Scherbl, M. Renouf, C. Marmet, L. Poquet, I. Cristiani, S. Dahbane, S. Emandy-Azar, J. Sauser, J. Galan, F. Dionisi and E. Richling, Eur. Food Res. Technol., 2017, 243, 791-806.

210 E. Azzini, R. Bugianesi, F. Romano, D. Di Venere, S. Miccadei, A. Durazzo, M. S. Foddai, G. Catasta, V. Linsalata and G. Maiani, Br. J. Nutr., 2007, 97, 963-969.

211 M. R. Olthof, P. C. Hollman and M. B. Katan, J. Nutr., 2001, 131, 66-71.

212 M. Monteiro, D. Farah, D. Perrone, L. C. Trugo and C. Donangelo, Chlorogenic acid compounds from coffee are differentially absorbed and metabolized in humans, $J$. Nutr., 2007, 137, 2196-2201.

213 A. Farah, M. Monteiro, C. M. Donangelo and S. Lafay, J. Nutr., 2008, 138, 2309-2315.

214 A. Stalmach, H. Steiling, G. Williamson and A. Crozier, Arch. Biochem. Biophys., 2010, 501, 98-105.

215 A. R. Rechner, J. P. Spencer, G. Kuhnle, U. Hahn and C. A. Rice-Evans, Free Radical Biol. Med., 2001, 30, 12131222.

216 M. Xie, G. Chen, B. Hu, L. Zhou, S. Ou, X. Zeng and Y. Sun, J. Agric. Food Chem., 2016, 64, 9624-9630.

217 C. Buchanan, G. Wallace and S. C. Fry, J. Sci. Food Agric., 1996, 71, 459-469.

218 M. F. Andreasen, P. A. Kroon, G. Williamson and M. T. Garcia-Conesa, J. Agric. Food Chem., 2001, 49, 56795684.

219 T. L. Farrell, M. Gomez-Juaristi, L. Poquet, K. Redeuil, K. Nagy, M. Renouf and G. Williamson, Mol. Nutr. Food Res., 2012, 56, 1413-1423.

220 J. A. da Encarnaçao, T. L. Farrell, A. Ryder, N. U. Kraut and G. Williamson, Mol. Nutr. Food Res., 2015, 59, 231-239.

221 C. C. Wong, W. Meinl, H. R. Glatt, D. Barron, A. Stalmach, H. Steiling, A. Crozier and G. Williamson, J. Nutr. Biochem., 2010, 21, 1060-1068.

222 D. Couteau, A. L.McCartney, G. R. Gibson, G. Williamson and C. B. Faulds, J. Appl. Microbiol., 2001, 90, 873-881.

223 L. Poquet, M. N. Clifford and G. Williamson, Drug Metab. Dispos., 2008, 36, 190-197.

224 M. R. Olthof, P. C. Hollman, M. N. Buijsman, J. M. van Amelsvoort and M. B. Katan, J. Nutr., 2003, 133, 1806-1814.

225 R. Suri and A. Crozier, J. Trop. Agric. Food Sci., 2012, 40, 221232.

226 I. A. Ludwig, M. P. de Pēna, C. Cid and A. Crozier, BioFactors, 2013, 39, 623-632.

227 I. B. Jaganath, W. Mullen, C. A. Edwards and A. Crozier, Free Radical Biol. Med., 2006, 40, 1035-1046. 
228 I. B. Jaganath, W. Mullen, M. E. J. Lean, C. A. Edwards and A. Crozier, Free Radical Biol. Med., 2009, 47, 1180-1189.

229 C. Czank, A. Cassidy, Q. Zhang, D. J. Morrison, T. Preston, P. A. Kroon, N. P. Botting and C. D. Kay, Am. J. Clin. Nutr., 2013, 97, 995-1003.

230 R. M. de Ferrars, C. Czank, Q. Zhang, N. P. Botting, P. A. Kroon, A. Cassidy and C. D. Kay, Br. J. Pharmacol., 2014, 171, 3268-3282.

231 I. A. Ludwig, P. Mena, L. Calani, G. Borges, G. Pereira-Caro, L. Bresciani, D. Del Rio, M. E. J. Lean and A. Crozier, Free Radical Biol. Med., 2015, 89, 758-769.

232 G. Pereira-Caro, G. Borges, J. J. J. van der Hooft, M. N. Clifford, M. E. J. Lean, D. Del Rio, S. A. Roberts, M. Kallerhals and A. Crozier, Am. J. Clin. Nutr., 2014, 100, 1385-1391.

233 G. Pereira-Caro, G. Borges, I. Ky, A. Ribas, D. Del Rio, M. N. Clifford, S. A. Roberts and A. Crozier, Mol. Nutr. Food Res., 2015, 59, 465-475.

234 G. Pereira-Caro, I. A. Ludwig, T. Polyviou, D. Malkova, A. Garcia, J. M. Morenon-Rojas and A. Crozier, J. Agric. Food Chem., 2016, 64, 5724-5735.

235 S. Roowi, A. Stalmach, W. Mullen, M. E. J. Lean, C. A. Edwards and A. Crozier, J. Agric. Food Chem., 58, 1296-1304.

236 J. I. Ottaviani, G. Borges, T. Momma, J. P. E. Spencer, C. L. Keen, A. Crozier and H. Schroeter, Sci. Rep., 2016, 6, 29034, DOI: 101038/srep29034.

237 J. A. da Encarnacao, T. L. Farrell, A. Ryder, N. U. Kraut and G. Williamson, Mol. Nutr. Food Res., 2015, 59, 231-239.

238 T. Erk, G. Williamson, M. Renouf, C. Marmet, H. Steiling, F. Dionisi, D. Barron, R. Melcher and E. Richling, Mol. Nutr. Food Res., 2012, 56, 1488-1500.

239 A. Stalmach, G. Williamson and A. Crozier, Food Funct., 2014, 5, 1727-1737.

240 G. Borges, M. E. J. Lean, S. A. Roberts and A. Crozier, Food Funct., 2013, 4, 754-762.

241 G. S. Duarte and A. Farah, J. Agric. Food Chem., 2001, 59, 7925-7931.

242 D. Tagliazucchi, A. Helal, E. Verzelloni and A. Conte, J. Agric. Food Chem., 2012, 60, 11056-11064.

243 M. Renouf, C. Marmet, P. Guy, A. L. Fraering, K. Longet, J. Moulin, M. Enslen, D. Barron, C. Cavin, F. Dionisi, S. Rezzi, S. Kochhar, H. Steiling and G. Williamson, $J$. Nutr., 2010, 140, 259-263.

244 S. V. Prigent, H. Gruppen, A. J. Visser, G. A. van Koningsveld, G. A. de Jong and G. A. Voragen, J. Agric. Food Chem., 2003, 51, 5088-5095.

245 C. Dupas, A. Marsset Baglieri, C. Ordonaud, D. Tome and M. N. Maillard, Mol. Nutr. Food Res., 2006, 50, 1053-1060.

246 W. T. Phillips, J. G. Schwartz, R. Blumhardt and C. A. McMahan, J. Nucl. Med., 1991, 32, 377-381.

247 D. Gentilcore, R. Chaikomin, K. L. Jones, A. Russo, C. Feinle-Bisset, J. M. Wishart, C. K. Rayner and M. Horowitz, J. Clin. Endocrinol. Metab., 2006, 91, 20622067.
248 A. Farah, T. De Paulis, D. P. Moreira, L. C. Trugo and P. R. Martin, J. Agric. Food Chem., 2006, 54, 374-381.

249 R. Mateos, L. Goya and L. Bravo, J. Agric. Food Chem., 2006, 54, 8724-8732.

250 L. C. Trugo and R. Macrae, Analyst, 1984, 109, 263-266.

251 A. K. Sandhu, Y. Huang, D. Xiao, E. Park, I. Edirisinghe and B. Burton-Freeman, J. Agric. Food Chem., 2016, 64, 48914899.

252 C. Manach, D. Milenkovic, T. Van de Wiele, A. RodriguesMateos, B. de Roos, M. T. Garcia-Conesa, R. Landberg, E. R. Gibney, M. Heinonen, F. Tomaa-Barberan and C. Morand, Mol. Nutr. Food Res., 2017, 61(6), 1600557.

253 A. Nkondjock, Cancer Lett., 2009, 277, 121-125.

254 S. K. Bøhn, N. C. Ward, J. M. Hodgson and C. D. Croft, Food Funct., 2012, 3, 575-591.

255 I. A. Ludwig, M. N. Clifford, M. E. J. Lean and A. Crozier, Food Funct., 2014, 5, 1695-1717.

256 M. N. Clifford, Planta Med., 2004, 12, 1103-1114.

257 B. Halliwell, J. Rafter and A. Jenner, Am. J. Clin. Nutr., 2005, 81, 268S-276S.

258 A. Scalbert, I. T. Johnson and M. Saltmarsh, Am. J. Clin. Nutr., 2005, 81, 215S-217S.

259 D. Del Rio, A. Rodrigues-Mateos, J. P. E. Spencer, M. Tognolini, G. Borges and A. Crozier, Antioxid. Redox Signaling, 2013, 18, 1818-1892.

260 A. M. Rodriguez-Mateos, D. Vauzour, C. G. Kreuger, D. Shanmuganayagam, J. Reed, L. Calani, P. Mena, D. Del Rio and A. Crozier, Arch. Toxicol., 2014, 88, 1803-1853.

261 E. Van Rymenant, J. Van Camp, C. Boydens, L. Vanden Daele, P. Beerens, P. Brouckaert, G. Smagghe, A. Kerimi, G. Williamson, C. Grootaert and J. Van der Voorde, J. Nutr. Biochem., 2017, 44, 44-51.

262 H. P. Amin, C. Czank, S. Raheem, Q. Zhang, N. P. Botting, A. Cassidy and C. D. Kay, Mol. Nutr. Food Res., 2015, 59, 1095-1106.

263 E. F. Warner, Q. Zhang, K. S. Raheem, D. O'Hagan, M. A. O'Connell and C. Kay, J. Nutr., 2015, 146, 465-473.

264 I. Krga, L.-E. Monfoulet, A. Konic-Ristic, S. Mercier, M. Glibetic, C. Morand and D. Milenkovic, Arch. Biochem. Biophys., 2016, 599, 51-59.

265 M. Monagas, N. Khan, C. Andrés-Lacueva, M. Urpí-Sardá, M. Vázquez-Agell, R. M. Lamuela-Raventós and R. Estruch, Br. J. Nutr., 2009, 102, 201-206.

266 G. Baeza, E.-M. Bachmair, S. Wood, R. Mateos, L. Bravo and B. de Roos, Food Funct., 2017, 8, 1333-1342.

267 G. Assmann, P. Cullen, F. Jossa, B. Lewis and M. Mancini, Arterioscler., Thromb., Vasc. Biol., 1999, 19, 1819-1824.

268 A. González-Sarrías, M. A. Núñez-Sáchez, F. A. TómasBarberán and J. C. Espin, J. Agric. Food Chem., 2016, 65, 752-758.

269 E. Verzelloni, C. Pellacani, D. Tagliazucchi, S. Tagliaferri, L. Calani, L. G. Costa, F. Brighenti, G. Borges, A. Crozier, A. Conte and D. del Rio, Mol. Nutr. Food Res., 2011, 55, S35-S43.

270 G. Williamson and M. N. Clifford, Biochem. Pharmacol., 2017, 139, 24-39. 